\title{
Identification of interacting partners of mammalian target of rapamycin complex 1 (mTORC1) assembly in human lymphocytes
}

\author{
Dissertation \\ for the award of the degree \\ "Doctor of Philosophy (Ph.D.)" \\ Division of Mathematics and Natural Sciences \\ of the Georg-August University, Goettingen
}

\author{
Submitted by \\ Hazir Rahman \\ from Mardan, Pakistan
}

Goettingen, 2012 
D7

Reviewer 1: Prof. Dr. Stefanie Pöggeler

Director, Department of Genetics of Eukaryotic Microorganisms, Institute of Microbiology and Genetics,

Georg-August University, Goettingen, Germany.

Reviewer 2: $\quad$ Prof. Dr. Jürgen Brockmöller

Director, Department of Clinical Pharmacology,

University Medical Centre,

Georg-August University, Goettingen, Germany.

Date of oral examination: 20/01/2012 


\section{Declaration}

I hereby declare that the Ph.D. thesis entitled "Identification of interacting partners of mammalian target of rapamycin complex 1 (mTORC1) assembly in human lymphocytes" is my unaided work, with no other sources than quoted. The material of this thesis has not been submitted elsewhere for any academic qualification.

Hazir Rahman 


\section{Table of contents}

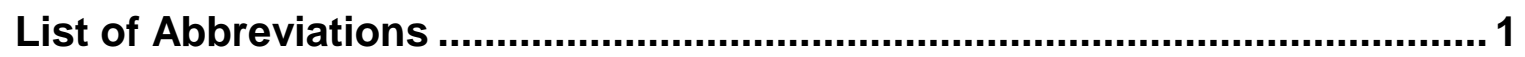

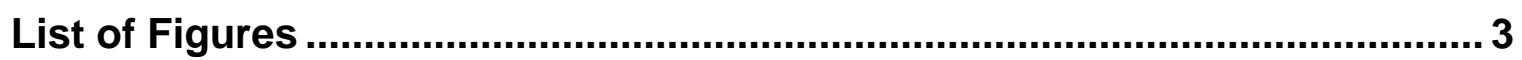

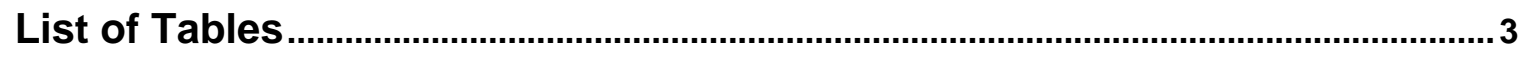

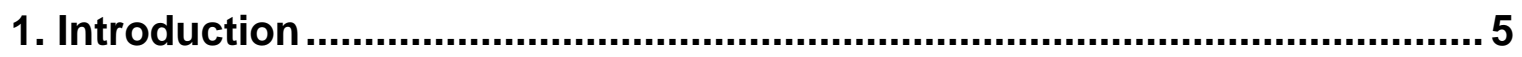

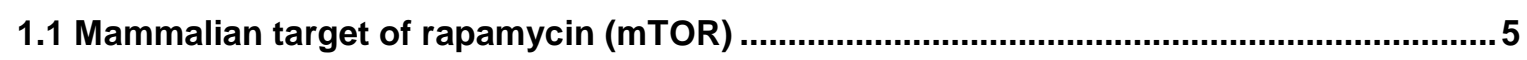

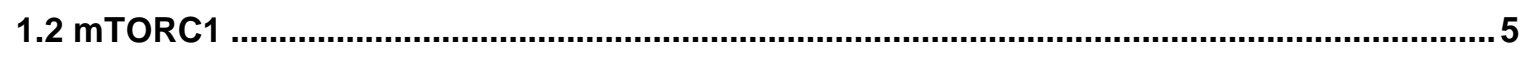

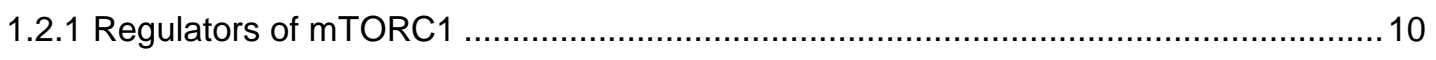

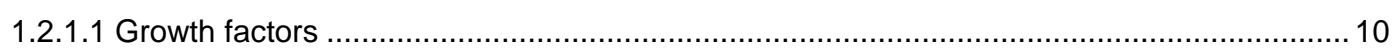

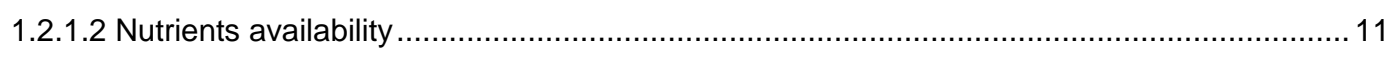

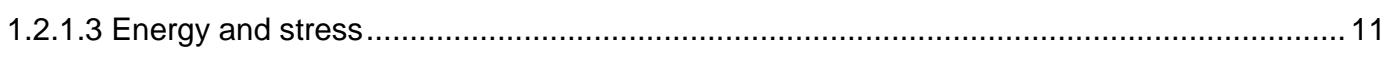

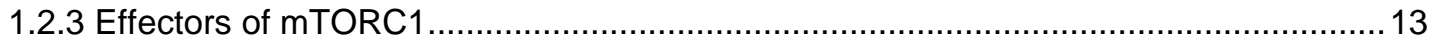

1.3 mTORC2

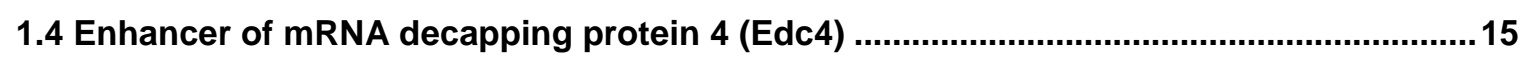

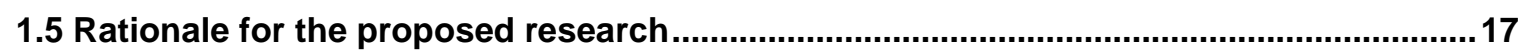

2. Materials and methods ..................................................................... 18

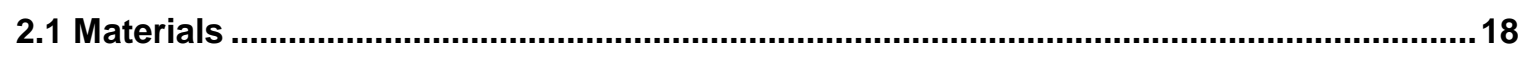

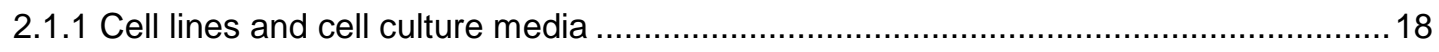

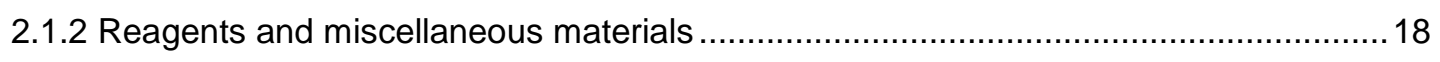

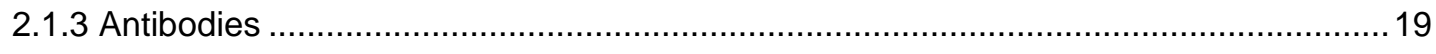

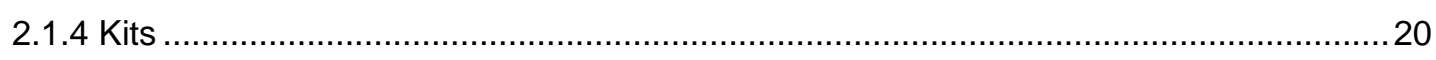

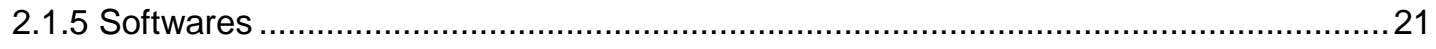

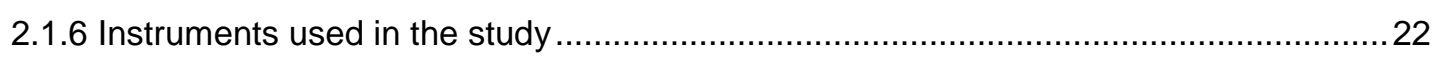

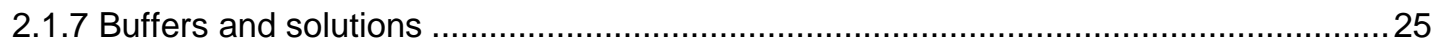

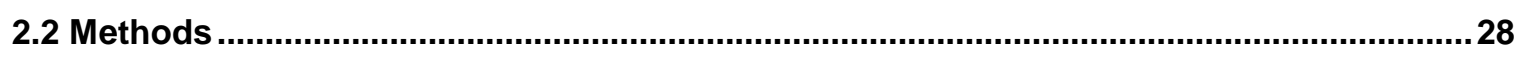

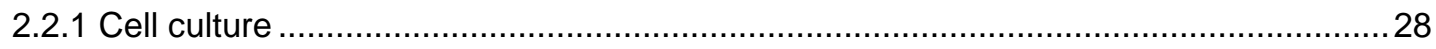


2.2.2 Cell lysis and endogenous mTORC1 purification .28

2.2.3 Mammalian cells transfection and myc-tag mTORC1 purification.............................29

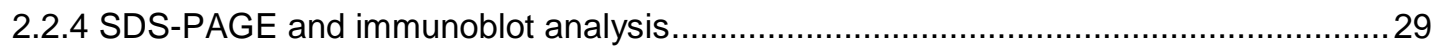

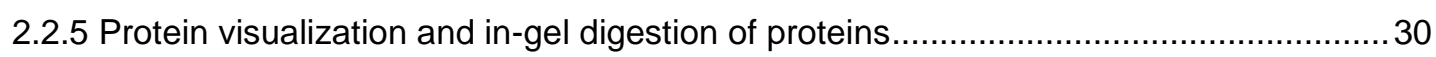

2.2.6 Peptide sequence analysis by nano-LC ESI Q-TOF MS/MS, and database search ...30

2.2.7 Functional annotation and protein-protein interaction prediction............................31

2.2.8 Confocal immunofluorescence microscopy ................................................... 31

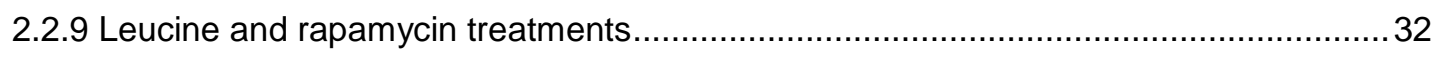

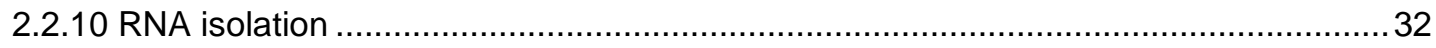

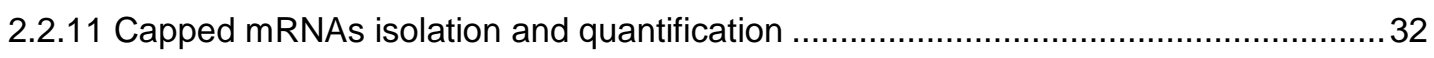

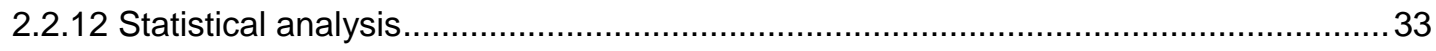

3. Identification of interacting partners of mammalian target of rapamycin complex 1 (mTORC1) assembly in human lymphocytes............................... 34

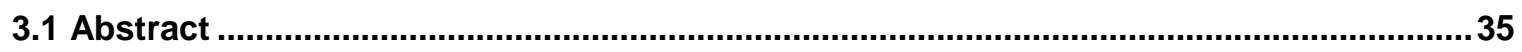

3.2 Introduction

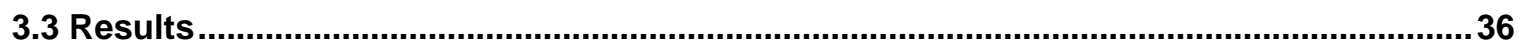

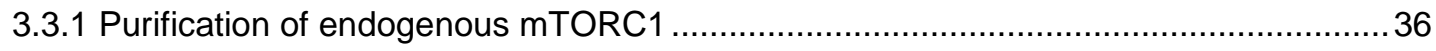

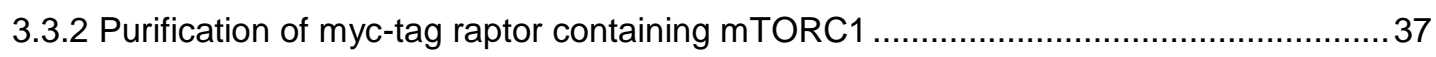

3.3.3 Identification of novel interacting partner of mTORC1 using nano-LC ESI Q-TOF

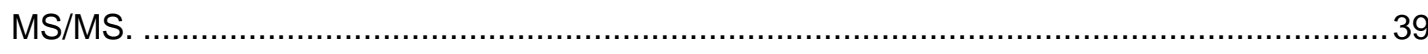

3.3.4 Functional annotation of newly identified mTORC1 interacting proteins ................... 41

3.3.5 Immunoblot confirmation of Edc4, dynamin 2 and hnRNP A2/B1 protein .................41

3.3.6 In silico prediction of the mTOR interaction with the newly identified partners ............42

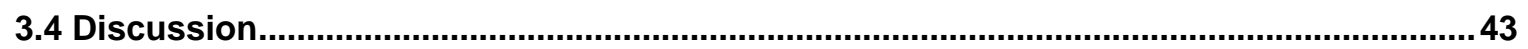

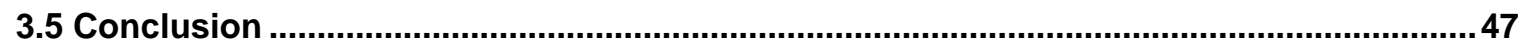

4. Enhancer of mRNA decapping protein 4 is the novel interacting partner of mTORC1 involved in mRNA decapping....................................................48 


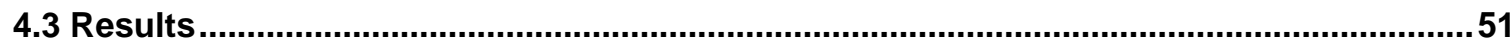

4.3.1 Edc4 is an interacting partner of raptor containing component of mTORC1 $1 . \ldots \ldots \ldots \ldots . . . .51$

4.3.2 Edc4 interacts with mTORC1 but not with mTORC2 …......................................... 52

4.3.3 Edc4 co-localized with raptor containing mTOR complex .......................................53

4.3.4 Both leucine starvation and rapamycin treatment enhanced total Edc4 protein expression

4.3.5 Edc4 and raptor interaction was rapamycin sensitive and rapamycin reduced the

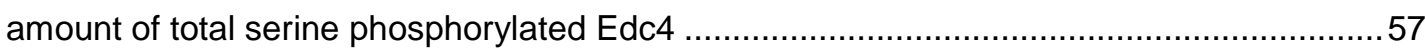

4.3.6 Rapamycin enhanced the mRNA decapping activity ...................................................59

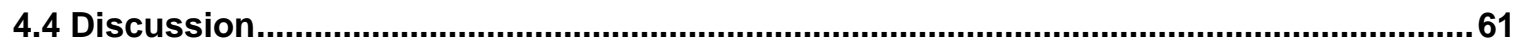

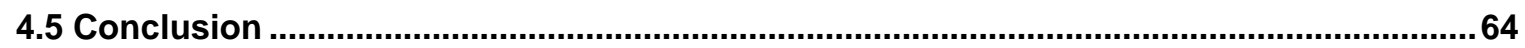

5. Fetal calf serum heat inactivation and lipopolysaccharide contamination influence the human T lymphoblast proteome and phosphoproteome....... 65

5.1 Abstract .66

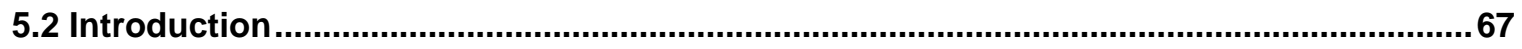

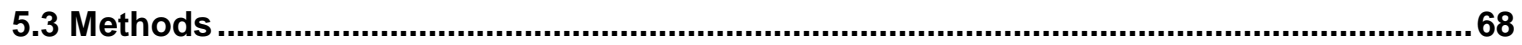

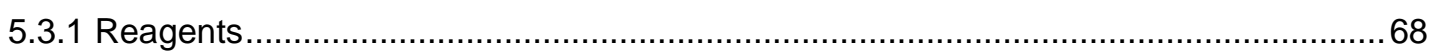

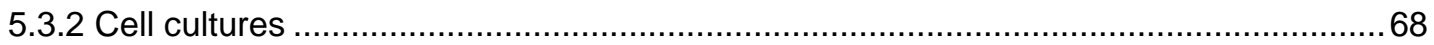

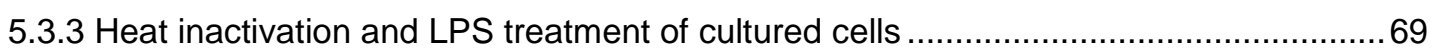

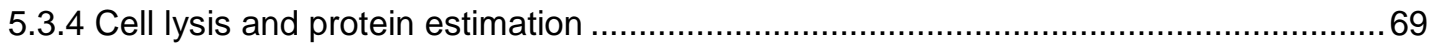

5.3.5 Sample preparation and two-dimensional gel electrophoresis (2-DE) ........................69

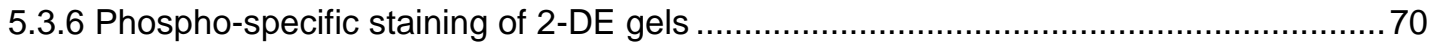

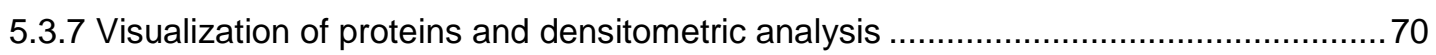

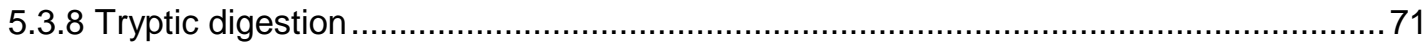

5.3.9 Peptide sequence analysis using nano LC ESI Q-TOF MS/M and database search ..71

5.3.10 SDS-PAGE and Western blotting .72 
5.3.11 Statistical analysis

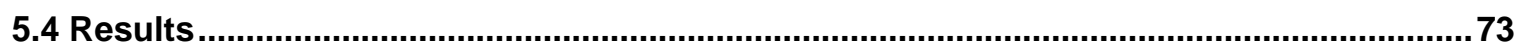

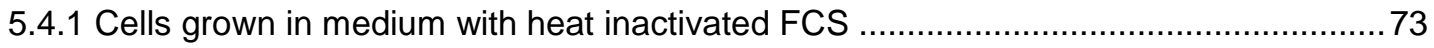

5.4.2 Proteins with altered expression as a function of FCS-LPS concentrations .................78

5.4.3 Proteins regulated by both LPS concentration and heat treatment of FCS...............79

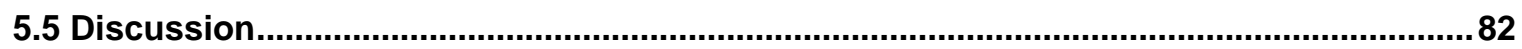

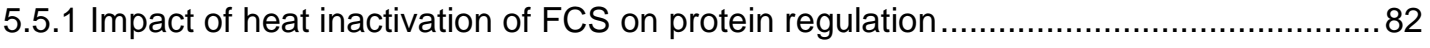

5.5.2 Impact of LPS contamination in FCS on protein regulation .................................. 83

5.5.3 Protein regulation by combined changes in LPS concentrations and heat treatment of FCS.

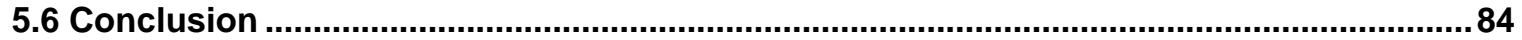

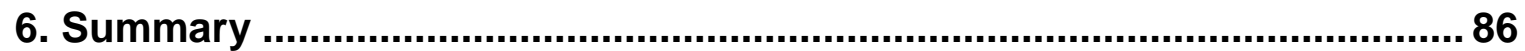

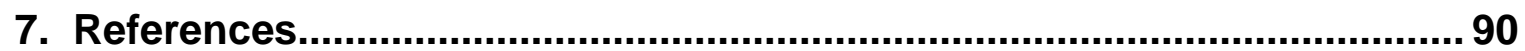

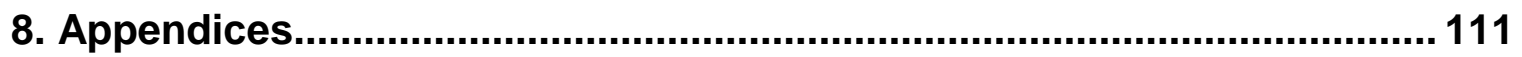

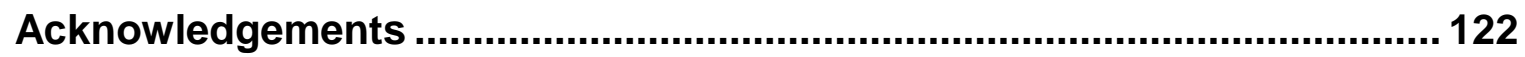

Curriculum Vitae ................................................................................. 123 


\section{List of Abbreviations}

$\begin{array}{ll}\text { AMPK } & \text { 5' adenosine monophosphate-activated protein kinase } \\ \text { ATP } & \text { Adenosine triphosphate } \\ \text { BPB } & \text { Bromophenol blue } \\ \text { BSA } & \text { Bovine serum albumin } \\ \text { Co-IP } & \text { Co-immunoprecipitation } \\ \text { DA } & \text { Diamide } \\ \text { Deptor } & \text { DEP-domain-containing mTOR-interacting protein } \\ \text { DMEM } & \text { Dulbecco's modified eagle medium } \\ \text { DMSO } & \text { Dimethylsulfoxide } \\ \text { ECL } & \text { Enhanced chemiluminescence } \\ \text { EDTA } & \text { Ethylene diamine tetra acetic acid } \\ \text { eEF2 } & \text { Translation elongation factor 2 } \\ \text { EGFR } & \text { Epidermal growth factor receptor } \\ \text { ER } & \text { Endoplasmic reticulum } \\ \text { ESI QTOF-MS } & \text { Electrospray ionization quadrupoles time-of-flight mass } \\ \text { FAT } & \text { spectrometry } \\ \text { 4E-BP1 } & \text { FRAP-ataxia-teleangiectasia } \\ \text { FATC } & \text { EIF4e binding protein 1 } \\ \text { FCS } & \text { FRAP, ATM, TRRAP C-terminal } \\ 5 '-T O P & \text { Fetal calf serum } \\ \text { FIP200 } & \text { 5' terminal tract oligopyrimidine } \\ \text { FKBP12 } & \text { FAK family kinase-interacting protein 200 } \\ \text { FRAP } & \text { FK506 binding protein 12 } \\ \text { FRB } & \text { FKBP-rapamycin-associated protein } \\ \text { GAP } & \text { FKBP12-rapamycin binding domain } \\ \text { GSK3 } & \text { GTPase activating protein } \\ \text { GßL } & \text { Glycogen synthase kinase 3 } \\ \text { HEAT } & \text { G protein beta subunit-like } \\ \text { HEK-293 } & \text { Huntingtin, elongation factor 3, PR65/A, TOR } \\ \text { HIF1 } & \text { Human embryonic kidney-293 } \\ \end{array}$




\begin{tabular}{|c|c|}
\hline HRP & Horseradish peroxidase \\
\hline IGF & Insulin-like growth factor \\
\hline IGF1 & Insulin growth factor 1 \\
\hline IGFR & Insulin-like growth factor receptor \\
\hline $\lg G$ & Immunoglobulin G \\
\hline IP & Immunoprecipitation \\
\hline IRS1 & Insulin receptor substrate 1 \\
\hline kDA & Kilo dalton \\
\hline LC MS/MS & Liquid chromatography and tandem mass spectrometry \\
\hline mATG13 & Autophagy-related protein 13 \\
\hline mSIN1 & $\begin{array}{l}\text { Mammalian stress-activated protein kinase interacting } \\
\text { protein }\end{array}$ \\
\hline mTORC1 & Mammalian target of rapamycin complex 1 \\
\hline mTORC2 & Mammalian target of rapamycin complex 2 \\
\hline mTOR & Mammalian target of rapamycin \\
\hline$\mu \mathrm{g}$ & Micro gram \\
\hline$\mu \mathrm{l}$ & Micro liter \\
\hline NRD & Negative regulatory domain \\
\hline PAO & Pheylarsine \\
\hline PBS & Phosphate buffered saline \\
\hline PDGFR & Platelet-derived growth factor receptor \\
\hline PDK1 & Phospholipid-dependent kinase 1 \\
\hline PDK2 & Phospholipid-dependent kinase 2 \\
\hline PI3K & Phosphoinositide-3-kinase \\
\hline PIC & Kinase translation pre-initiation complex \\
\hline PIKK & Phosphatidylinositol 3-kinase-related kinase \\
\hline PIP2 & Phosphatidylinositol-4,5-phosphate \\
\hline PIP3 & Phosphatidylinositol-3,4,5-phosphate \\
\hline PRAS40 & Proline rich AKT substrate $40 \mathrm{kDa}$ \\
\hline Protor1 & Protein observed with rictor 1 \\
\hline Protor2 & Protein observed with rictor 2 \\
\hline PRR5 & Proline-rich protein 5 \\
\hline PRR5L & Proline-rich protein 5 like protein \\
\hline
\end{tabular}




\section{List of Figures}

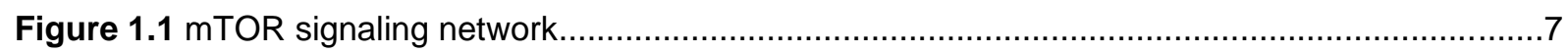

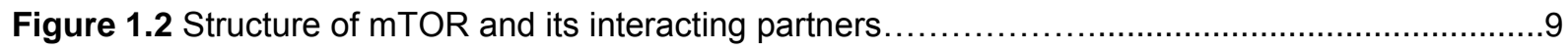

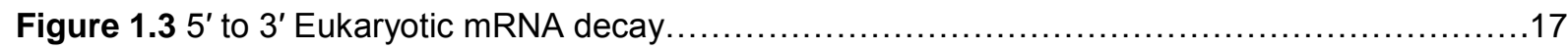

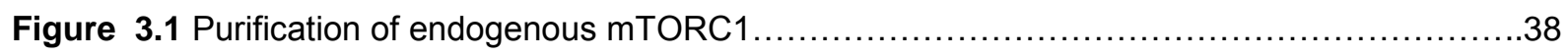

Figure 3.2 Purification of myc-tag raptor component of mTORC1 ...................................

Figure 3.3 Functional annotations of newly identified $\mathrm{mTORC} 1$ interacting proteins....................41

Figure 3.4. Immunoblot confirmation of Edc4, dynamin 2, and hnRNP A2/B1 proteins in human T

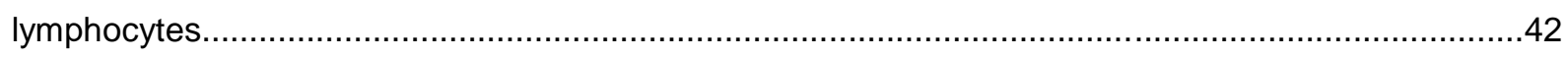

Figure 3.5 Biological interaction predictions of mTORC1 interacting proteins $\ldots \ldots \ldots \ldots \ldots \ldots \ldots \ldots . . . \ldots 3$

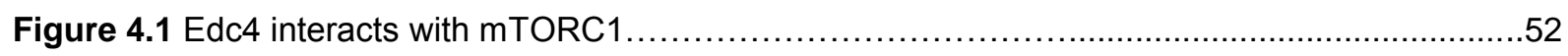

Figure 4.2 Edc4 interacts with mTORC1, but not with mTORC2 …...........................................53

Figure 4.3 Edc4 showed high co-localization with raptor component of mTORC1 $1 \ldots \ldots \ldots \ldots \ldots \ldots \ldots \ldots 5$

Figure 4.4 Leucine starvation and rapamycin treatment increased the Edc4 protein expression.........56

Figure 4.5 Edc4 and raptor interaction is rapamycin sensitive and rapamycin reduce the Edc4

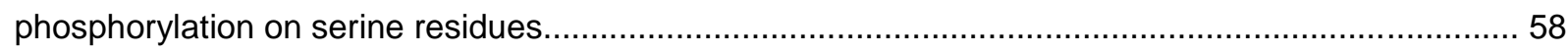

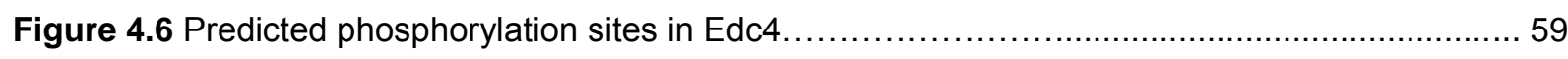

Figure 4.7 Rapamycin enhances the mRNA decapping activity ...................................60

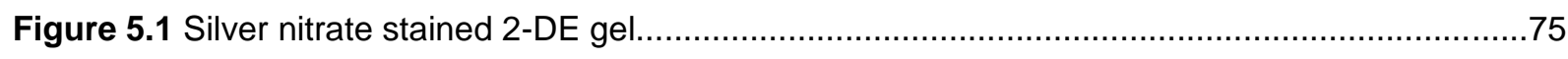

Figure 5.2 Graphical display of selected proteins significantly regulated in CCRF-CEM cells in silver

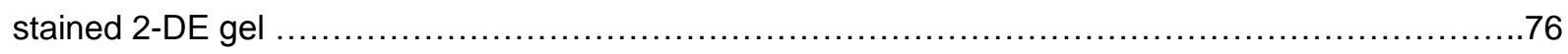

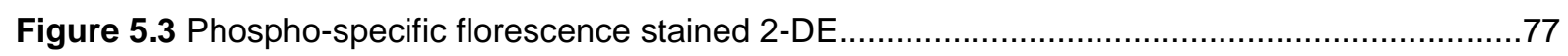

Figure 5.4 Proteins significantly regulated in CCRF-CEM cells in phospho-specific stained 2DE gel.78

Figure 5.5 Immunoblot analysis of superoxide dismutase 2 (SOD2) expression..............................79

Figure 6.1 mTORC1 interactomics; mTORC1 interplay in the mRNA decapping through interaction with Edc4

Appendix Figure 1 SDS-PAGE anlalysis of mTORC1 interacting proteins ........................111 


\section{List of Tables}

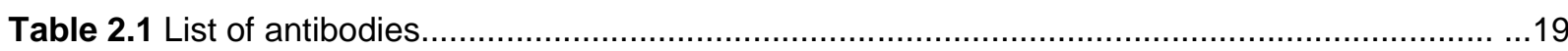

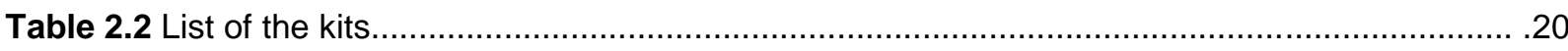

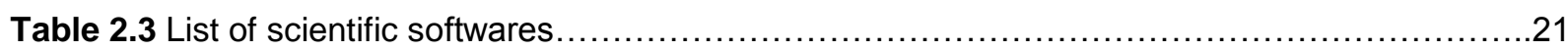

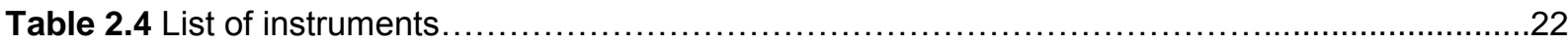

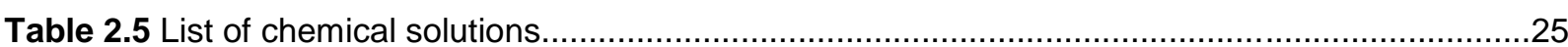

Table 3.1 Novel interacting partners of raptor component of mTORC1 identified using LC

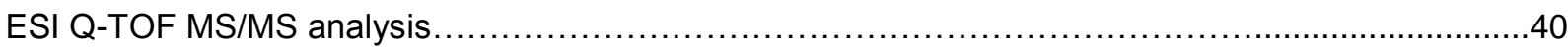

Table 5.1 Differentially regulated proteins by LPS and heat inactivation of FCS...............................80

Table 5.2 Differentially phosphorylated proteins by LPS and heat inactivation of FCS ........................81

Appendix Table 1: List of mTORC1 interacting proteins spectra identified by ESI Q-TOF

MS/MS analysis.

Appendix Table 2: MS/MS spectral data of differentially regulated proteins identified by Q-TOF analysis 


\section{Introduction}

\subsection{Mammalian target of rapamycin (mTOR)}

mTOR is a serine/threonine kinase which belongs to the phosphatidylinositol 3-kinase-related kinase (PIKK) family. It is essential for cell growth, proliferation, survival, and development [1-3]. At a molecular level, mTOR regulates transcription [2,4], translation [5,6], ribosome biogenesis [7], nutrient transport [8], lipid biosynthesis [9], autophagy [10], and actin cytoskeleton organization [11]. In humans, mTOR deregulation is implicated in parasitic infections [12], fungal infections [13], bacterial infections [14], viral infections [1517], autoimmune disorders [2,18,19], tuberous sclerosis [2], diabetes [20,21], obesity [22], neurological disorders [23-26], cardiac diseases [27], renal disease [28], and various cancers [25,26,29,30]. Previous studies demonstrated that stimuli which are required to activate or inhibit downstream effectors of mTOR, such as ribosomal protein S6 kinase 1 (S6K1) and elF4E binding protein 1 (4EBP1) fail to change in vitro mTOR kinase activity [31,32]. This inconsistency led to the assumption that in vivo mTOR might exist as a complex with one or more proteins that are destroyed during isolation of mTOR [32]. Recent literature supports the notion that mTOR controls cell growth and survival via an assembly of multi-protein signaling complexes [11,32-36]. mTOR exists in two distinct complexes defined by regulatory associated proteins of mTOR (raptor) and rapamycin insensitive companion of mTOR (rictor) as mTOR complex 1 (mTORC1) and mTOR complex 2 (mTORC2) respectively (Figure 1.1). These interacting proteins act as a scaffold for assembling complex and recruiting substrates and regulators [37].

\section{2 mTORC1}

mTORC1 was the first described TOR complex that is involved in anabolic and catabolic processes [38-40]. Seven interacting partners of mTORC1 have been described so far: mTOR, raptor, G protein beta subunit-like (GßL), proline rich Akt substrate $40 \mathrm{kDa}$ (PRAS40), DEP-domain-containing mTOR-interacting protein (deptor), RAS-related C3 botulinum toxin substrate 1 (rac1), and ragulator 
[32-36]. The cellular localization of mTORC1 is reported to include mitochondria, neuronal membranes, the nucleus, endoplasmic reticulum, Golgi apparatus, and lysosomes [6].

mTOR, a catalytic component of mTORC1 and mTORC2, was also named as FKBP-rapamycin-associated protein (FRAP), sirolimus effector protein (SEP), or rapamycin and FKBP target 1 (RAFT1) [41-43]. mTOR was first identified as TOR in Saccharomyces cerevisiae [44,45]. The name changed to mTOR when it was discovered that the protein possesses approximately $65 \%$ identity in its carboxy-terminal (C-terminus) domains and more than $40 \%$ homology in overall sequence to the TOR1 and TOR2 proteins of budding yeast [46]. TOR1 and TOR2 are high molecular weight proteins and are involved in translation [32]. TOR is comprised of several domains, seems to be highly conserved from yeast to mammalian cells, and shares $95 \%$ identity at the amino acid level [47]. mTOR itself is composed of 2549 amino acids and has a molecular mass of approximately $289 \mathrm{kDa}$ [48]. Structurally, mTOR possesses, at the N-terminus region, up to twenty tandem Huntingtin, elongation factor 3, PR65/A, TOR (HEAT) repeats and contain approximately 80 amino acids that are arranged in two anti-parallel $\alpha$-helices [38]. HEAT repeats are present in many proteins and mediate protein-protein interactions [49].

The kinase domain of mTOR is present at the C-terminus half and possesses sequence similarity with the catalytic domain of phosphatidylinositol 3kinase (PI3K) [47]. Immediately upstream of the kinase domain is the FRB domain, which is the binding site for FKBP12-rapamycin complex [47]. In addition, mTOR contains a relatively large FRAP-ataxia-teleangiectasia (FAT) domain immediately downstream to HEAT repeats [47]. The extreme carboxyterminal portion contains a second FAT domain known as FRAP, ATM, TRRAP C-terminal (FATC). The FATC domain is essential for the function of mTOR, and a single amino acid deletion in the FATC domain is sufficient to inhibit mTOR catalytic activity [47]. mTOR has a negative regulatory (NRD) domain between the catalytic and FATC domains [47]. NRD possesses two important adjacent phosphorylation sites (Thr 2446 and Ser 2448) for Akt mediated activation of mTOR [47] (Figure 1.2). 


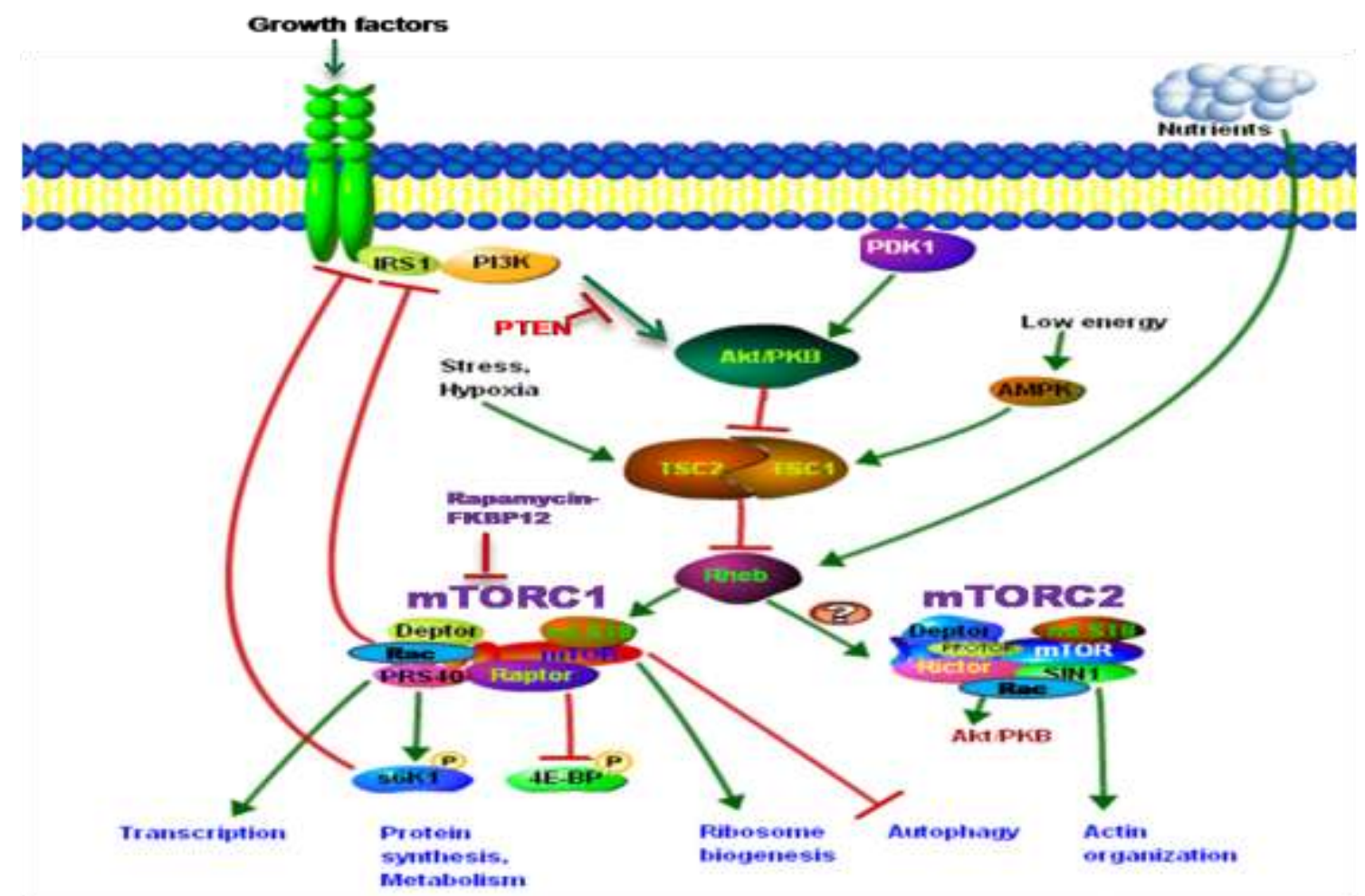

\section{Figure 1.1: mTOR signaling network.}

mTOR is present in two distinct complexes, mTORC1 and mTORC2. mTORC1, a rapamycin sensitive protein complex is composed of mTOR, raptor, GBL (mLST8), PRS40, rac1, and deptor. mTORC2, a rapamycin resistant complex is composed of mTOR, rictor, G $\beta \mathrm{L}$, $\sin 1$, protor, rac, and deptor. mTORC1 is the key sensor for the availability of growth factors, nutrients, and energy required to promote cellular growth under favorable conditions, or catabolic processes during stress and hypoxic conditions. mTOR signaling through the PI3K/Akt pathway is modulated by mitogenic stimuli from growth factors that bind with the tyrosine kinase receptor. This receptor then recruits and phosphorylates the IRS-1 and is followed by subsequent activation of PI3K and Akt. Alternatively, low ATP levels lead to the AMPK-dependent activation of the TSC1/TSC2 complex to reduce mTORC1 signaling. Nutrient availability is sensed by $\mathrm{mTORC} 1$ via rheb mediated activation of mTORC1. Active mTORC1 has a number of downstream biological functions including transcription, translation via the phosphorylation of downstream targets (4EBP1 and S6K1), ribosome biogenesis, and repression of autophagy and metabolism. The mTORC1 and S6K1 regulate IRS-1 expression via negative feedback loops. mTORC2 promotes cell survival by activating Akt and regulates cytoskeletal dynamics; however, the upstream regulators of mTORC2 are not yet defined. The image above was created using pathway builder provided by http://www.proteinlounge.com. The green arrows signify activating connections, whereas red lines represent inhibitory inputs. 
Raptor, a $149 \mathrm{kDa}$ polypeptide, binds directly to mTOR, and is thought to function as a scaffold protein which recruits mTOR substrates [32]. Raptor is an essential component of the mTORC1 complex and its knockout in mice is embryonically lethal [1,32]. Experimental evidence suggests that raptor is required for the proper folding and/or stability of mTOR kinase [32]. Human raptor possesses a unique raptor $\mathrm{N}$-conserved (RNC) domain at the $\mathrm{N}$-terminus followed by three HEAT repeats and seven tryptophan-aspartate (WD) repeats [32]. Thus the domain structure of raptor is consistent with its role as an adaptor in mTOR activity [32]. Raptor interaction with mTOR is regulated by the nutrient status of the cell. Nutrient starvation leads to a strong interaction between raptor and mTOR and thus inhibits the mTOR kinase activity; while a weaker interaction was observed between these two proteins after nutrient stimulation which itself increases the mTOR kinase activity [32]. Recent studies demonstrate that the raptor phosphorylation by AMPK inhibits the $\mathrm{mTORC1}$, while its phosphorylation by ERK1/2 modulates mTORC1 activity [50,51]. In 2003, Kim et al, reported GßL as an mTORC1 interacting protein and positive regulator of $\mathrm{mTORC} 1[1,33]$. In addition GBL interacts with $\mathrm{mTORC2}$, and its presence is essential for rictormTOR interaction [1]. Gene deletion of $G \beta L$ resulted in the down regulation of S6K1 phosphorylation at Thr389, which is a frequently used phospho-site to read-out the mTOR kinase activity [33,52,53].

mTOR interacting protein PRAS40, was first characterized by Sancak and coworkers in 2007 [35]. mTOR interacts with PRAS40 and phosphorylates it at multiple sites [54,55]. The van der Haar group reported that PRAS40 directly interacts with the mTOR catalytic domain [56], whereas Sancak and colleagues demonstrated that its association with $\mathrm{mTOR}$ is via raptor [35]. Several reports have implicated PRAS40 as a negative regulator of mTOR that inhibits mTOR autophosphorylation and kinase activity toward 4E-BP1, and PRAS40 itself $[35,57]$. Contrary to previous reports, PRS40 is also believed to be a positive regulator of mTOR kinase activity [58,59]. Deptor, another mTOR interacting protein is a negative regulator of both mTOR complexes [60]. Deptor binds with mTOR via its PDZ domain and regulates mTOR functions [60,61]. Deptor loss of function results in an increase in cell size and mediates protein synthesis $[60,62]$. 


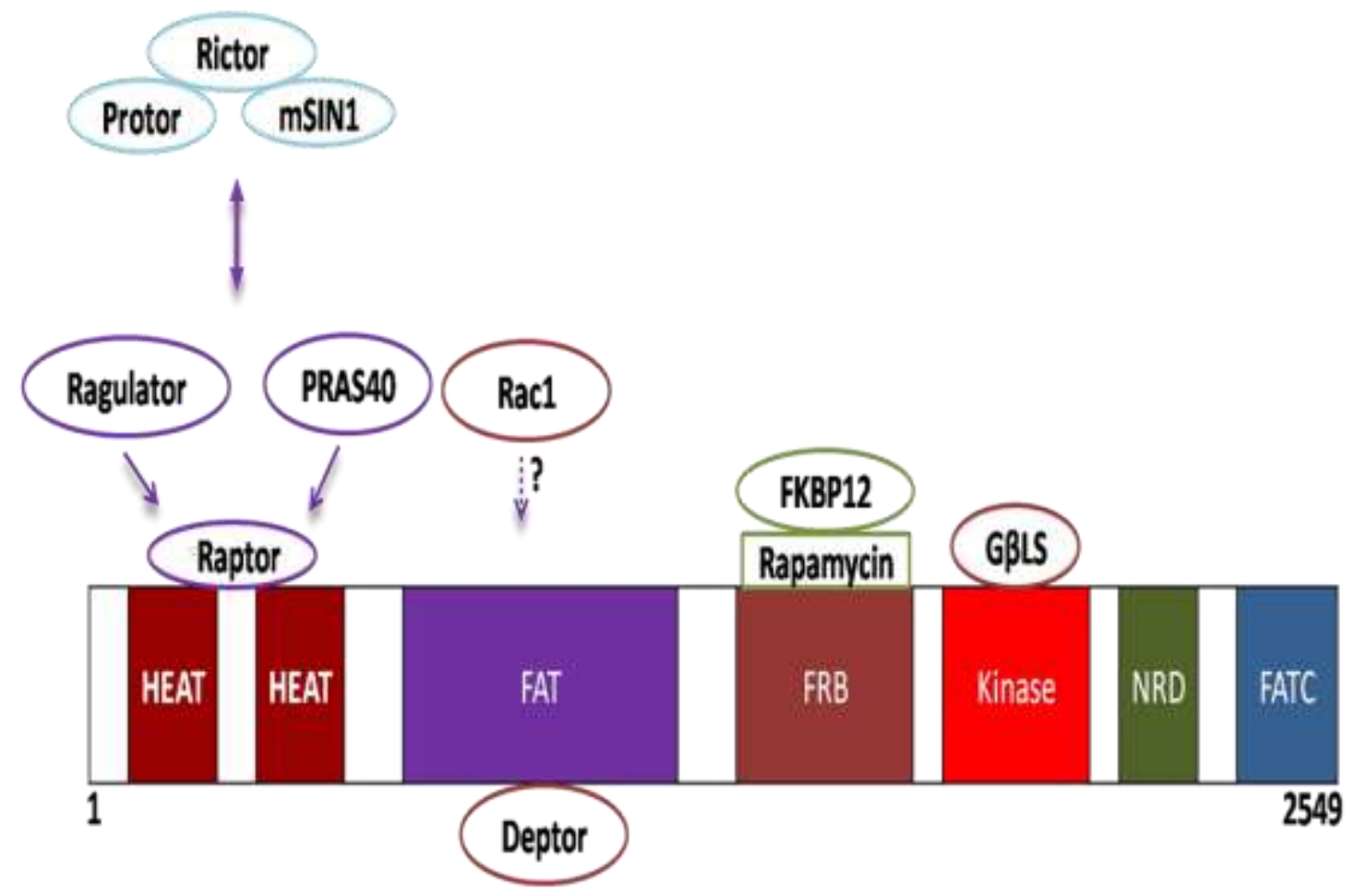

\section{Figure 1.2: mTOR protein and its known interacting partners.}

mTOR protein kinase consists of 2549 amino acids residues and has mutidomain structure. At its $\mathrm{N}$-terminus, it possesses up to 20 tandem HEAT repeats consisting of approximately 80 amino acidswhich mediate protein-protein interactions. Adjacent to HEAT repeats mTOR has a relatively large FAT domain. FRB domain is present downstream to FAT and provides binding site for FKBP12-rapamycin complex. The catalytic domain of mTOR is present at the C-terminus half. mTOR also has an NRD domain next to kinase domain and possess important regulatory phosphorylation sites. The extreme carboxy-terminal has a second FAT domain, named as FATC, which is essential for the mTOR function. It has been proposed that the FAT and FATC domain of mTOR interacts to attain a configuration that exposes the catalytic domain.

Ragulator protein was recently identified as a new component of mTORC1 [36]. Ragulator interacts with Rag proteins and mediates translocation of mTORC1 to the lysosomal surface, which is necessary for amino acids to activate mTORC1 signaling [36,63]. Rac1 is another, recently known interacting protein of mTORC1 which is a member of the Rho family of GTPases, and a crucial regulator of both mTORC1 and mTORC2 [34]. Rac1 appears to bind directly to mTOR, facilitating localization of both mTORC1 and mTORC2 at specific membranes sites, and activates their kinase function. Gene deletion of rac1 in primary cells inhibits activation of mTORC1 and mTORC2 signaling pathways [34]. 
Most of the mTORC1 components and functions are elucidated by using rapamycin, a macrolide molecule which specifically inhibits mTORC1 kinase activity [64]. Rapamycin, or sirolimus, was first isolated from the soil bacterium Streptomyces hygroscopicus found on Rapa Nui, also known as Easter Island [65]. The drug was first named rapamycin for Rapa Nui and was originally developed as an antifungal agent. Later, rapamycin's potent immunosuppressive and antiproliferative properties were discovered [19,65-67]. Rapamycin inhibits mTORC1 by binding to its intracellular receptor FK506 binding protein 12 (FKBP12) which interacts directly with the FKBP-rapamycin-binding (FRB) domain of mTOR $[42,43]$. Rapamycin inhibits the response to interleukin 2 (IL-2), and blocks the activation of $\mathrm{T}$ and $\mathrm{B}$ lymphocytes, thereby preventing cell cycle progression in G1 phase, and inhibiting cell proliferation [68,69]. At present, rapamycin is approved by the US Food and Drug Administration (FDA) as an immunosuppressive drug for kidney transplant patients, as cardiology drug to inhibit the restenosis after coronary artery stents, and for the treatment of advanced renal cell carcinoma [70-72].

\subsubsection{Regulators of mTORC1}

mTORC 1 kinase activity is regulated via growth factors, nutrients, energy, and stress signals [37].

\subsubsection{Growth factors}

mTOR signaling through the PI3K/Akt pathway is modulated by mitogenic stimuli from growth factors that bind to certain membrane receptors $[2,3,73]$. These receptors include epidermal growth factor receptor (EGFR), insulin growth factor 1 (IGF1), insulin-like growth factor receptor (IGFR), and platelet-derived growth factor receptor (PDGFR). The PI3K/Akt pathway can also be initiated by insulin via insulin receptor substrate 1 (IRS1) [2,74]. The binding of IGF to its tyrosine kinase receptor recruits and phosphorylates the IRS-1, which subsequently activates PI3K [75]. PI3K activation leads to the conversion of phosphatidylinositol-4,5-phosphate (PIP2) to phosphatidylinositol-3,4,5phosphate (PIP3), a crucial step negatively regulated by phosphatase and tensin homolog (PTEN) [38,76]. PIP3 accumulation recruits Akt to the cell membrane, 
where Akt is directly phosphorylated at Thr308 by phospholipid-dependent kinase 1 (PDK1), and additionally phosphorylated at Se473 by phospholipid-dependent kinase 2 (PDK2) [77-80]. PDK2 has now been identified as mTORC2 [77]. Akt phosphorylates mTOR, kinase through the tuberous sclerosis complex (TSC) [81]. TSC consists of tuberous sclerosis complex 1 (TSC1, hamartin), and tuberous sclerosis complex 2 (TSC2, tuberin) proteins. TSC1 stabilizes TSC2, while TSC2 acts as a GTPase-activating protein (GAP) for the small GTPase rheb (Ras homolog enriched in brain) [82-85]. GTP-bound rheb potently activates mTORC1, which further leads to activation of S6K1 (S6 kinase 1) and 4E-BP1 (eukaryotic initiation factor binding protein) inhibition, and thereby stimulates capdependent translation $[3,86]$. Although growth factors augment the mTORC1 signaling; mTORC1 limits the response to growth factors through a negative feedback loop via direct physical interaction with IRS1 [87]. The negative input from mTORC1 on the insulin pathway has several clinical implications e.g., the failure of rapamycin to inhibit tumor growth might be due to a loss of a negative feedback loop which leads to increase PI3K activity [88,89]. Future investigation of this regulatory loop may help to understand the molecular mechanisms of diabetes.

\subsubsection{Nutrients availability}

Cells response to nutrient restriction through the induction or repression of metabolic pathways [90]. The availability of nutrients such as amino acids regulates mTORC1 in a rheb dependent but in a TSC1/TSC2 independent manner. The exact mechanisms responsible for amino acid mediated mTORC1 regulation is not well understood [32,91,92]; However a recent study proposed a model where amino acids induce the translocation of mTORC1 to the lysosomal surface, and increase the rate of translation via $\mathrm{S} 6$ kinase activation and 4E-BP1 inhibition [6,36]. 


\subsubsection{Energy and stress}

mTORC1 activity is regulated by cellular energy level and stress signals such as hypoxia, genotoxic responses, and redox imbalance [3]. mTORC1 senses the cellular energy level via adenosine monophosphate-activated protein kinase (AMPK) [93]. Energy depletion activates AMPK, which is likely to mediate phosphorylation of TSC2 and leads to a shutdown of mTORC1 signaling possibly via rheb inhibition [93,94]. In another model ATP depletion activates AMPK mediated phosphorylation of raptor at the Ser722 and Ser792 residues, thereby providing a docking site for 14-3-3 protein which inhibits mTOR kinase activity [95]. A recent study indicates that inhibitors of mitochondrial respiration arrest mTORC1 even in the absence of AMPK, which suggests the existence of additional mechanisms of $\mathrm{mTORC} 1$ regulation through altered cellular energy levels [96].

Hypoxia or low oxygen stress inhibits mTORC1 signaling by REDD1 (regulated the development and DNA damage response 1) protein via TSC1-TSC2 activation [97,98]. Moreover, mTORC1 is responsible for sensing the genotoxic stress or DNA damage [99]. p53 is a central coordinator for genotoxic responses $[100,101]$. In response to DNA damage, p53 induces PTEN, TSC2 and REDD1, which all act as mTORC1 inhibitors [102,103]. p53 induction in response to genotoxic stress, supresses mTORC1 at multiple levels, and thus leads to inhibition of translation and transcription [102,103]. The activity of mTORC1 is sensitive to cellular redox status [104]. Reducing agents like British anti-lewisite (BAL) inhibit mTORC1 via strengthening of raptor to mTOR binding [104]. In contrast, oxidizing agents like phenylarsine oxide (PAO) and diamide (DA) activate mTORC1 signaling via the TSC-rheb pathway even in the absence of nutrient signals [104,105]; however these oxidants have no effect on mTOR-rictor interaction [104]. 


\subsubsection{Effectors of mTORC1}

mTORC1 is a key protein complex responsible for transmitting extracellular and intracellular signals to regulate metabolic processes $[6,38]$. Under nutrient rich conditions $\mathrm{mTORC1}$ increases the rate of translation and transcription via two well characterized mTORC1 effectors, S6K1 and 4E-BP1 $[2,6,32]$. S6K1 is a mitogen activated serine/threonine protein kinase that is required for cell growth [32,53]. Raptor component of mTORC1 binds to the TOR signaling (TOS) motif of S6K1, which leads to the mTORC1 mediated S6K1 phosphorylation at Thr389 [52,53,106]. Following mTORC1 mediated phosphorylation, S6K1 is further phosphorylated by PDK1 at Thr229 [5]. The active S6K1 phosphorylates S6 protein of the 40S ribosomal subunit which is involved in the translation of 5 '-terminal tract oligopyrimidine (5'-TOP) mRNAs [5]. In addition to S6 protein, S6K1 phosphorylates IRS1, glycogen synthase kinase 3 (GSK3), translation elongation factor 2 (eEF2), and Bcl-2-associated death promoter (Bad) [107]. S6K1 regulates IRS1 via a negative feedback loop as S6K1 phosphorylates IRS-1 on Ser302, Ser270, Ser307, Ser636, and Ser1101 residues $[108,109]$. S6K1 mediated phosphorylation of IRS1 interfers with its interaction with the insulin receptor, thus inhibiting insulin signaling [109,110]. This suggests $\mathrm{S} 6 \mathrm{~K} 1$ as a potential therapeutic target in restoring insulin sensitivity [110]. Furthermore, in response to both mitogen and nutrient-derived stimuli, S6K1 functions in a positive feedback manner by phosphorylating mTOR at Ser-2448 [52]. Julien and Carriere reported that mTORC1 mediated S6K1, phosphorylates rictor on Thr1135 and regulates mTORC2 functions, which highlight the indirect role of $\mathrm{mTORC} 1$ in the regulation of $\mathrm{mTORC2}$ [111]. Recent reports have demonstrated that S6K1 is activated by genotoxic stress and phosphorylate double minute 2 protein (Mdm2) which results in p53 induction [112].

A second major mTORC1 effector is 4E-BP1 which is involved in the regulation of cap-dependent mRNA translation [6]. 4E-BP1 acts as a translational repressor, it binds and inhibits elF4E which is a member of translation initiation complex elF4F [113]. mTORC1 inhibits 4E-BP1 activity via phosphorylation at Thr37 and Thr46, which are required for subsequent 4E-BP1 phosphorylation at 
Ser65 and Thr70 residues [114,115]. Hyper-phosphorylation of 4E-BP1 dissociates it from elF4E binding [115]. elF4E is then free to recruit elF4G and elF4A to the $5^{\prime}$-mRNA cap site [47]. The elF3, 40S ribosomal subunits and the ternary complex (elF2/Met-tRNA/GTP) are also recruited to the $5^{\prime}$-mRNA cap which results in the assembly of the translation pre-initiation complex (PIC), and activation of cap-dependent translation [47].

mTORC1 plays an important role in regulating cell mass by inhibiting cellular degradation or autophagy $[116,117]$. Autophagy sequesters degradable contents into autophagosomes which are then transported to lysosomes where proteases and hydrolases break down the luminal contents and recycle the resulting macromolecules [118]. Under nutrient rich conditions, mTORC1 (via raptor) binds to the autophagic proteins complex having Unc-51-like kinase 1 (ULK1), autophagy-related protein 13 (mAtg13), and FAK family kinaseinteracting protein 200 (FIP200). Following the mTORC1 binding to autophagic proteins, mTOR kinase phosphorylates ULK1 and mAtg13 [119], which inhibits autophagy, and promotes translation [119]. Under nutrient starved conditions, dissociation of mTORC1 from the ULK1-mAtg13-FIP200 complex, leads to the activation of ULK1. The activated ULK1 phosphorylates mAtg13 and FIP200, and thus encourages autophagy $[118,119]$.

mTORC1 regulates ribosome biogenesis, which is an anabolic process and uses a large proportion of cellular energy [5,7,120]. mTORC1 controls ribosome biogenesis by affecting the synthesis of ribosomal RNA (rRNA) and ribosomal proteins (RPs) [7]. Ribosomal synthesis essentially requires all three nuclear RNA polymerases: Pol I for the rRNA synthesis, Pol II for RP genes transcription, and Pol III for the synthesis of 5S RNA $[7,25]$. Pol I requires three basal factors for transcription initiation. These are TIFIA (transcription initiation factor IA), TIFIB (transcription initiation factor IB), and UBF (upstream binding factor) [121]. mTORC1 inhibition by rapamycin treatment induces Pol II gene expression and suppresses the initiation of Pol I and Pol III mediated transcription [122]. In addition, rapamycin has a significant effects on the global suppression of the majority of RP genes [123]. 


\section{3 mTORC2}

mTORC2, a rapamycin insensitive complex, is involved in cytoskeletal organization, cell proliferation, and cell size regulation [11,124]. The binding partners of mTORC2 include: rictor, GßL, mammalian stress-activated protein kinase interacting protein (mSIN1), protein observed with rictor 1 (protor-1), protein observed with rictor 2 (protor-2), rac1, and deptor [11,33,34,60,125,126]. Rictor is an approximately $192 \mathrm{kDa}$ protein, which was identified in mTOR immunoprecipitates from HeLa cells. Rictor is present exclusively in mTORC2, its association with mTOR is rapamycin insensitive, and it is indispensable for mTORC2 activity $[1,11,104]$. An endogenous equilibrium is proposed to exist whereby raptor and rictor compete for mTOR binding [11]. mTORC2 activates AKT phosphorylation on Ser473 via rictor and regulates cell survival in TSC2 null cells [127]. $\mathrm{mSinl}$, is an interacting partner of $\mathrm{mTORC} 2$ that is exclusively present in the rictor containing mTOR complexes [128]. mSinl has five spliced variants of which three can bind with mTORC2 [129]. Mice with mSinl knockout die at an early developmental stage, and knockdown results in a decrease in rictor phosphorylation, which disrupts the rictor-mTOR complex [125,130]. Protor-1, also known as proline-rich protein 5 (PRR5), binds directly with mTOR, and its knockdown inhibits Akt and S6K1 phosphorylation [131,132]. Protor-2 or PRR5L (proline-rich protein 5 like protein) is present in mTORC2 while it is absent from mTORC1 [57]. Unlike other mTORC2 components, protor-2 is not required for mTORC2 kinase function [57].

\subsection{Enhancer of mRNA decapping protein 4 (Edc4)}

In eukaryotes, gene expression is controlled at both the mRNA translation and degradation levels in the cytoplasm by the regulation of mRNA 5' N7-methylguanosine ( $\left.{ }^{\mathrm{m} 7} \mathrm{GpppN}\right)$ cap [133]. mRNA cap is pivotal for the nuclear export of mRNAs, protects them from exonucleolytic degradation and promotes their translation [133-135]. Cap is protected from decapping machinery through its interaction with the cytosolic cap binding proteins including elF4E and eIF4G of the elF4F complex [136]. Translation is down-regulated when elF4E is captured 
by 4E-BP1, a known downstream effector of mTORC1 signaling [4]. The mTORC1 interaction with 4E-BP1 is mediated by raptor and leads to 4E-BP1 phosphorylation [47]. Hyper-phosphorylation of 4E-BP1 mediates the release of elF4E from 4E-BP1 binding and allows elF4E to bind with the 5' mRNA cap. The elF4E binding with mRNA cap blocks the access of decapping complex towards $5^{\prime}$ mRNA cap and results in the activation of cap-dependent translation $[114,135,137,138]$. In contrast, mRNA decapping machinery removes the ${ }^{\mathrm{m} 7}$ GpppN cap from mRNA and leads to reduced mRNA translation and promotes mRNA degradation [139]. The mRNA decapping process is considered to take place in the processing bodies ( $P$ bodies) [140]. $P$ bodies are the cytosolic self assembled aggregations of messenger ribonuclear proteins (mRNPs) involved in mRNA turnover, RNA interference (RNAi), miRNA-mediated gene silencing and translation repression [139-141]. $P$ bodies are also considered as a potential site for the decapping of mRNA since the decapping proteins Dcp1a (enzymes mRNA-decapping enzyme 1a), Dcp2 (mRNA-decapping enzyme 2) and additional proteins reside in these cytosolic granules [142-144]. In yeast, Dcp2 directly interacts with Dcp1a and requires the enhancer of mRNA decapping 1-3 (Edc1-3), LSm1-7, RNA helicase 1, and Pat1 for its catalytic activity [145]. In higher eukaryotes, decapping requires an additional protein called the enhancer of mRNA decapping 4 (Edc4) (Hedls in humans; VARICOSE in Arabidopsis thaliana and Ge-1 in Drosophila melanogaster) which is essential for the in vitro catalytic activity of Dcp2 [146-148]. Recently a role for Edc4 was also suggested in miRNA mediated translational repression [146,149] (Figure 1.3). Edc4 is a important component of $\mathrm{P}$ bodies and its knockdown leads to the loss of $\mathrm{P}$ bodies in human cells and in Drosophila melanogaster $[140,146,148]$. The localization of decapping enzyme complex Dcp1a and Dcp2 in the P bodies is dependent on the presence of Edc4, and depletion of the decapping enzyme complex blocks the accumulation of Dcp1a and Dcp2 in the P bodies [146]. 


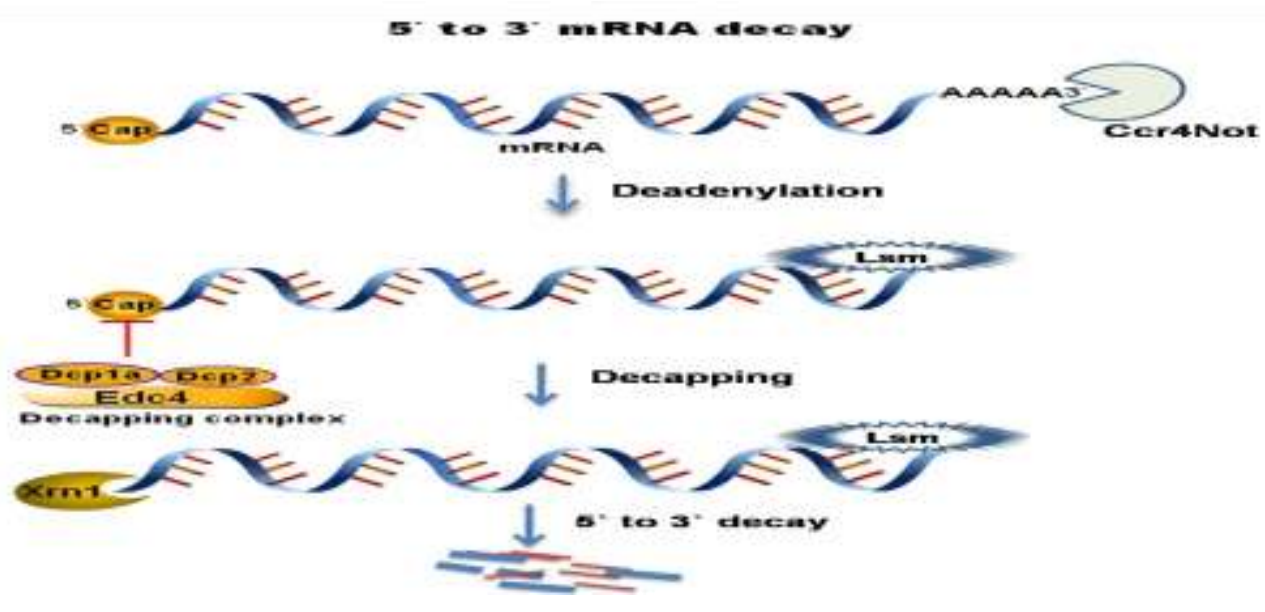

Figure 1.3: 5' to 3' eukaryotic mRNA decay.

In eukaryotes, mRNA decay is initiated by the removal of a 3-poly (A) tail by Ccr4Not deadenylases. Following deadenylation, mRNA is degraded in a $5^{\prime}$ to $3^{\prime}$ decay manner. In the $5^{\prime}$ to 3 ' decay pathway, the Lsm protein complex associates with the $3^{\prime}$ end of the mRNA transcript and activates the decapping process by recruiting the Edc4/Dcp1a/Dcp2 complex at the $5^{`}$ end to remove the cap. Removal of the 5 cap allows the exoribonuclease, Xrn1p to degrade mRNA ( the image above was created using the pathway builder provided by http://www.proteinlounge.com).

The inhibition of TOR appears to accelerate the mRNAs turnover by mRNA deadenylation dependent decapping pathway [47,150]. Rapamycin mediated inhibition of TOR in yeast induced the expression of various decapping proteins [150], however the exact role of mTORC1 signaling in the mRNA decay via Edc4 is not yet clear.

\subsection{Rationale for the proposed research}

mTOR is a potent protein kinase involved in various biological processes through its interaction with different proteins. The aim of the present study was to identify the novel interacting partners of mTORC 1 in human cells using an affinity purification approach coupled with nano-LC Q-TOF MS/MS analysis. For this purpose, we used both endogenous and myc-tag purification strategies. Parallel purification of rictor, an essential and exclusive interactor of mTORC2, was utilized to ensure the purification of only mTORC1 via raptor. Further studies characterized the novel interactor of mTORC1 "the enhancer of mRNA decapping protein (Edc4)" as an important protein component of mRNA decapping machinery. This study reports a new role of mTORC1 in the mRNA decapping process via regulation of Edc4. 


\section{Materials and methods}

\subsection{Materials}

\subsubsection{Cell lines and cell culture media}

T lymphocytes (CCRF-CEM) and human embryonic kidney (HEK) 293 cells were purchased from DSMZ (German collection of microorganisms and cell cultures, Braunschweig, Germany); RPMI 1640 and DMEM, Dulbecco's phosphate buffer saline (PBS) and 10\% fetal bovine serum (FBS) obtained from PAA Laboratories Colbe, Germany; Penicillin and streptomycin were from Biochrome, Berlin, Germany. RPMI 1640 without leucine was purchased from Sigma-Aldrich, Steinheim, Germany.

\subsubsection{Reagents and miscellaneous materials}

Reagents were obtained from the following sources: Lipofectamine LTX, Opti MEM, Dynabeads G, TRIzol and 4,6-diamidino-2-phenylindole (DAPI) were from Invitrogen, Darmstadt, Germany. CHAPS buffer was from Applichem, Darmstadt, Germany. Triton X-100 lysis buffer was from Cell Signaling Technology, MA, USA. Complete protease and phosphatase inhibitors cocktail were from Roche, Mannheim, Germany. Rapamycin was from LC Laboratories, MA, USA. Dithiothreitol (DTT), trypsin, triflouroacetic acid (TFA), formic acid (FA), acitonitril $(A C N)$, ammonium bicarbonate (AMBIC), leucine were from Sigma-Aldrich, Steinheim, Germany. Silver nitrate was from Carl Roth, Karlsruhe, Germany, and Fluoromount was from DAKO, Hamburg, Germany. Enhanced chemiluminscent (ECL) reagent and Amersham Hyperfilms were from GE Healthcare, Buckinghamshire, UK. 8 chamber well slides (Lab-Tek ${ }^{\mathrm{TM}}$ II; Thermo were from Fisher Scientific, Bonn, Germany. PVDF membrane was from Millipore, Schwalbach Germany, and myc-tag raptor pRK5 plasmid was gifted by Dr. Doss Sarbassove (The University of Texas, USA). If the name of any reagent not listed here otherwise referred in the text. 


\subsubsection{Antibodies}

Antibodies used for Western blotting (WB), immunoprecipitation (IP) and immunofluorescence (IF) are listed in the following table.

Table 2.1: List of antibodies.

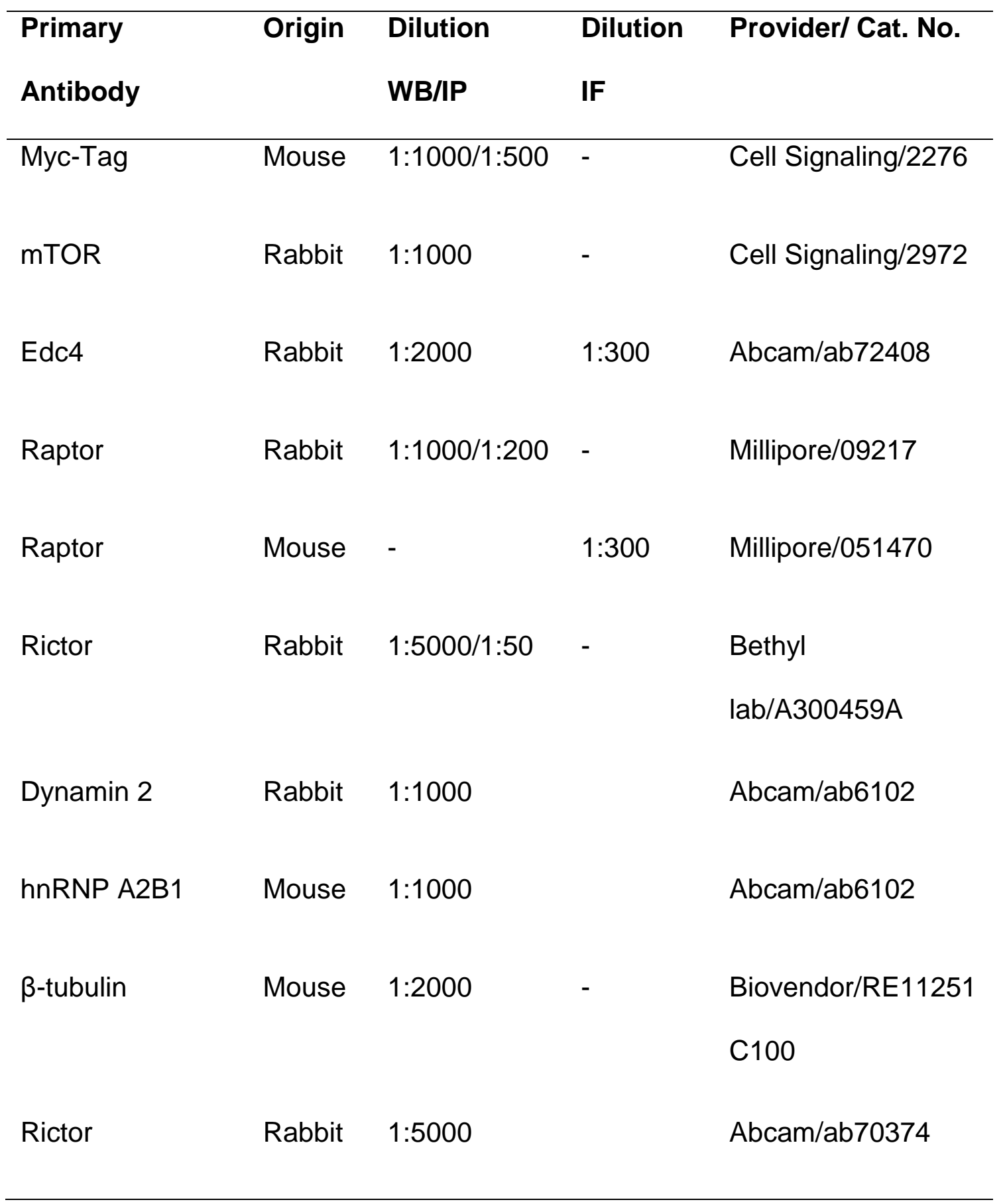




\begin{tabular}{lllll}
\hline $\begin{array}{l}\text { Secondary } \\
\text { antibody }\end{array}$ & Origin & $\begin{array}{l}\text { Dilution } \\
\text { WB }\end{array}$ & $\begin{array}{l}\text { Dilution } \\
\text { IF }\end{array}$ & Company/ Cat. No. \\
\hline Anti mouse HRP & Goat & $1: 3000$ & - & Bio-Rad/1706516 \\
Anti rabbit HRP & Goat & $1: 3000$ & - & Bio-Rad/1706515 \\
Anti mouse & Goat & - & $1: 200$ & Dianova/115165146 \\
Cydye3 & & & & \\
Anti rabbit AF488 & Goat & - & $1: 200$ & Molecular \\
& & & & Probes/A11070 \\
\hline
\end{tabular}

\subsubsection{Kits}

All the listed kits were used according to the vendor's instructions.

Table 2.2: List of the kits.

\begin{tabular}{lll}
\hline Name & Company/ Cat. No. & Application \\
\hline ProtoScript $\circledast$ & E6300 & cDNA Synthesis Kit \\
High speed plasmid maxi kit & Qiagen/12662 & $\begin{array}{l}\text { Plasmid DNA } \\
\text { preparation }\end{array}$ \\
High speed plasmid maxi kit & Qiagen/12663 & $\begin{array}{l}\text { Plasmid DNA } \\
\text { preparation }\end{array}$ \\
QIAquick gel extraction kit & Qiagen/28704 & DNA gel extraction \\
& & \\
Eukayotic mRNA isolation kit & Epicentre & Capped mRNA \\
& Biotechnologies/MOE5 & isolation \\
& 1010 & \\
Co-immunoprecipitation kit & Pierce/23620 & Immunoprecipitation \\
\hline
\end{tabular}




\subsubsection{Softwares}

The following scientific software's were used to accomplish the study.

Table 2.3: List of scientific softwares.

\begin{tabular}{|c|c|c|}
\hline Program & Use & References \\
\hline ImageJ 1.43u & Densitometric analysis & $\mathrm{NIH}, \mathrm{MD}, \mathrm{USA}$. \\
\hline Lablmage 2.7.1 & Densitometric analysis & $\begin{array}{l}\text { Kapelan GmbH, Leipzig, } \\
\text { Germany. }\end{array}$ \\
\hline Graphpad Prism 5 & Statistical analysis & $\begin{array}{l}\text { GraphPad Software Inc. } \\
\text { California, USA. }\end{array}$ \\
\hline WCIF ImageJ & Colocalization analysis & NIH, MD, USA. \\
\hline Axiovision & Colocalization analysis & Carl Zeiss, Jena, Germany. \\
\hline $\begin{array}{l}\text { Zeiss LSM } \\
4.2 .0 .121\end{array}$ & Immunofluorescence & $\begin{array}{l}\text { Microlmaging GmbH, } \\
\text { Goettingen, Germany. }\end{array}$ \\
\hline $\begin{array}{l}\text { MassLynx version } \\
4.0\end{array}$ & $\begin{array}{l}\text { LC MS/MS data } \\
\text { acquisition }\end{array}$ & Micromass, Manchester, UK. \\
\hline $\begin{array}{l}\text { Protein Lynx Global } \\
\text { Server version } 2.2\end{array}$ & $\begin{array}{l}\text { LC MS/MS data } \\
\text { analyzer }\end{array}$ & Micromass, Manchester, UK. \\
\hline Mascot & $\begin{array}{l}\text { MS/MS peak lists } \\
\text { search }\end{array}$ & Matrix science, London, UK. \\
\hline GeneMania & $\begin{array}{l}\text { Protein protein } \\
\text { interaction }\end{array}$ & University of Toronto, Canada. \\
\hline String & $\begin{array}{l}\text { Protein protein } \\
\text { interaction }\end{array}$ & EMBL, Heidelberg, Germany. \\
\hline Cytoscape & $\begin{array}{l}\text { Protein protein } \\
\text { interaction }\end{array}$ & NRNB, USA. \\
\hline NetPhos 2.0 Server & Phospho-sites analysis & CBSA, Lyngby, Denmark. \\
\hline Phosphosite Plus & Phospho-sites analysis & $\begin{array}{l}\text { Cell Signaling Technology, } \\
\text { MA, USA. }\end{array}$ \\
\hline
\end{tabular}




\subsubsection{Instruments used in the study}

Table 2.4: List of instruments.

\begin{tabular}{|c|c|c|}
\hline Instruments & Product ID/Cat.No. & Vendor \\
\hline \multirow[t]{4}{*}{ Bio-safety Cabinet } & Hera safe KS & Heraeus, Osterode, \\
\hline & & Germany. \\
\hline & SterilGard 3 Advance & Baker comapany, \\
\hline & & Sanford, USA. \\
\hline \multirow[t]{12}{*}{ Incubator } & Cytosperm 2 & Heraeus, Osterode, \\
\hline & & Germany. \\
\hline & BBD 6220 & Heraeus, Osterode, \\
\hline & & Germany. \\
\hline & Certomat R & Sartorius, Goettingen, \\
\hline & & Germany. \\
\hline & Memmert & Memmert, Schwabach, \\
\hline & & Germany. \\
\hline & Biometra WT17 & Biometra, Goettingen, \\
\hline & & Germany. \\
\hline & Rotamax 120 & Heidolph Instruments, \\
\hline & & Schwabach, Germany. \\
\hline \multirow[t]{8}{*}{ Centrifuges } & Rotina 380 & Hettich,Tuttlingen, \\
\hline & & Germany. \\
\hline & Minifuge $T$ & Hettich,Tuttlingen, \\
\hline & & Germany. \\
\hline & Rotina 35R & Hettich, Tuttlingen, \\
\hline & & Germany. \\
\hline & $5415 \mathrm{C}$ & Eppendorf, Hamburg, \\
\hline & & Germany. \\
\hline
\end{tabular}




\begin{tabular}{|c|c|c|}
\hline & Abbot 3530 & $\begin{array}{l}\text { Abbot, Delekenheim, } \\
\text { Germany. }\end{array}$ \\
\hline & MHK 2 & $\begin{array}{l}\text { Sarstedt, Numrecht, } \\
\text { Germany. }\end{array}$ \\
\hline \multirow[t]{6}{*}{ Spectrophotometers } & EL 808 & $\begin{array}{l}\text { Biotech instruments, } \\
\text { Winooski-vermont, USA. }\end{array}$ \\
\hline & DU 7500 & $\begin{array}{l}\text { Beckman, Krefeld, } \\
\text { Germany. }\end{array}$ \\
\hline & Gene Quant 2 & $\begin{array}{l}\text { Pharmacia Biotech, } \\
\text { Cambridge, England. }\end{array}$ \\
\hline & KC4 & $\begin{array}{l}\text { Biotek, Friedrichshall, } \\
\text { Germany. }\end{array}$ \\
\hline & Nanodrop 2000c & $\begin{array}{l}\text { Thermo Scientific, RF, } \\
\text { USA. }\end{array}$ \\
\hline & Agilent 2100 Bioanalyzer & $\begin{array}{l}\text { Agilenttechnologies, } \\
\text { Waldbronn, Germany. }\end{array}$ \\
\hline \multirow[t]{3}{*}{ Power supply } & Power Pac 300 & $\begin{array}{l}\text { Bio-Rad, Munich, } \\
\text { Germany. }\end{array}$ \\
\hline & Power Pac 1000 & $\begin{array}{l}\text { Bio-Rad, Munich, } \\
\text { Germany. }\end{array}$ \\
\hline & EPS 500/400 & $\begin{array}{l}\text { Pharmacia fine } \\
\text { chemicals, Uppsala, } \\
\text { Sweden. }\end{array}$ \\
\hline \multirow[t]{2}{*}{$\begin{array}{l}\text { Electrophoresis } \\
\text { apparatus }\end{array}$} & Mini-Protean® III & $\begin{array}{l}\text { Bio-Rad, Munich, } \\
\text { Germany. }\end{array}$ \\
\hline & Transblot SD & $\begin{array}{l}\text { Bio-Rad, Munich, } \\
\text { Germany. }\end{array}$ \\
\hline Confocal microscope & Axiovert $200 \mathrm{M}$ & Carl Zeiss, Jena, \\
\hline
\end{tabular}




\begin{tabular}{|c|c|c|}
\hline & & Germany. \\
\hline Inveted microscope & Diavert & Leitz, Wetzlar, Germany. \\
\hline \multirow[t]{2}{*}{ Water bath } & 1003 & $\begin{array}{l}\text { GFL, Burgwedel, } \\
\text { Germany. }\end{array}$ \\
\hline & LS 10 & $\begin{array}{l}\text { Schutt Labortechnik, } \\
\text { Goettingen, Germany. }\end{array}$ \\
\hline \multirow[t]{2}{*}{ Mixer } & HP0306449 & $\begin{array}{l}\text { H+P Labottechnik, } \\
\text { Munich, Germany. }\end{array}$ \\
\hline & Gene 2 & $\begin{array}{l}\text { Schutt Labortechnik, } \\
\text { Goettingen, Germany. }\end{array}$ \\
\hline Dynabeads rack & MagnaRack 15000 & Invitrogen, CA, USA. \\
\hline Autoclave & Technomara & $\begin{array}{l}\text { Technomara, Fernwald, } \\
\text { Germany. }\end{array}$ \\
\hline Ice machine & Ice maker & $\begin{array}{l}\text { Ziegra, Isernhagen, } \\
\text { Germany. }\end{array}$ \\
\hline Sonicator & Bsonifier 250 & $\begin{array}{l}\text { G. Heinemann, } \\
\text { Schwabisch Gmud, } \\
\text { Germany. }\end{array}$ \\
\hline Microwave oven & ER $6320 \mathrm{PW}$ & $\begin{array}{l}\text { Brother International, } \\
\text { Bad Vilbel, Germany. }\end{array}$ \\
\hline $\mathrm{pH}$ meter & pH 526 & $\begin{array}{l}\text { WTW, Weilheim, } \\
\text { Germany. }\end{array}$ \\
\hline Heated magnetic stirrer & iKAMAG RCT & $\begin{array}{l}\text { IKA-Labortechnik, } \\
\text { Staufen, Germany. }\end{array}$ \\
\hline Thermomixer & Compact 5436 & $\begin{array}{l}\text { Eppendorf, } \\
\text { Hamburg,Germany. }\end{array}$ \\
\hline Balance & R180DD1 & Sartorious, Goettingen, \\
\hline
\end{tabular}


Germany.

Freeze drier

Vacuum drier

Gel drier

Scanner

Gene Pulser Xcell

electroporation unit

UV-transilluminator

Gel documantation unit

Real time PCR

Thermal Cycler

Mass spectrometer
Alpha 14 LD

UNIVAPO 150H

GD583

CanoScan 8400F

FL5100

1652660

200x $200 \mathrm{~mm}$

DVP 1200

Light cycler

TGradient

PC9501261

QTOF ultima Global
SciQuip Ltd. Shropshire, UK.

UNIEQUIP, Martinsried, Germany.

Bio-Rad, Munich, Germany.

Canon, Krefeld, Germany.

Fuji, Darien, Japan.

Bio-Rad, Munich, Germany.

Bachofer, Reutlingen, Germany.

SEIKO Precision Inc. Japan.

Roche, Mannheim, Germany.

Biometra, Goettingen, Germany.

Biometra, Goettingen, Germany.

Micromass, Manchester, UK.

\subsubsection{Buffers and solutions}

Table 2.5: List of chemical solutions 


\begin{tabular}{|c|c|}
\hline \multirow[t]{4}{*}{ CHAPS buffer lacking $\mathrm{NaCl}$} & 40 mM HEPES [pH 7.4] \\
\hline & $0.3 \%$ CHAPS \\
\hline & EDTA-free protease and phosphatase \\
\hline & inhibitors \\
\hline \multirow[t]{5}{*}{ CHAPS buffer with $\mathrm{NaCl}$} & 40 mM HEPES [pH 7.4] \\
\hline & $150 \mathrm{mM} \mathrm{NaCl}$ \\
\hline & $0.3 \%$ CHAPS \\
\hline & EDTA-free protease and phosphatase \\
\hline & inhibitors \\
\hline \multirow[t]{11}{*}{ Triton X-100 Lysis buffer } & $20 \mathrm{M}$ Tris- $\mathrm{HCl}[\mathrm{pH} 7.5]$ \\
\hline & $150 \mathrm{mM} \mathrm{NaCl}$ \\
\hline & $1 \mathrm{mM} \mathrm{Na}_{2} \mathrm{EDTA}$ \\
\hline & 1 mM EGTA \\
\hline & $1 \%$ Triton-100 \\
\hline & $2.5 \mathrm{mM}$ sodium pyrophosphate \\
\hline & $1 \mathrm{mM}$ beta-glycerophosphate \\
\hline & $1 \mathrm{mM} \mathrm{Na}_{3} \mathrm{VO}_{4}$ \\
\hline & $1 \mu \mathrm{g} / \mathrm{ml}$ leupeptin \\
\hline & EDTA-free protease and phosphatase \\
\hline & inhibitors per $20 \mathrm{ml}$ \\
\hline \multirow[t]{3}{*}{ Electrophoresis buffer (5x) } & 0.025 M Tris- $\mathrm{HCl}[\mathrm{pH} 8.3]$ \\
\hline & 0.192 M Glycine \\
\hline & $0.1 \%$ SDS \\
\hline \multirow[t]{5}{*}{ Laemmli buffer (2x) } & 0.125 M Tris- $\mathrm{HCl}[\mathrm{pH} 6.8]$ \\
\hline & $4 \%$ SDS \\
\hline & $20 \%$ glycerol \\
\hline & $0.2 \mathrm{mM}$ DDT \\
\hline & $0.03 \mathrm{mM}$ bromophenol blue \\
\hline Transblot buffer for nitrocellulose & 25 mM Tris- $\mathrm{HCl}[\mathrm{pH} 8.3]$ \\
\hline \multirow[t]{2}{*}{ membrane } & 192 mM glycine \\
\hline & $20 \%$ methanol \\
\hline Transblot buffer for PVDF & 25 mM Tris- $\mathrm{HCl}$ [pH 8.3] \\
\hline membrane (semi dry) & 192 mM glycine \\
\hline
\end{tabular}




\begin{tabular}{|c|c|}
\hline \multirow{3}{*}{ 10X Tris buffere saline (TBS) } & $10 \%$ methanol \\
\hline & 50 mM Tris- $\mathrm{HCl}[\mathrm{pH} 7.5]$ \\
\hline & $200 \mathrm{mM} \mathrm{NaCl}$ \\
\hline 1xTBS-T & TBS and Tween-20 (0.05\%) \\
\hline Blocking buffer & $5 \%$ Milk Powder in TBS-T \\
\hline \multirow[t]{3}{*}{ Stripping buffer } & 50 mM Tris-HCl [pH 7] \\
\hline & $2 \%$ SDS \\
\hline & $50 \mathrm{mM}$ DTT \\
\hline \multirow[t]{3}{*}{ Trypsin digestion buffer } & $0.1 \mu \mathrm{g} / \mu \mathrm{l}$ trypsin \\
\hline & $1 \mathrm{M}$ calcium chloride \\
\hline & $1 \mathrm{M}$ ammonium bicarbonate $[\mathrm{pH} 7.4]$ \\
\hline \multicolumn{2}{|l|}{ Silver staining solutions } \\
\hline \multirow[t]{2}{*}{ Fixation solution } & $50 \%$ methanol \\
\hline & $12 \%$ acetic acid \\
\hline Wash solution I & $50 \%$ ethanol \\
\hline Wash solution 2 & $30 \%$ ethanol \\
\hline Sensitizing solution & $0.8 \mathrm{mM} \mathrm{Na}_{2} \mathrm{~S}_{2} \mathrm{O}_{3}$ in $\mathrm{dd} \mathrm{H}_{2} \mathrm{O}$ \\
\hline \multirow[t]{2}{*}{ Silver nitrate solution } & $0.2 \% \mathrm{AgNO}_{3}$ \\
\hline & $0.026 \%$ formaldehyde in $\mathrm{ddH}_{2} \mathrm{O}$ \\
\hline \multirow[t]{3}{*}{ Developing solution } & $6 \% \mathrm{Na}_{2} \mathrm{CO}_{3}$ \\
\hline & $0.0185 \%$ formaldehyde \\
\hline & $16 \mu \mathrm{M} \mathrm{Na}_{2} \mathrm{~S}_{2} \mathrm{O}_{3}$ in $d d \mathrm{H}_{2} \mathrm{O}$ \\
\hline \multirow[t]{2}{*}{ Stop solution } & $50 \%$ methanol \\
\hline & $12 \%$ acetic acid \\
\hline Storage solution & $5 \%$ acetic acid solution \\
\hline
\end{tabular}




\subsection{Methods}

\subsubsection{Cell culture}

CCRF-CEM and HEK293 cells were grown in RPMI-1640 and DMEM medium supplemented with $10 \%$ FCS, 100,000 U/L penicillin and $100 \mu \mathrm{g} / \mathrm{L}$ streptomycin under $95 \%$ humidity and $5 \% \mathrm{CO} 2$ conditions at $37^{\circ} \mathrm{C}$.

\subsubsection{Cell lysis and endogenous mTORC1 purification}

Cells were rinsed with cold PBS and lysed on ice cold CHAPS buffer lacking $\mathrm{NaCl}$ to isolate mTOR complexes (Peterson et al. 2009). Cell lysates were centrifuged at $13000 \mathrm{rpm}$ for 15 minutes at $4^{\circ} \mathrm{C}$ followed by pre-clearing with dynabeads G. Antibodies for immunoprecipitation (IP) and co-immunoprecipitation (Co-IP) were added to the lysate and incubated for 30 minutes at $4^{\circ} \mathrm{C}$. Dynabeads G $(40 \mu l)$ were added to the antibody and lysate mixture, and incubated for overnight at $4{ }^{\circ} \mathrm{C}$. Immunoprecipitation of specific rictor containing mTORC2 using rictor antibody was incorporated as a negative control to validate the purity of specific raptor containing mTORC1. Mock IP or antibody minus control was used to exclude false interaction of lysate proteins with the dynabeads. In addition, blocking peptide (BP) was synthesized (Seq Laboratories, Goettingen, Germany), which represents the epitope of a raptor antibody. BP was incorporated as a negative IP control (only for CCRF-CEM cells), to exclude any nonspecific lysate protein interaction with the antibody. For the blocking peptide IP control, $30 \mu \mathrm{g} \mathrm{BP}$ was added to $3 \mu \mathrm{gg}$ raptor antibody and incubated overnight at $4^{\circ} \mathrm{C}$. After incubation added the antibody and blocking peptide mixture to the cell lysate and dynbeads for overnight incubation at $4^{\circ} \mathrm{C}$. Immunoprecipitates were washed once with CHAPS buffer lacking $\mathrm{NaCl}$ and three times with CHAPS buffer containing $150 \mathrm{mM} \mathrm{NaCl}$. Washes were saved for parallel runs with IP elute on immunoblotting. Samples were eluted in $2 \mathrm{X}$ Laemmli buffer at $95^{\circ} \mathrm{C}$ for 10 minutes and resolved on $6 \%$ SDS-PAGE. For experiments with cell lysates, Triton X-100 containing lysis buffer was used. 


\subsubsection{Mammalian cells transfection and myc-tag mTORC1 purification}

CCRF-CEM and HEK293 cells were seeded in 6 well plates for myc-tag raptor pRK5 transfection. Lipofectamine LTX and Plus reagent were used according to the vendor's recommendations (Invitrogen, Darmstadt, Germany). Briefly, $3 \mu \mathrm{g}$ myc-tag raptor pRK5 plasmid and $3 \mu \mathrm{l}$ Plus reagent were added to Opti MEM and incubated for five minutes. $4 \mu \mathrm{l}$ of Lipofectamine LTX was added to the mixture and incubated for 30 minutes at room temperature. The mixture was added to the cells and incubated at $37^{\circ} \mathrm{C}$ in a $\mathrm{CO}_{2}$ incubator for 48 hours. Cells were rinsed with cold PBS and lysed on ice cold CHAPS buffer lacking $\mathrm{NaCl}$ to isolate mTOR containing complexes. Cell lysates were separated from insoluble cell debris by centrifugation at $13000 \mathrm{rpm}$ for 15 minutes at $4^{\circ} \mathrm{C}$. A myc-tag Co-IP kit was used according to manufacturer's instructions (Thermo Scientific Pierce, Rockford, USA). Briefly, lysates were added to the spin column followed by addition of myc-tag monoclonal antibody conjugated beads and incubated overnight at $4^{\circ} \mathrm{C}$. Mock IP was run as a negative control. Immunoprecipitates were washed once with CHAPS buffer lacking $\mathrm{NaCl}$ and three times with CHAPS buffer containing $\mathrm{NaCl}$ and the washes saved. The samples were eluted with glycine buffer ( $\mathrm{pH} 2.8)$, neutralized by addition of $1 \mathrm{M}$ Tris- $\mathrm{HCl}(\mathrm{pH} 9.5)$, and processed for SDS-PAGE.

\subsubsection{SDS-PAGE and immunoblot analysis}

Proteins elutes were resolved on 6\% SDS-PAGE and blotted onto PVDF membrane (Millipore, Schwalbach Germany) using the semidry Trans-Blot SD cell system (Bio-Rad, Munich, Germany) for 30 minutes at 17 Volts in a transfer buffer. The membrane was blocked with $5 \%$ skimmed milk powder prepared in TBS-T buffer for one hour at room temperature and washed three times with TBS-T buffer. Primary antibody was added for overnight incubation at $4^{\circ} \mathrm{C}$. After three washes with TBS-T, the membrane was incubated in HRP-conjugated secondary antibodies for one hour at room temperature and then washed three times in TBS$\mathrm{T}$ for 10 minutes each. The signals on the blot were detected using enhanced chemiluminscent $(\mathrm{ECL})$ reagent (GE Healthcare, Buckinghamshire, UK) and then 
developed on Amersham Hyperfilm (GE Healthcare, Buckinghamshire, UK). Signal intensities for each immunoblot were quantified using the Lab Image software version 2.71 (Kapelan, Leipzig, Germany).

\subsubsection{Protein visualization and in-gel digestion of proteins}

Following confirmation of mTORC1 specific purification on immunoblotting, the remaining IP elutes were run on the 12.5\% SDS-PAGE and stained with colloidal Coomassie blue (Carl Roth, Karlsruhe, Germany), or silver nitrate as previously described [151]. Protein bands from the gel were excised and prepared for in-gel digestion as described by (Shevchenko et al. 1996) with some modifications. Briefly, excised gel spots were destained with potassium ferricynaide $(30 \mathrm{mM})$ and sodium thiosulfate $(100 \mathrm{mM})$. Washed the gel slices with ACN $(50 \%)$ and AMBIC (100 mM) followed by drying in a vacuum centrifuge. The dried gel pieces were digested with trypsin digestion buffer for 45 minutes on ice. The surplus amount of trypsin solution was replaced by the same volume of 100 $\mathrm{mM} A M B I C$ without trypsin and incubated overnight at $37^{\circ} \mathrm{C}$. The peptides were extracted with increasing concentrations of $\mathrm{ACN}$ and TFA and dried by vacuum centrifugation.

\subsubsection{Peptide sequence analysis by nano-LC ESI Q-TOF MS/MS, and database search}

The peptides were reconstituted in an aqueous solution of $0.1 \%$ formic acid. For LC-MS/MS analysis, $1 \mu$ l of the reconstituted peptide sample was introduced on to two consecutive C18-reversed phase chromatography columns (C18 pepMap100 nano analytical column: $75 \mu \mathrm{m} \times 15 \mathrm{~cm}$; $3 \mu \mathrm{m}$ particle size and C18 pepMap: $300 \mu \mathrm{m} \times 5$ mm; $5 \mu \mathrm{m}$ particle size, and; LC Packings, Emsdetten, Germany) using a CapLC nano-flow auto sampler (Waters, Eschborn, Germany). The single sample run time was set for 60 minutes. Protein peptides were chromatographically resolved and analyzed on a Q-TOF Ultima Global mass spectrometer (Micromass, Manchester, UK) equipped with positive ion mode ESI Z-spray source as described elsewhere [152]. The data acquisitions were performed using MassLynx ( $v$ 4.0) software on a Windows NT PC. The peak lists were searched using the online MASCOT (http://www.matrixscience.com) 
algorithm against the Swiss-Prot (525997 sequences; 185874894 residues) and NCBInr (14269787 sequences; 4888943253 residues) protein databases. The data were analyzed against the search parameters to allow with one maximum missed cleavage site; MS/MS tolerance of $\pm 0.5 \mathrm{Da}$; peptide tolerance of $\pm 0.5 \mathrm{Da}$ and monoisotopic mass value with unrestricted protein mass and modifications of cysteine carboamidomethylation and methionine oxidation, when appropriate. Proteins were identified from the database on the basis of at least two or more peptides whose ion scores exceeded the threshold, $p<0.05$ which indicated the $95 \%$ confidence level for the matched peptides. The LC-MS/MS analysis was repeated independently a total of eight times for endogenous mTORC1 purification and four times for myc -tag mTORC1 purifications.

\subsubsection{Functional annotation and protein-protein interaction prediction}

Functional annotation to all newly identified proteins was given by matching their accession number and obtained amino acid sequences using universal protein (UniProt ([153]) and NCBI Kognitor databases [154]. Moreover in silico protein-protein interaction prediction was obtained from a web base interface GeneMANIA (http://www.genemania.org) which is a biological interaction prediction tool [155] used to validate mTORC1 interaction with the newly identified proteins.

\subsubsection{Confocal immunofluorescence microscopy}

CCRF-CEM cells grown on 8 chamber well slides (Lab-Tek ${ }^{\text {TM }}$ II (Thermo Scientific Pierce, Rockford, USA) were fixed in freshly prepared 3.7\% paraformaldehyde for 5 minutes at room temperature. The cells were rinsed and permeated with $0.2 \%$ Triton $\mathrm{X}-100$ in PBS for 15 minutes. The cells were incubated with $1 \%$ BSA in PBS for 30 minutes to block nonspecific binding of antibodies. After thorough rinsing in PBS, rabbit anti-Edc4 (1:300) and mouse antiraptor $(1: 300)$ antibodies were added to the cells, and the mixture incubated overnight at $4^{\circ} \mathrm{C}$. After washing, the cells were probed with fluorescein labelled secondary antibodies, anti-mouse Cydye3 (1:200) and anti-rabbit Alexa Fluor 488 (1:200) for one hour at room temperature. Nuclei were counter stained with 4,6- 
diamidino-2-phenylindole (DAPI) for 10 minutes, mounted with Fluoromount (DAKO, Hamburg, Germany) and visualized with a confocal microscope (Axiovert 200M, Carl Zeiss, Jena, Germany). The DAPI staining in the blue channel has been shown to indicate the outline of the nuclei [156]. The three channel images and an overlay image of red and green channels were recorded using the Axiovision software (Carl Zeiss, Jena, Germany). Quantitative co-localization analysis was carried out using the WCIF Image $J$ software (http://www.uhnres.utoronto.ca/facilities/wcif/imagej).

\subsubsection{Leucine and rapamycin treatments}

Cells were grown for 24 hours in RPMI-1640 supplemented with 10\% FCS. The medium was then replaced with RPMI-1640 without leucine for 2 hours and then stimulated with $2 \mathrm{mM}$ leucine for 30 minutes [157] or treated with $0.1 \mu \mathrm{M}$ and $2.5 \mu \mathrm{M}$ rapamycin [158] for one hour. Cells were lysed, their contents resolved on SDS-PAGE and immunoblotted to observe changes in the expression of Edc4 after both leucine and rapamycin treatment.

\subsubsection{RNA isolation}

Total cellular RNA was isolated using TRIzol method [159]. Briefly, CCRFCEM cells were grown, and treated with $0.1 \mu \mathrm{M}, 2.5 \mu \mathrm{M}$ rapamycin and vehicle control (DMSO) for one hour followed by homogenization in TRIzol reagent. RNA was extracted using a chloroform/isopropanol precipitation method. The RNA concentration was quantified with Agilent 2100 Bioanalyzer (Agilent technologies, Waldbronn, Germany). The integrity of the extracted RNA was ascertained by electrophoresis on $1.5 \%$ agarose gel.

\subsubsection{Capped mRNAs isolation and quantification}

Capped mRNAs were isolated from total RNA as described by the vendor (Epicentre Biotechnologies, WI, USA). Briefly, $5 \mu \mathrm{g}$ total RNA was incubated with the reaction mixture (RNase-free water, 10X reaction buffer $A$, riboGuard RNase inhibitor, 1 unit of terminator exonuclease) at $30^{\circ} \mathrm{C}$ for 60 minutes in a 
thermocycler. The reaction was terminated by adding stop solution (EDTA $5 \mathrm{mM}$ ). Lithium chloride precipitation was performed at $-20^{\circ} \mathrm{C}$ for 30 minutes to enrich mRNA and to get rid of EDTA, tRNA, and other small RNA species, followed by centrifugation at $14000 \mathrm{rpm}$ for 30 minutes at $4^{\circ} \mathrm{C}$. The mRNA pellet was then washed with $70 \%$ ethanol to remove residual salts. The RNA pellet was resuspended in RNase-free water. The successful removal of 18S and 28S rRNA from total RNA content was confirmed by $1.5 \%$ agarose gel electrophoresis. Capped mRNAs were quantified with use of the Agilent 2100 Bioanalyzer (Agilent technologies, Waldbronn, Germany).

\subsubsection{Statistical analysis}

All experiments in this study were repeated at least four times and results are expressed as mean \pm SEM with significance measured using the Student's $t$ test $(p<0.05)$. 


\section{Identification of interacting partners of mammalian target of rapamycin complex 1 (mTORC1) assembly in human lymphocytes}

Hazir Rahman ${ }^{1,2}$, Muhammad Qasim ${ }^{1,2}$, Michael Oellerich ${ }^{1}$, Abdul R Asif ${ }^{1}$

1. Department of Clinical Chemistry, University Medical Centre, Goettingen, Germany.

2. Department of Microbiology, Kohat University of Science and Technology, Kohat, Pakistan.

(Submitted) 


\subsection{Abstract}

The mammalian target of rapamycin complex 1 (mTORC1) senses the availability of growth factors, nutrients, cellular energy level, and is actively involved in cellular transcription and translation processes. The present study was undertaken to identify proteins that specifically interact with mTORC1 to enable this crucial cell signaling hub to carry out its biological functions. Human $T$ lymphocytes (CCRF-CEM) and human embryonic kidney (HEK293) cell lines were used to identify new interacting partners of mTORC1. Endogenous mTORC1 along with its interacting proteins were purified using raptor specific antibodies, separated by 1DE, in-gel tryptic digested and identified by nano-LC ESI Q-TOF MS/MS analysis. In parallel, CCRF-CEM and HEK-293 cells were transfected with myc-tag raptor, myc-tag purified and identified by MS/MS analysis to validate the endogenous purification results. A total of 10 novel interacting proteins (hnRNP A2/B1, SRSF7, RP-P0, NCL, DNM2, GAPDH, 2-OADH, GLT25D1, PHB2, Edc4) were identified in both endogenous and myc-tag mTORC1 purifications. The selected proteins (Edc4, DNM2, and hnRNP A2/B1) were further immunoblotted with relevant specific antibodies to verify the interaction. These interacting proteins may offer new targets for therapeutic interventions in human diseases caused by disturbed mTORC1 signaling.

\subsection{Introduction}

The mammalian target of rapamycin (mTOR) is a serine threonine kinase that belongs to the phosphatidylinositol kinase-related protein kinase (PIKK) family which regulates cell growth, cell proliferation and cell survival $[88,160]$. It was first reported as TOR in Saccharomyces cerevisiae and then found in higher eukaryotes as the specific target of rapamycin, a macrolide antibiotic produced by a soil bacterium Streptomyces hygroscopicus [2,161]. Rapamycin inhibits mTOR by binding with its intracellular receptor, FK506 binding protein 12 (FKBP12), and interacts directly with the FKBP12-rapamycin binding (FRB) domain of mTOR $[42,43]$. mTOR kinase exists in two distinct multiprotein complexes, mTOR complex 1 (mTORC1), and mTOR complex 2 (mTORC2) [11]. Regulatory 
associated proteins of mTOR (raptor) and rapamycin insensitive companion of mTOR (rictor) are mutually exclusive in mTOR complexes [11,32]. mTORC1 is a rapamycin sensitive protein complex involved in energy and nutrient sensing, translation, transcription, autophagy, and lipid biosynthesis [37,162-164]. mTOR kinase in mTORC1 executes a range of biological functions with the help of its interacting proteins, which act as a scaffolds for assembling the complex and recruiting substrates and regulatory proteins $[11,32-36,60]$. In this context, it is crucial to identify new interacting partners to which $\mathrm{mTORC} 1$ might be associated in vivo.

In the present study a total of 10 novel interacting proteins were identified in the mTORC1 specific purifications using nano-LC ESI Q-TOF MS/MS analysis. In addition Edc4, DNM2, and hnRNP A2/B1 proteins signal were detected by immunoblotting in $\mathrm{mTORC} 1$ purified elute which confirm the mass spectrometric identification of mTORC1 specific purification, Furthermore insilico protein-protein interaction tools validate the data. These newly identified interacting partners of mTORC1 may help broaden our understanding of mTORC1 signaling in health and disease.

\subsection{Results}

\subsubsection{Purification of endogenous mTORC1}

The endogenous mTORC1 complex along with its interacting proteins was immunopurified from the CCRF-CEM and HEK293 total cell lysates (TCLs) using raptor monoclonal antibody. Immunoprecipitated elutes were resolved on SDSPAGE and immunoblotted individually with mTOR, raptor and rictor antibodies. In parallel rictor IP elute was prepared and processed similarly to check for contamination of $\mathrm{mTORC2}$ in raptor IP and vice versa. mTOR signal was detected in both the raptor and rictor IP which confirmed the successful coimmunoprecipitation of mTOR complexes. Immunoblotting with raptor antibody detected raptor signal only in the raptor IP elute; whereas, no rictor signal was detected in the raptor IP elute, indicating successful mTORC1 specific purification. Likewise in the rictor IP elute rictor signal was detected while no raptor signal was detected in the rictor IP elute, which confirmed specific mTORC2 purification. Mock IP or antibody minus control showed no cross-reactivity of raptor containing 
mTORC1 with the beads on immunoblot analysis. Raptor signal was not detected in either the last wash or in the raptor blocking peptide IP which provided further evidence of the specific raptor containing mTORC1 purification. Following immunoblotting confirmation of mTORC1 specific purification, the remaining IP elutes were resolved on 1-DE and stained with stained with Coomassie blue (Appendix Fig. 1A). The entire raptor IP and mock IP lanes from the Coomassie stained gel were excised and tryptic digested for protein identification. Proteins were identified by nano-LC ESI Q-TOF MS/MS analysis in four independent experiments each with CCRF-CEM and HEK293 cells respectively (Fig. 3.1 A \& B). All proteins identified from the mock IP were considered background contaminants and subtracted from the list of proteins identified from the raptor IP elution.

\subsubsection{Purification of myc-tag raptor containing mTORC1}

The newly identified proteins of endogenous mTORC1 were further confirmed by virtue of the transfecting myc-tag raptor components of mTORC1 in HEK293 and CCRF-CEM cells, and the mTORC1 components were immunopurified using myc-tag monoclonal antibody conjugated beads. After immunoprecipitation, the samples were eluted in gylcine buffer and followed by immunoblotting (Fig. 3.2). After immunoblotting the remaining elutes were resolved on SDS-PAGE, silver stained and excised for mass spectrometry analysis (Appendix Fig. 1B). 


\section{A. CCRF-CEM cells}

IP antibody:
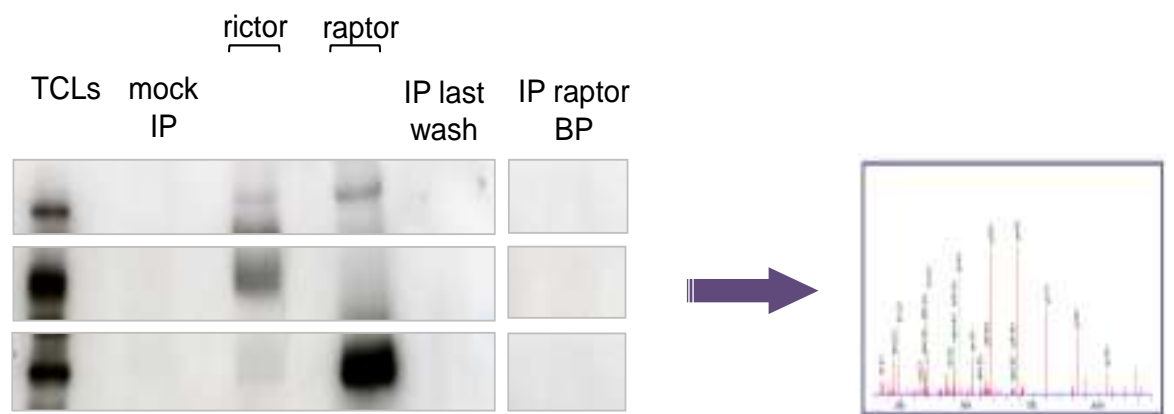

MS/MS analysis

\section{B. HEK293 cells}

IP antibody:
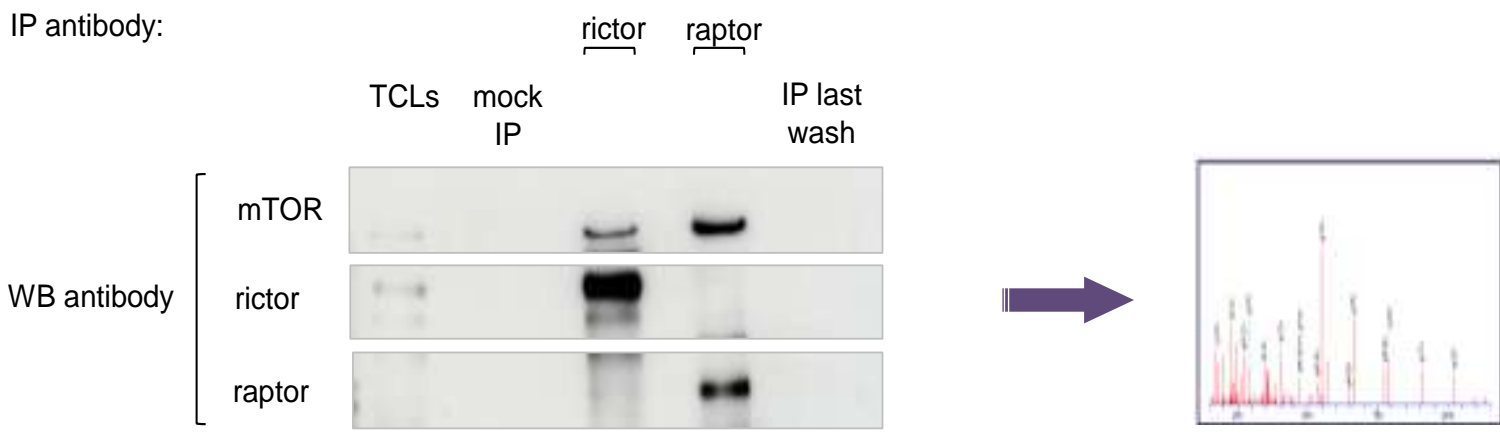

MS/MS analvsis

Figure 3.1: Purification of endogenous mTORC1.

(A) CCRF-CEM or (B) HEK293 cells were grown for 48 hours in complete medium and lysed in 0.3\% CHAPS buffer as described in methods section. Endogenous mTOR complexes were immunopurified from total cell lysates (TCLs) using raptor or rictor antibodies. IP elute were resolved on SDS-PAGE and immunobloltting with mTOR antibody. Detection of mTOR signal in both the raptor and rictor IP elutes reflected successful co-immunoprecipitation of mTOR complexes. Blotting with raptor antibody detected raptor signal in raptor IP elute while it was absent from the rictor and mock IP (negative controls) elutes. Rictor signal was not detected in the raptor IP, which confirmed the specific purification of mTORC1 and no contamination of mTORC2 component. Furthermore no raptor signal was detected in the rictor IP elute. Similarly no raptor signal was detected in the raptor IP when raptor blocking peptide (BP) and last IP wash was used which further validating the purity of $\mathrm{mTORC} 1$ specific purification. The remaining elutes were run on $12.5 \%$ SDS-PAGE and stained with Coomassie blue. Protein bands were excised from the gel and tryptic digested for nano-LC ESI Q-TOF MS/MS analysis. All experiments were independently repeated four times in each cell line (CCRF-CEM cells: $n=4$, HEK293 cells: $n=4$ ) (IP: Immunoprecipitation, WB: Western blot). 


\section{A. CCRF-CEM cells}

IP: myc tag antibody

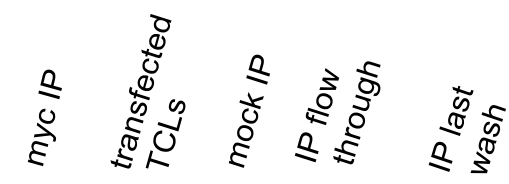

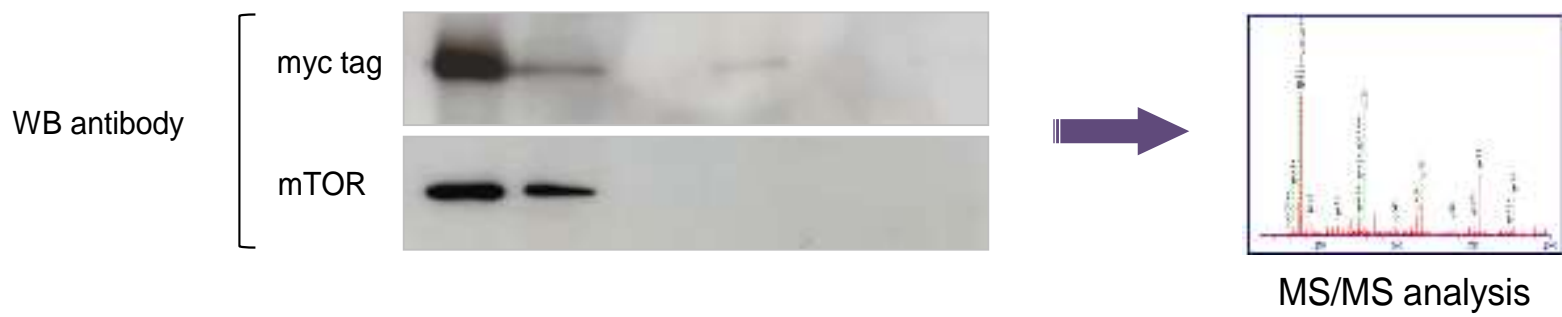

\section{B. HEK293 cells}

IP: myc tag antibody

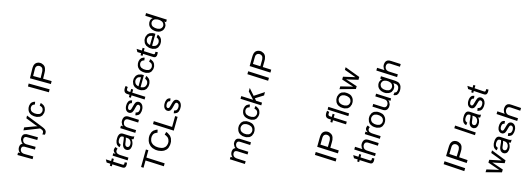

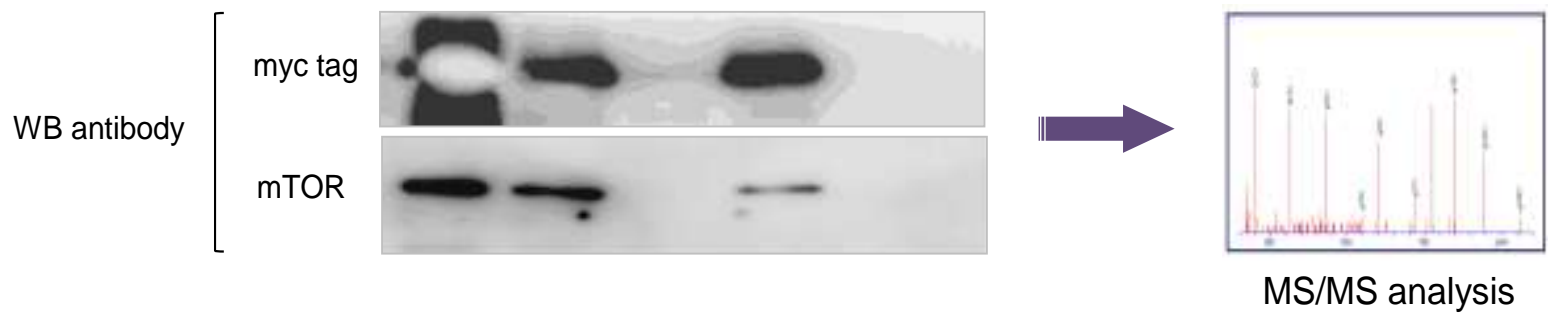

Figure 3.2: Purification of myc-tag raptor component of $m T$ mTORC1.

(A) CCRF-CEM or (B) HEK293 cells were transiently transfected with myc-raptor pRK5 plasmid using Lipofactamin LTX reagent. After 48 hours of transfection, cells were lysed and myc-tag raptor component of mTORC1 was immunoprecipitated with monoclonal myc-tag antibody conjugated beads. IP elutes were resolved on SDS-PAGE and immunblotted with myc-tag antibody. Myc-tag raptor signal was detected in the anti myc-tag IP elute while it was missing from the mock IP and last IP wash, which confirmed the immunoprecipitation of specific myc-tag raptor component of mTORC1. mTOR signal was detected in the anti myc-tag IP elute confirming the coimmunoprecipitation of mTORC1. The remaining elutes were separated on 1-DE, silver stained, and gel bands were excised for nano-LC ESI Q-TOF MS/MS analysis (CCRF-CEM cells: $n=2$, HEK293 cells: $n=2$ ) (trans. TCLs: transfected total cell lysates, ft: flow through).

\subsubsection{Identification of novel interacting partner of mTORC1 using nano-LC ESI Q-TOF MS/MS.}

Proteins were identified by ESI Q-TOF MS/MS analysis in four independent experiments each in CCRF-CEM and HEK293 cells respectively. All the proteins identified from the mock IP were considered as background contaminants and subtracted from the list of proteins identified from the raptor IP elute. We identified total 10 proteins common in both endogenous and myc-tag mTORC1 purifications. 


\section{Table 3.1: Novel interacting partners of raptor component of mTORC1 identified using LC ESI Q-TOF MS/MS analysis.}

\begin{tabular}{|c|c|c|c|c|c|c|c|}
\hline \multirow{2}{*}{$\begin{array}{l}\text { Accession } \\
\text { No. }\end{array}$} & \multirow[t]{2}{*}{ Protein Name } & \multirow{2}{*}{$\begin{array}{c}\text { Mass } \\
(\mathrm{kDa})\end{array}$} & \multirow[t]{2}{*}{${ }^{\mathrm{a}}$ Protein Functions } & \multicolumn{2}{|c|}{ CCRF-CEM } & \multicolumn{2}{|c|}{ HEK-293 } \\
\hline & & & & $\begin{array}{c}\text { Endogenous } \\
n=4\end{array}$ & $\begin{array}{c}\text { Transfected E } \\
n=2\end{array}$ & $\begin{array}{l}\text { Endogenous } \\
\qquad n=4\end{array}$ & $\begin{array}{c}\text { Transfected } \\
\quad \mathrm{n}=2\end{array}$ \\
\hline \multicolumn{8}{|c|}{ RNA processing } \\
\hline Q6P2E9 & $\begin{array}{c}\text { Enhancer of } \\
\text { mRNA } \\
\text { decapping } \\
\text { protein } 4\end{array}$ & 151.5 & $\begin{array}{l}\text { mRNA decapping, } \\
\text { catalyze the } \\
\text { bridging reaction } \\
\text { between Dcp1a and } \\
\text { Dcp2 }\end{array}$ & $\sqrt{ }$ & $\sqrt{ }$ & $\sqrt{ }$ & $\sqrt{ }$ \\
\hline P22626 & $\begin{array}{l}\text { Heterogeneous } \\
\text { nuclear } \\
\text { ribonucleoprotei } \\
\text { ns A2/B1 }\end{array}$ & 37.5 & $\begin{array}{l}\text { mRNA splicing, } \\
\text { transport and } \\
\text { synthesis }\end{array}$ & $\sqrt{ }$ & $\sqrt{ }$ & $\sqrt{ }$ & $\sqrt{ }$ \\
\hline Q16629 & $\begin{array}{l}\text { Splicing factor } \\
\text { arginine/serine } \\
\text { rich } 7\end{array}$ & 27.3 & $\begin{array}{l}\text { Member of } \\
\text { spliceosome } \\
\text { complex, involved } \\
\text { in the mRNA } \\
\text { processing }\end{array}$ & $\sqrt{ }$ & $\sqrt{ }$ & $\sqrt{ }$ & $\times$ \\
\hline \multicolumn{8}{|c|}{ Translation and transcription } \\
\hline P05388 & $\begin{array}{l}60 S \text { acidic } \\
\text { ribosomal } \\
\text { protein P0 }\end{array}$ & 34.2 & $\begin{array}{l}\text { Translation, } \\
\text { Ribosome } \\
\text { biogenesis }\end{array}$ & $\sqrt{ }$ & $\sqrt{ }$ & $\sqrt{ }$ & $\sqrt{ }$ \\
\hline P19338 & Nucleolin & 76.5 & $\begin{array}{l}\text { Translation, } \\
\text { Ribosome } \\
\text { biogenesis, RNA } \\
\text { processing }\end{array}$ & $\sqrt{ }$ & $\sqrt{ }$ & $\sqrt{ }$ & $\sqrt{ }$ \\
\hline \multicolumn{8}{|c|}{ Intracellular trafficking, secretion, and vesicular transport } \\
\hline P50570 & Dynamin 2 & 98 & $\begin{array}{l}\text { Endocytosis and } \\
\text { exocytosis }\end{array}$ & $\sqrt{ }$ & $\sqrt{ }$ & $\sqrt{ }$ & $\sqrt{ }$ \\
\hline \multicolumn{8}{|c|}{ Carbohydrate transport and metabolism } \\
\hline P04406 & $\begin{array}{l}\text { Glyceraldehyde } \\
\text {-3-phosphate } \\
\text { dehydrogenase }\end{array}$ & 36 & $\begin{array}{l}\text { Has a key role in } \\
\text { the energy } \\
\text { production }\end{array}$ & $\sqrt{ }$ & $\sqrt{ }$ & $\sqrt{ }$ & $\sqrt{ }$ \\
\hline Q02218 & $\begin{array}{l}\text { 2-Oxoglutarate } \\
\text { dehydrogenase } \\
\text { mitochondrial }\end{array}$ & 115.8 & $\begin{array}{l}\text { Catalyzes the } \\
\text { decarboxylation of } \\
\text { 2-oxoglutarate to } \\
\text { succinyl-CoA }\end{array}$ & $\sqrt{ }$ & $\sqrt{ }$ & $\sqrt{ }$ & $\sqrt{ }$ \\
\hline \multicolumn{8}{|c|}{ PTM, Protein turnover, and chaperones } \\
\hline Q8NBJ5 & $\begin{array}{c}\text { Glycosyl } \\
\text { transferase } 25 \\
\text { domain1 }\end{array}$ & 71.5 & $\begin{array}{l}\text { Involved in protein } \\
\text { gylcosylation }\end{array}$ & $\sqrt{ }$ & $\sqrt{ }$ & $\sqrt{ }$ & $\times$ \\
\hline Q99623 & Prohibitin 2 & 33.2 & $\begin{array}{l}\text { Regulate cell } \\
\text { growth and protein } \\
\text { turnover }\end{array}$ & $\sqrt{ }$ & $\sqrt{ }$ & $\sqrt{ }$ & $\sqrt{ }$ \\
\hline
\end{tabular}


We identified 10 proteins including (hnRNP A2/B1, SRSF7, RP-P0, NCL, DNM2, GAPDH, 2-OADH, GLT25D1, PHB2, Edc4) common in both type of purification after substracting the protein coming in the mock IP (negative) control (Table 3.1) while the spectral information for the newly identified proteins are provided in Appendix Table 1.

\subsubsection{Functional annotation of newly identified mTORC1 interacting proteins}

The mTORC1 specific interacting proteins were identified by nano-LC ESI Q-TOF MS/MS analysis. The biological functions to the identified proteins were assigned using Kognitor and UniProt databases [153,154]. The highest number of interacting proteins falls in the category of RNA processing (30\%) while least were in the vesicular trafficking category (10\%) (Fig. 3.3).
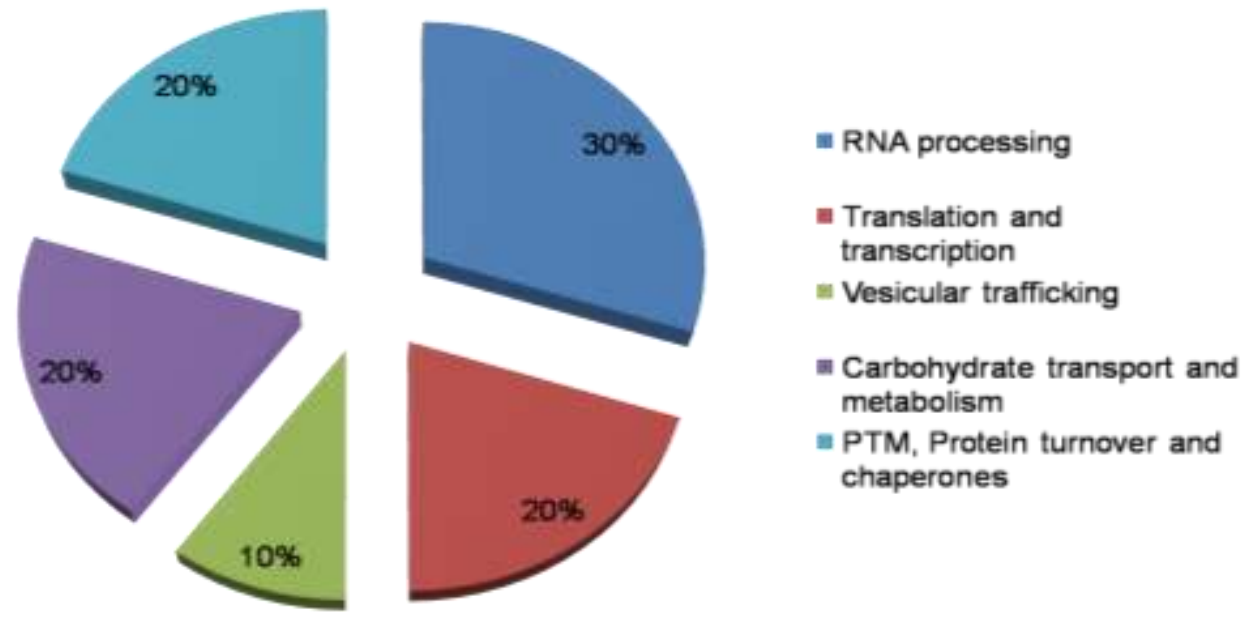

Figure 3.3: Functional annotations of newly identified mTORC1 interacting proteins.

The mTORC1 specific interacting proteins were identified by nano-LC ESI Q-TOF MS/MS analysis. The biological functions to the identified proteins were assigned using Kognitor and UniProt $[153,154]$ databases. The highest number of interacting proteins falls in the category of RNA processing (30\%) while least was in the vesicular trafficking category $(10 \%)$.

\subsubsection{Immunoblot confirmation of Edc4, dynamin 2 and hnRNP A2/B1 protein}

To validate protein identification on MS/MS, confirmatory immunoblotting for selected proteins were employed. We did immunoblotting for raptor, mTOR, 
Edc4, dynamin 2 and hnRNP A2/B1 protein after IP with raptor antibody. mTOR signal was detected which showed successful co-immunoprecipitation of mTORC1. Raptor band was detected which reflects immunoprecipitation of mTORC1. In addition immunoblotting with rictor antibody detected no signal for rictor, which confirmed the mTORC1 specific purification and no contamination of mTORC2 component. Furthermore immunoblotting with raptor, mTOR, Edc4, dynamin 2 and hnRNP A2/B1 antibodies detected corresponding band for each protein, which further confirmed our mass spectrometric identifications (Fig. 3.4).

IP antibody:

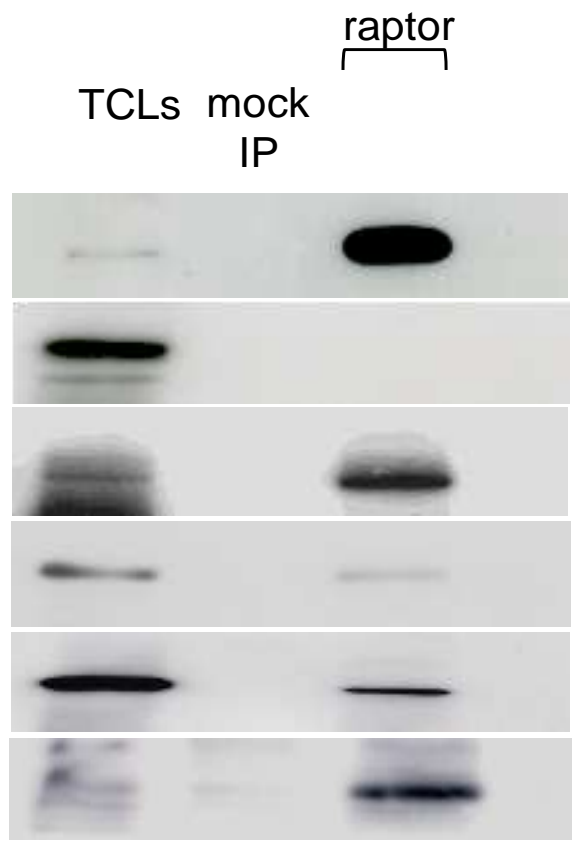

Figure 3.4: Immunoblot confirmation of Edc4, dynamin 2, and hnRNP A2/B1 proteins in human T lymphocytes.

CCRF-CEM cells were lysed in CHAPS buffer and raptor containing component of mTORC1 were co-immunoprecipitated from the CCRF-CEM cell lysate using raptor antibody. mTOR signal in raptor IP elute reflected successful co-immunoprecipitation of mTORC1, while rictor signal was not detected in the raptor IP, which confirmed the specific purification of mTORC1. Detection of Edc4, dynamin 2, and hnRNP A2/B1 signal in the raptor IP confirmed the interaction of these proteins with raptor component of mTORC1.

\subsubsection{In silico prediction of the mTOR interaction with the newly identified partners}

LC ESI QTOF MS/MS analysis identified 10 noval interacting proteins associated with mTORC1. A web based interface GeneMANIA was used to 
predict mlolecular interaction which finds association data based on protein and genetic interactions, pathways, co-expression, co-localization, protein domain similarity, and orthologs [155]. The highlighted nodes represent mTOR or RPTOR (raptor) interacting proteins. Among the newly identified proteins EDC4, NCL, DNM2, HNRNPA2B1,OGDH showed direct interaction with mTOR, while SRSF7, RPLP0, GAPDH, PHB2 showed indirect interaction with mTOR or RPTOR (Fig. 3.5).

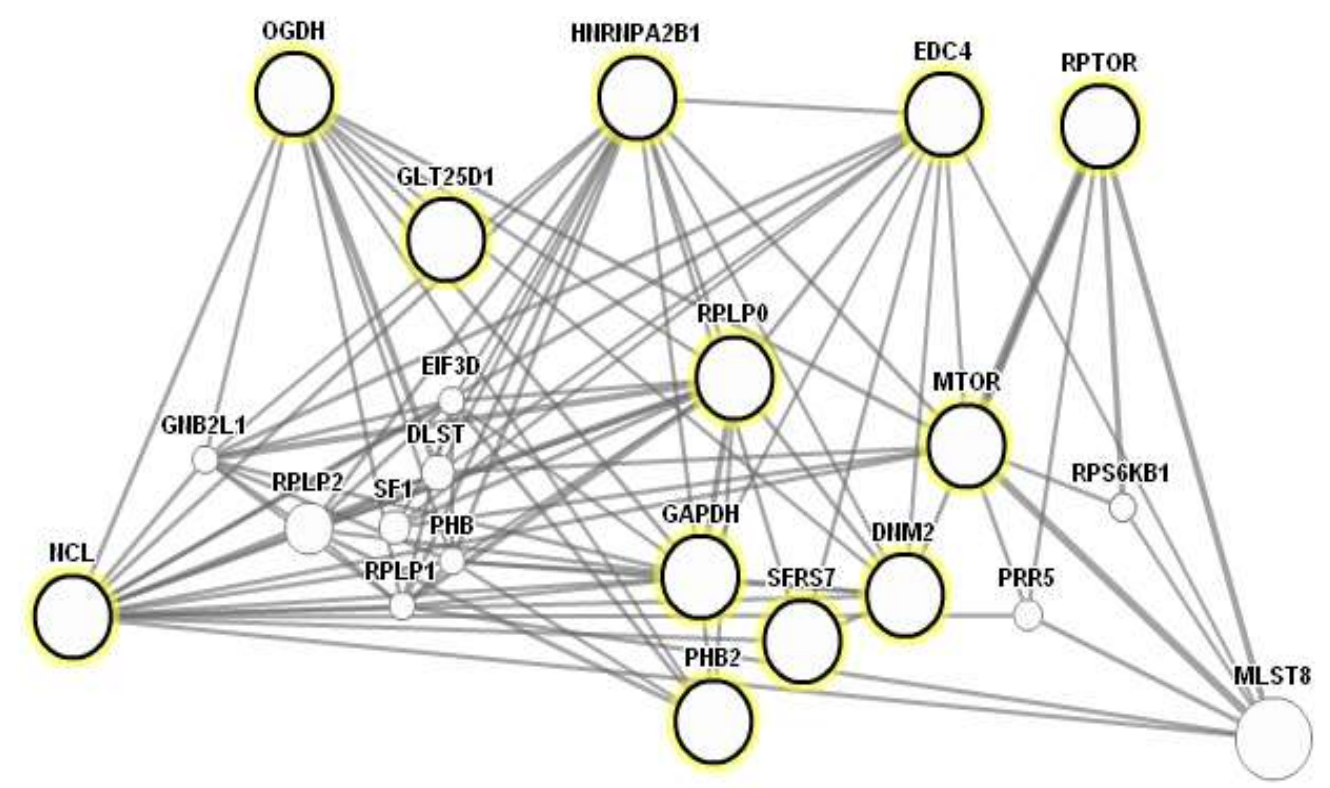

Figure 3.5: Biological interaction predictions of $\mathrm{mTORC1}$ interacting proteins.

A total of 10 novel mTORC1 interacting proteins were identified by LC-MS/MS analysis. A web based interface GeneMANIA was used to predict molecular interaction [155]. The highlighted nodes represent mTOR or RPTOR (raptor) interacting proteins. Among the newly identified proteins Edc4, NCL, DNM2, hnRNPA2/B1, and OGDH showed direct interaction with mTOR, while SRSF7, RPLP0, GAPDH, and PHB2 showed indirect interaction with mTOR or RPTOR.

\subsection{Discussion}

The flow of cellular functions depends largely on signaling pathways that are regulated by specific protein-protein interactions [165]. These interactions often involve assembly of large protein complexes containing many different protein kinases, their substrates, and scaffold proteins [38]. mTOR kinase form two dynamic protein complexes, differ in their composition, regulation and functions $[11,32]$. A growing body of literature has reported new interacting partners of 
mTORC1 [32,33,35,36,60]. Although recent approaches based on mass spectrometry are sufficient to identify interacting partners of multiprotein complexes [166]: a frequently encountered problem is caused by the difficulty encountered in obtaining sufficient amounts of highly purified protein complexes. The present study employed an endogenous mTORC1 protein purification strategy using co-immunoprecipitation which is a rigorous method to validate the significance of protein interactions. In parallel, the myc-tag raptor component of mTORC1 pRK5 vector expression [32] in T lymphocytes and HEK293 cells was used to recover the raptor component of mTORC1 and associated interacting partners using affinity column and monoclonal myc-tag antibody conjugated with agarose beads. In this method the IP elute was relatively free from myc-tag antibody contamination as the agarose beads were covalently linked with myc-tag antibody. The specificity of these interactions were ensured by integrating appropriate purification controls. The co-purified elutes were resolved on 1-DE and the mTORC1 specific purification was confirmed by immunoblotting followed by nano-LC ESI Q-TOF MS/MS analysis to identify the proteins. In this study we report 10 novel interacting partners of $\mathrm{mTORC} 1$ which are involved in important cellular functions as revealed by the NCBI Kognitor and UniProt databases $[153,154]$. Moreover the biological interaction prediction tool further [155] indicated a potential for interaction of $\mathrm{mTORC} 1$ with the newly identified proteins.

In the present study we identified three mRNA processing proteins, heterogeneous nuclear ribonucleoproteins A2/B1 (hnRNP A2/B1), splicing factor arginine/serine rich 7 (SRSF7) and Edc4 as mTORC1 interacting partners. hnRNP A2/B1 is the major protein present in hnRNPs RNA binding complex [167]. hnRNP A2/B1 involved in mRNA processing and translation, and shuttles between the nucleus and cytoplasm [168]. Specific interactions of mTOR and S6K2 with hnRNPs are important in the regulation of cell proliferation [169]. SRSF7 is a member of spliceosome complex, involved in the mRNA processing and translation [170]. Splicing factor 2 (SF2/ASF) interacts both with the PP2A phosphatase and mTOR, and accelerates hyperphosphorylation of the elF4Ebinding proteins (4E-BPs), thereby blocking 4E-BPs inhibitory activity on eukaryotic translation initiation factor 4E (elF4E) [171]. Edc4 is an important 
protein involved in mRNA decapping which is an essential step in the mRNA degradation[146].

Two interacting proteins identified in the category of translation and transcription was 60S acidic ribosomal protein P0 (RPP0) and nucleolin (NCL). RP-PO is a multifunctional protein required for efficient protein translation of the $60 S$ ribosome [172]. Recently the physical interaction of 605 ribosomal proteins was demonstrated with mTORC2 [173]. This interaction leads to the activation of mTORC2 in Hela cells [173]. mTORC1 has an important role in ribosome synthesis [174]. In this context RP-P0 association with mTORC1 could be important for ribosome biogenesis. NCL is a $76.6 \mathrm{kDa}$ nucleolar phosphor-protein which is involved in ribosome biogenesis, transport, cell proliferation and cell growth [175]. Several structural domains in the NCL allow its interaction with different proteins [176]. It interacts with the FK506-binding proteins (FKBPs), a cellular receptor for rapamycin and regulator of NCL functions [177]. Phosphorylation of NCL on the serine and threonine residues is responsible for functional input of NCL in various biological processes $[175,178]$ which make it an ideal candidate for mTOR interaction. Insulin induces the phosphorylation of nucleolin and increases ribosomal RNA transport [178]. mTORC1 is the crucial molecule in the regulation of ribosome biogenesis and is also stimulated by insulin and amino acids [3].

Dynamin 2 (DNM2), a large GTPase associated with vesicular trafficking [179] was identified as an interacting partner of mTORC1 [179]. DNM2 interacts and co-localizes with various proteins in the endomembrane compartments [180]. The localization of mTORC1 in the endoplasmic reticulum and the Golgi apparatus, and its role in the membrane trafficking has been demonstrated in both yeasts and in Drosophila [181-183]. DNM2 interaction with mTORC1 could help mTORC1 translocation into intracellular membrane compartments, where mTORC1 regulators reside [184].

In the category of carbohydrate transport and metabolism, both 2oxoglutarate dehydrogenase (2-OADH) and Glyceraldehyde-3-phosphate dehydrogenase (GAPDH) were identified as interacting partners. 2-OADH is the 
part of mitochondrial enzyme complex 2-oxoglutarate dehydrogenase complex (2$\mathrm{ODHC}$ ), which catalyzes the decarboxylation of 2-oxoglutarate to succinyl-CoA in the tricarboxylic acid (TCA) cycle [185]. 2-OADC interacts with cofactors including lipoic acid to regulate cellular metabolism [185]. mTORC1 is implicated in glycolytic flux and energy sensing [174]. GAPDH has been considered a glycolytic enzyme with a central role in cellular energy production [186]. In addition its role in the regulation of the cytoskeleton, transcription, RNA transport, and vesicular transport has been previously described $[187,188]$. GAPDH interaction with rheb under glucose starved conditions negatively regulates the mTORC1 signaling, thereby allowing mTORC1 to control cell growth at the expense of glucose [189]. GAPDH interaction with mTORC1 might directly attenuate rheb access towards mTORC1 and thus inhibit mTORC1.

We identified glycosyltransferase 25 family member 1 (GLT25D1) and prohibitin 2 (PHB2) as mTOR interacting proteins, involved in the post-translation modification, protein turnover, and chepeone functions. mTORC1 regulates biological processes by post-translational modification especially phosphorylation [162]. Glycosyl transferase is mainly co-localized in the endomembrane compartments [190], and glycosylation is important for growth factor activation of transmembrane receptors [191]. Recently, the Golgi phosphoprotein-3 (GOLPH3) involved in protein glycosylation has been reported to have implications in mTOR signaling [192]. PHB2 has a suggested role in the maintenance of mitochondrial morphology, and acts as a tumor and transcription repressor to regulate cell growth [193-195]. AKT, a positive regulator of cell growth interacts with PHB2 and inhibits the PHB2 mediated repression of MyoD expression, and promotes muscle differentiation [196].

In general there are three possibilities for mTORC1 interactions with the newly identified interacting proteins: (a) these interacting proteins may act as a direct substrate of $\mathrm{mTORC} 1$ and phosphorylation of such proteins via mTORC1 could be part of their regulatory mechanism[3], (b) the interacting proteins may bind to mTORC1 and enhance or inhibit the mTORC1 kinase activity[33,60], or (c) mTORC1 may compete with the inhibitor or activator of these proteins. 


\subsection{Conclusion}

In the present study we identified 10 new interacting proteins of mTORC1 using both endogenous purification and exogenous myc-tag purification strategies. Functional understanding of these new interacting proteins may be helpful in providing targets for new therapeutic interventions for human diseases in which mTORC1 signaling may be perturbed. 


\section{Enhancer of mRNA decapping protein 4 is the novel interacting partner of $\mathrm{mTORC} 1$ involved in mRNA decapping}

Hazir Rahman ${ }^{1,2}$, Muhammad Qasim $^{1,2}$, Michael Oellerich $^{1}$, Abdul R Asif $^{1}$

1. Department of Clinical Chemistry, University Medical Centre, Goettingen, Germany.

2. Department of Microbiology, Kohat University of Science and Technology, Kohat, Pakistan.

(Submitted) 


\subsection{Abstract}

The mammalian target of rapamycin complex 1 (mTORC1) is a rapamycin sensitive complex, and a key player in cellular transcription and translation processes. Decapping of $5^{\prime}$ mRNA cap is an important control point in the mRNA turnover. In higher eukaryotes the decapping machinery essentially needs enhancer of mRNA decapping protein 4 (Edc4). Previously it has been reported that inhibition of mTORC1 increased the expression of enhancer of mRNA decapping proteins in yeast; however, no direct evidence exists regarding involvement of mTORC1 in the regulation of Edc4. The present study was undertaken to characterize the role of $\mathrm{mTORC} 1$ in the regulation of its newly identified interacting partner, Edc4. mTORC1 interaction with Edc4 was validated on immunoblotting in mTORC1 specific purifications prepared from human $T$ lymphocytes (CCRF-CEM) and human embryonic kidney (HEK293) cells lysate. The interaction Edc4 with mTORC1 was further confirmed using coimmunoprecipitation, and confocal immunoflourescence analysis. Incubation of cells with rapamycin increased the total expression of Edc4 but decreased its interaction with mTORC1. In addition rapamycin increased the rate of mRNA decapping activity and significantly decreased the amount of total serine phosphorylated Edc4 in the cells. The present study has for the first time highlighted the role of mTORC1 in mRNA decapping via its interaction with Edc4.

\subsection{Introduction}

The mammalian target of rapamycin (mTOR) kinase regulates cell growth, cell proliferation and cell survival [3]. mTOR kinase exists in two distinct protein complexes, mTOR complex 1 (mTORC1), and mTOR complex 2 (mTORC2) $[11,197]$. mTORC1 or raptor containing mTOR complex, a rapamycin sensitive protein complex involved in nutrient and energy sensing, translation and transcription [37,162]. mTOR kinase in mTORC1 perform a range of biological functions with the help of its interacting partners $[11,32-36,60]$. In this context, it is crucial to identify and characterize the new interacting partners of mTORC1. 
Capping (5' N7-methyl-guanosine $(m 7 G p p p N))$ of mRNA is required for the integrity of newly synthesized mRNA [135]. It protects mRNA from exonucleolytic degradation and promotes the translation of most cellular mRNAs [139]. mTORC1 is involved in the cap dependent translation of mRNA and regulates the elF4Ebinding protein-1 (4E-BP1), an inhibitor of eukaryotic initiation factor 4E ( elF4E) [6]. elF4E is a member of the translation initiation complex elF4F, protects the $5^{\prime}$ mRNA cap from decapping and recruits the translation machinery for efficient translation initiation [113]. mRNA decapping is a crucial control of mRNA turnover as decapping irreversibly removes the cap and promotes mRNA decay [140]. Decapping of mRNA is considered to take place in the processing bodies ( $P$ bodies), which are the cytosolic self assembled aggregations of messenger ribonuclear proteins (mRNPs) involved in mRNA turnover, RNA interference (RNAi), miRNA-mediated gene silencing and translation repression [139,141,142].

In higher eukaryotes, decapping requires Edc4 for catalytic complex formation between Dcp1a and Dcp2, which are two major enzymes of mRNA decapping complex [146]. Edc4 was originally identified as the autoantigen in Sjogren's syndrome (a chronic autoimmune disease) patients sera [198]. Recently Edc4 was suggested to be involved in miRNA-mediated translation repression [149]. Edc4 is a central component of $P$ bodies and is essential for the integrity of $P$ bodies [148]. The localization of decapping protein complex Dcp1a and Dcp2 in the $\mathrm{P}$ bodies is dependent on the presence of Edc4, as depletion of Edc4 blocks the accumulation of decapping enzymes in the $P$ bodies $[148,199,200]$. mTORC1 inhibition increases the expression of decapping proteins in yeast [150], however no evidence exists regarding involvement of mTORC1 in the regulation of Edc4.

In the present study Edc4 was consistently identified in the mTORC1 specific purifications. Edc4 interaction with mTORC1 was confirmed by reverse co-immunoprecipitation and confocal immunoflourescence analysis. The importance of mTORC1 and Edc4 interaction was studied using rapamycin treatment and mRNA decapping assay. The study may broaden our understanding about the biological functions of mTORC1 signaling. 


\subsection{Results}

\subsubsection{Edc4 is an interacting partner of raptor containing component of mTORC1}

Edc4, a $151.5 \mathrm{kDa}$ protein was identified in the mTORC1 specific purification using LC ESI Q-TOF MS/MS analysis. Consistent identification of Edc4 in the raptor co-purified elutes from the T lymphocytes and HEK293 provided the initial evidence of Edc4 interaction with the raptor component of mTORC1. The observations were subsequently confirmed by immunoblotting the raptor co-purified elute individually with raptor and Edc4 antibody. A positive Edc4 signal was detected in the raptor specific IP elution, which identified Edc4 as a coprecipitating protein with the raptor component of mTORC1. Additionally the reverse co-immunoprecipitation with Edc4 antibody produced a protein band corresponding to raptor which provides additional evidence for their interaction (Fig. 4.1A).

To further verify the potential interaction of Edc4 with the raptor component of mTORC1, myc-tag raptor pRK5 plasmid was transiently transfected in CCRFCEM and HEK293 cells. Myc-tag raptor component of mTORC1 was specifically immunopurified with monoclonal myc-tag antibody. The myc-IP and mock IP elutes were separated on SDS-PAGE followed by immunoblotting. A strong signal of myc-raptor was detected in myc-IP. This confirmed successful transfection of myc-raptor pRK5 plasmid and the immunoprecipitation of the myc-raptor component of mTORC1. Immunoblotting with Edc4 antibody revealed signal of Edc4 in the myc-IP elutes (Fig. 4.1B). Edc4 presence in the endogenous and exogenous purification of mTORC1 established Edc4 as a new interacting partner of mTORC1. 
A

IP antibody:

IP

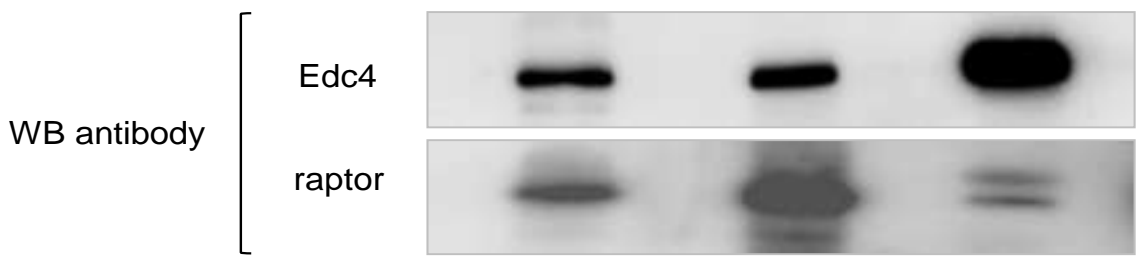

B

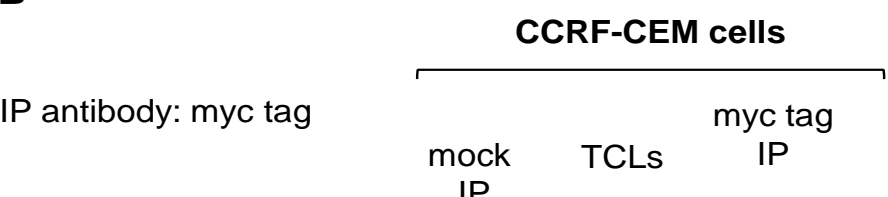

WB antibody $\left[\begin{array}{c|c|}\text { myc } \\ \text { tag } \\ \text { Edc4 }\end{array}\right.$

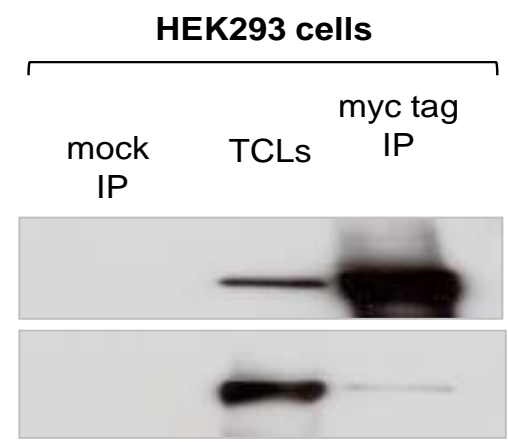

Figure 4.1: Edc4 interacts with mTORC1.

(A) CCRF-CEM cells were lysed in CHAPS buffer and Edc4 or raptor containing component of mTORC1 were co-immunoprecipitated from the CCRF-CEM cell lysate using Edc4 and raptor antibody respectively. Immunoblotting with raptor antibody confirmed the immunoprecipitation of raptor, while blotting with Edc4 antibody detected corresponding Edc4 signal in the raptor IP elute confirming co-precipitation of Edc4 with raptor. Furthermore in the Edc4 IP elute, raptor signal was detected, which reflected that Edc4 co-precipitating the raptor and confirming Edc4 interaction with raptor component of mTORC1. (B) CCRF-CEM cells and HEK293 cells were transiently transfected with myc-tag raptor pRK5 plasmid. After 48 hours of transfection, the cells were lysed in CHAPS buffer. Myc-tag raptor component of mTORC1 was specifically immunoprecipitated with myc-tag monoclonal antibody conjugated with agarose beads, separated on SDS-PAGE and immunblotted. Myc-tag antibody detected myc-tag raptor signal in the anti myc-tag IP elute while it was missing from the mock IP, which confirmed the immunoprecipitation of specific myc-tag raptor component of mTORC1. In addition, immunblotting with Edc4 detected raptor signal in the myc-tag IP elutes prepared from both cell lines that showed substantial association of Edc4 with myc-tag raptor component.

\subsubsection{Edc4 interacts with mTORC1 but not with mTORC2}

Next we investigated whether Edc4 is associated with only raptor containing mTORC1 or interacts with rictor containing mTORC2 as well. mTOR complexes from CCRF-CEM cell lysates were immunopurified with raptor and rictor antibodies. Raptor and rictor signals in the corresponding IP elutes were 
confirmed to check the specificity of our purifications. A signal for mTOR was found in both raptor and rictor IPs which indicated co-immunoprecipitation of mTOR complexes. Immunoblotting with Edc4 specific antibody detected a band corresponding to Edc4 in the raptor IP elute; however, no signal for Edc4 was detected in the rictor IP elution (Fig. 4.2). This indicated that Edc4 was only associated with the raptor containing component of mTORC1 and that it did not interact with mTORC2.

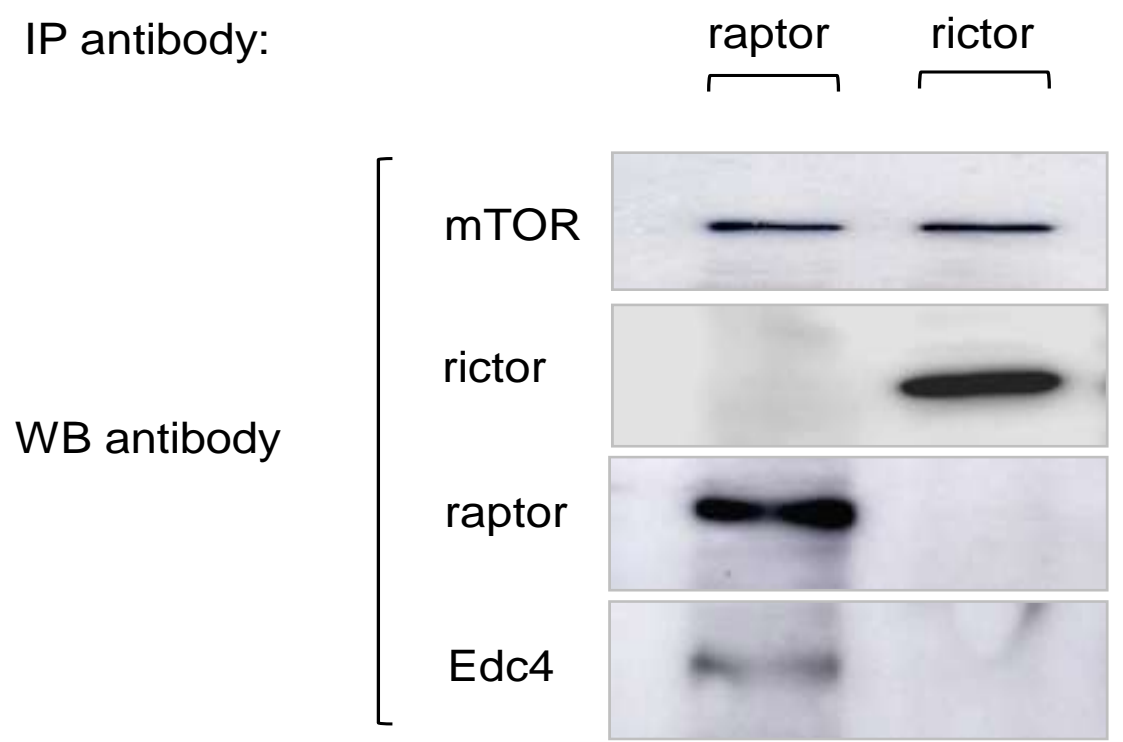

Figure 4.2: Edc4 interacts with mTORC1, but not with mTORC2.

CCRF-CEM cells were lysed in CHAPS buffer and endogenous mTOR complexes were immunopurified using raptor and rictor antibodies respectively. The IP elutes were resolved on SDS-PAGE and immunoblotting with mTOR antibody which detected corresponding signal in both the IPs. In IP elute blotted with anti-raptor antibody, no rictor signal was detected which described the specific mTORC1 purification while a strong raptor signal was noticed. In the rictor IP elute no raptor signal was detected which reflecting specific mTORC2 purification, while a prominent rictor signal was detected. After confirmation of specific mTOR complex purification, immunoblotting with Edc4 antibody detected Edc4 signal only in the raptor IP elute while no Edc4 signal was detected in the rictor IP elute confirming that Edc4 is only associated with mTORC1 but not with the mTORC2.

\subsubsection{Edc4 co-localized with raptor containing mTOR complex}

Endogenous and myc-tag purification of mTORC1 and coimmunoprecipitation assays provided considerable evidence that Edc4 is an mTORC1 associated protein. Immunofluorescence analysis of Edc4 (green) and 
raptor (red) was employed to view the co-localization of Edc4 with raptor component of mTORC1. The merged yellow color reflects co-localization of Edc4 and raptor inside and outside the P bodies (Edc4 is P bodies marker) [200] (Fig. 4.3). The images were processed to determine the extent of co-localization quantitatively using Image J WCIF software. The graphical display as a scatter plot of raptor and Edc4 pixels appeared as yellow hues near the centre of the $X Y$ axis. Statistical correlation using Pearson's method $[201,202]$ for two independent experiments showed coefficients of 0,863 and 0.754 respectively which suggested a high degree of co-occurrence of the raptor component of mTORC1 and Edc4. Similarly the Mander's overlap coefficients (R) [203] were 0.937 and 0.876 respectively, indicating a high co-localization pixels representing raptor and Edc4. Furthermore the Mander's co-localization coefficients for channel 1 (M1) were 0.889 and 0.999 from two consecutive experiments, describing the maximum number of raptor pixels co-localized with Edc4. The channel 2 co-localization coefficients (M2) were 0.946 and 1.000 respectively which represents the contribution of Edc4 channels co-localizing with raptor component of mTORC1 (Fig. 4.3). 


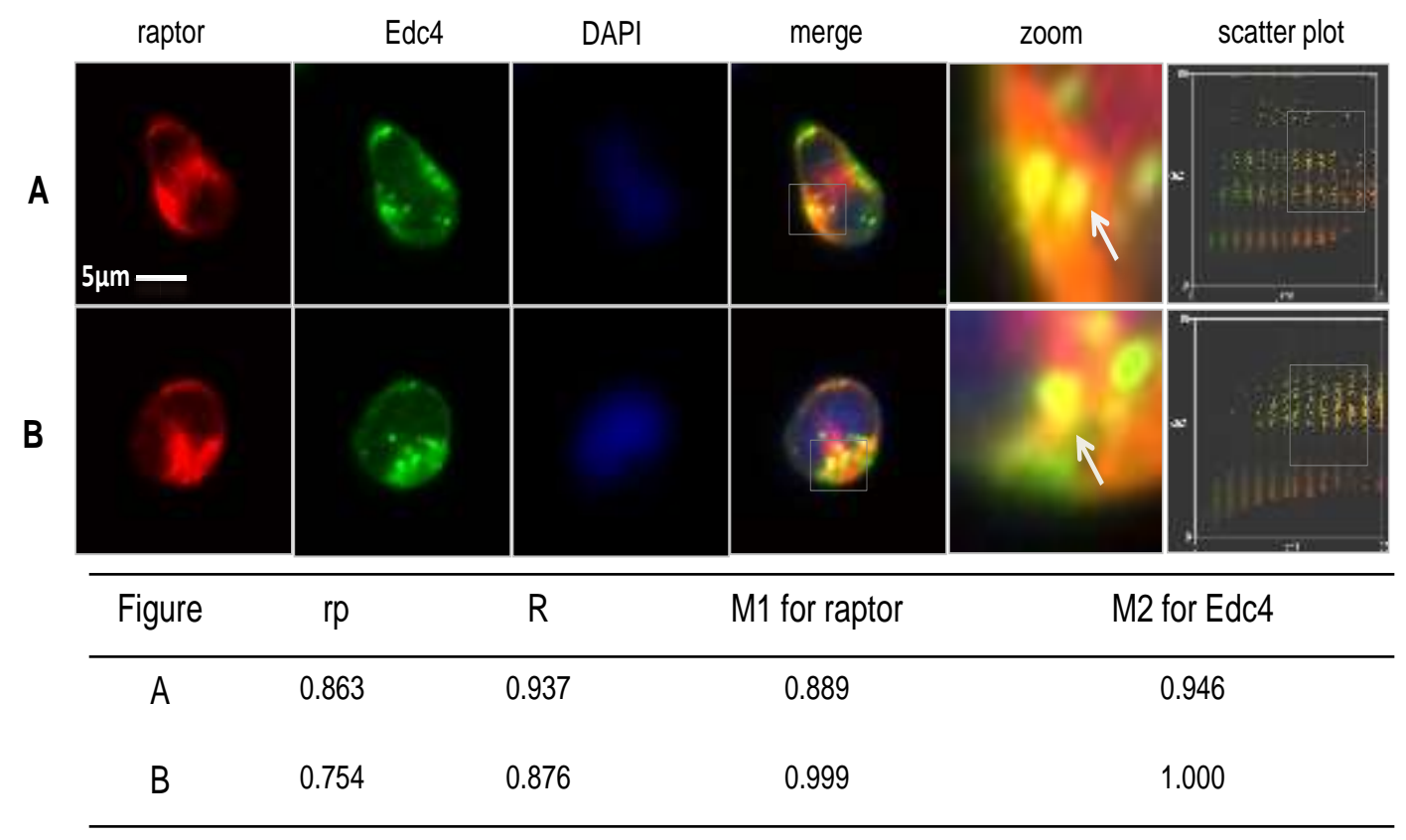

\section{Figure 4.3: Edc4 showed high co-localization with raptor component of mTORC1.}

CCRF-CEM cells were grown on 8 chamber well slide for 48 hours, fixed, permeabilized. And rabbit anti-Edc4 and mouse anti-raptor were added to the permeabilized cells and incubated overnight. Fluorescent signals were detected using labelled anti-mouse Cydye 3 and anti-rabbit Alexa Fluor 488. Raptor and Edc4 (P bodies marker) co-localization in CCRF-CEM cells were analyzed using Axiovert 200M confocal microscope and processed with Image $\mathrm{J}$ software. Overlay images with yellow region showed high co-localization of raptor (red) with Edc4 (green) inside and outside the $\mathrm{P}$ bodies (arrows indicated $\mathrm{P}$ bodies). The scatter plot of the individual pixels was obtained from the two source images. The threshold levels of red channel signals on $\mathrm{x}$-axis and green channel signals on $y$-axis determined the overlapping yellow marked region. Quantitative colocalization by employing statistical Pearson's correlation coefficient $(r p(-1 \leq r p \leq 1))$ measured the co-occurrence of the Edc4 and raptor pixels and showed high co-localization pixels between these two proteins. Furthermore Mander's overlap coefficient ( $(0 \leq R \leq 1))$ illustrated increased overlapping of Edc4 and raptor while co-localization coefficients $M 1$ and M2 demonstrated maximum co-localized pixels of interest of one channel with other channel. At least 30 cells were observed per experiment (Scale bars $=5 \mu \mathrm{m}$ ) and experiments were repeated five times (two experimental replicates $A$ and $B$ are shown). 


\subsubsection{Both leucine starvation and rapamycin treatment enhanced total Edc4 protein expression}

Both leucine starvation and rapamycin treatment are known to inhibit the mTORC1 signaling [32]. In order to check the influence of leucine or rapamycin on Edc4 expression, T lymphocytes cells were first leucine starved for two hours and then stimulated for 30 minutes with leucine or treated 1 hour with rapamycin. Both leucine starvation and rapamycin treatment significantly increased the expression of Edc4 as observed by immunoblotting in contrast results with leucine stimulated cells or cells grown in complete (regular) medium (Fig. 4.4).

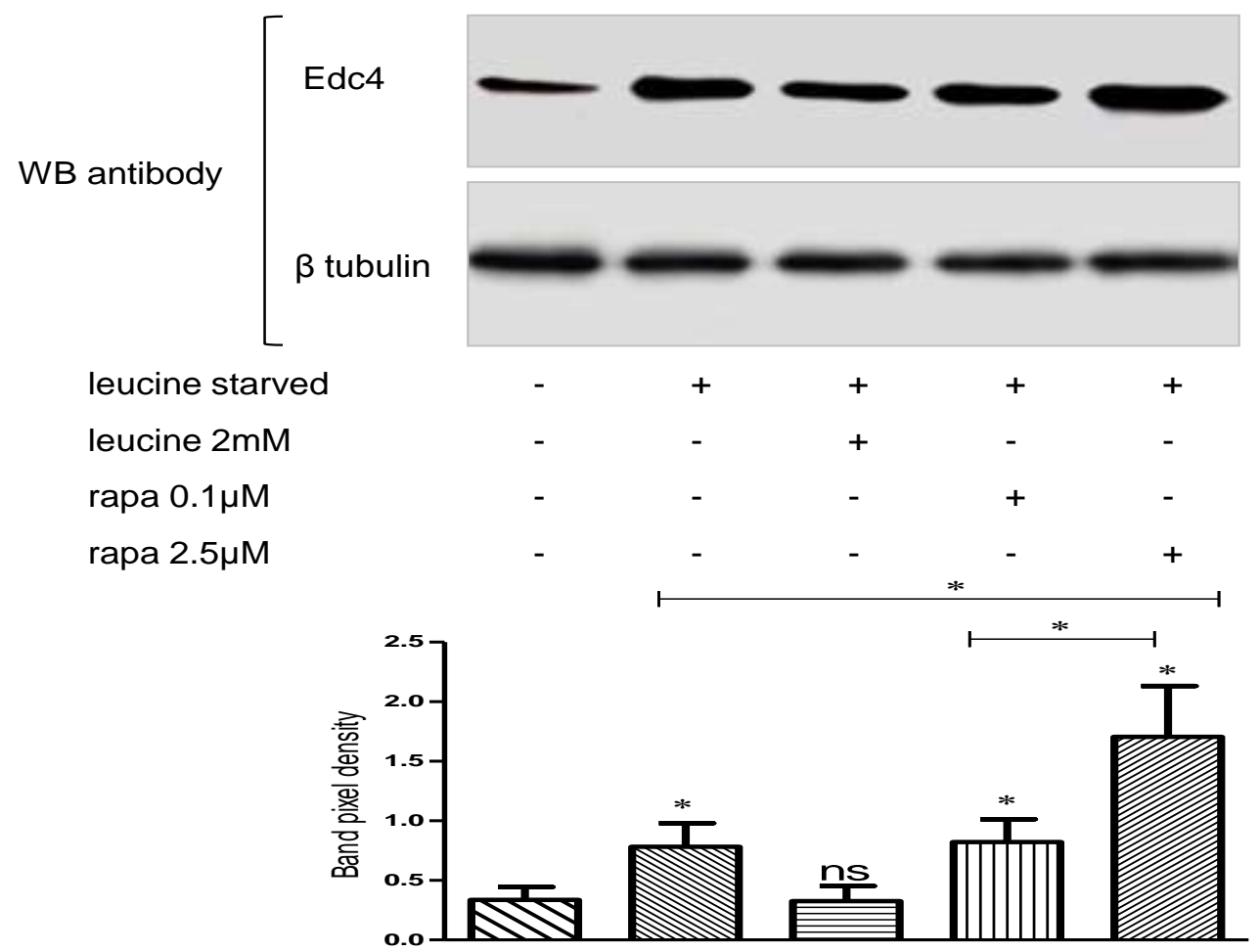

Figure 4.4: Leucine starvation and rapamycin treatment increased the Edc4 protein expression.

CCRF-CEM cells were grown in complete RPMI-1640 medium and were leucine starved for two hours followed by leucine stimulation $(2 \mathrm{mM})$ for 30 minutes or treated with rapamycin $(0.1 \mu \mathrm{M}$ and $2.5 \mu \mathrm{M})$ for one hour. Immunoblotting with Edc4 antibody detected significant change in the Edc4 expression in leucine starved and rapamycin treated cells as compared to control (without starvation). $\beta$ tubulin was used as a loading control. The representative data is mean \pm SEM of at least five independent experiments and the significance was determined by Student's $t$-test $\left({ }^{*}=p<\right.$ 0.05). 


\subsubsection{Edc4 and raptor interaction was rapamycin sensitive and rapamycin reduced the amount of total serine phosphorylated Edc4}

In order to explore the kind of interaction between Edc4 and raptor component of mTORC1, T lymphocytes were treated with rapamycin and DMSO for one hour. Cells were then lysed with CHAPS buffer followed by mTORC1 specific purification with raptor antibody. Immunoblotting showed almost equimolar amount of raptor immuoprecipitation in rapamycin and DMSO treated samples; however, immunblotting with Edc4 antibody detected only a weak Edc4 signal in the rapamycin treated samples as compared to DMSO treated samples. This suggests that the Edc4 and raptor interaction was decreased by rapamycin inhibition of mTORC1 (Fig. 4.5A). We further hypothesized that since mTOR is a serine threonine enzyme [38]. It might regulate Edc4 via phosphorylation. To understand the involvement of mTORC1 in Edc4 regulation, cells were treated with rapamycin and DMSO followed by specific immunoprecipitation of Edc4. The Edc4 IP samples were immunoblotted with phosphoserine antibody. Decrease in the phosphorylated Edc4 serine was detected in the samples following rapamycin treatment (Fig. 4.5B). These results provide the first evidence that mTORC1 regulation of Edc4 is through phosphorylation of serine sites on Edc4. Moreover using phosphosite prediction tool (Net.Phos) [204], Edc4 protein sequence analysis revealed 86 serine, 11 threonine and 4 tyrosine phosphorylation sites which support our result that Edc4 is a serine rich protein (Fig. 4.6). 
IP antibody:

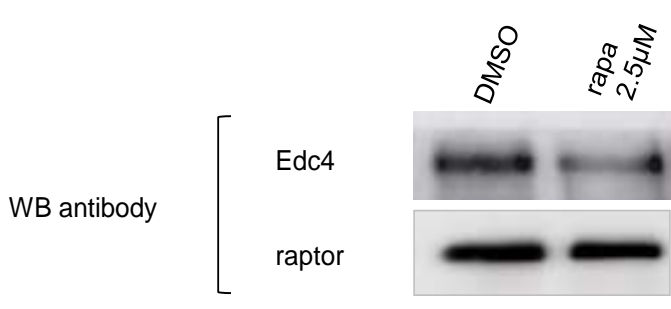

B

IP antibody:

Edc4
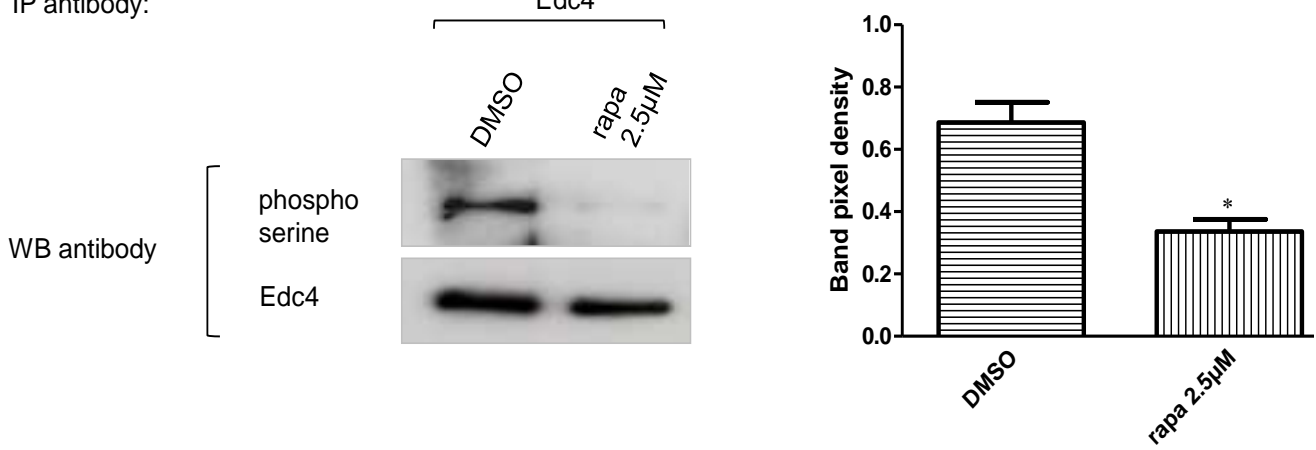

Figure 4.5: Edc4 and raptor interaction is rapamycin sensitive and rapamycin reduce the Edc4 phosphorylation on serine residues.

(A) CCRF-CEM cells were treated with rapamycin and DMSO for one hour followed by cell lysis in CHAPS buffer. Endogenous mTORC1 was specifically immunoprecipitated using raptor antibody and resolved on SDS-PAGE. Immunoblotting with raptor antibody showed raptor immunoprecipitation in stoichometric ratio in both DMSO and rapamycin treated samples. Further blotting with Edc4 antibody revealed decreased in Edc4 signal in the rapamycin treated as compared to DMSO $(n=4)$.

(B) CCRF-CEM cells were treated with rapamycin and DMSO for one hour and then lysed the cells. Edc4 was specifically immunoprecipitated using Edc4 antibody and the IP elute was resolved on SDS-PAGE. Immunoblot analysis with phosphoserine antibody detected decrease phosphorylation signal in the rapamycin treated sample as compared to DMSO while blotting with total Edc4 detected almost equal band intensity in both rapamycin and DMSO treated samples. The representative data are mean \pm SEM of at least four independent experiments and the significance was determined by Student's $t$-test $\left({ }^{*}=p<0.05\right)$. 


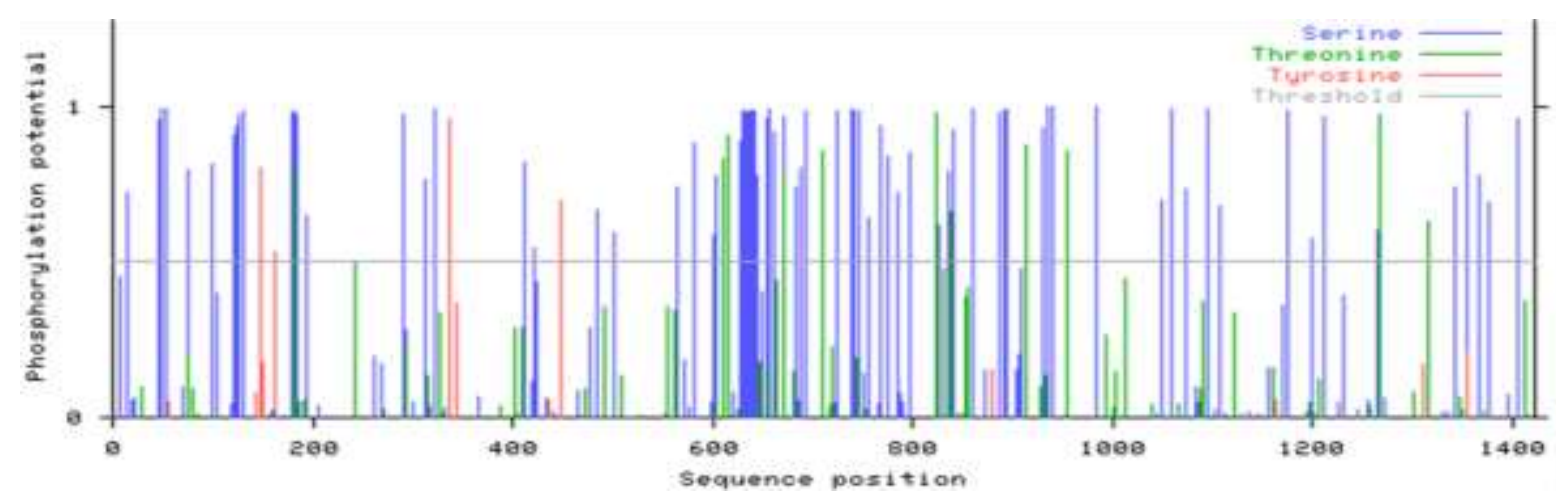

Figure 4.6: Predicted phosphorylation sites in Edc4.

In silico Edc4 protein sequence analysis revealed Edc4 as highly phosphorylated protein. Total 86 serine, 11 threonine and 4 tyrosine phosphorylation sites were predicted in Edc4 protein sequence where blue, green and red spectral lines represent serine, threonine and tyrosine respectively. There are 16 consecutive serine phosphorylation sites near 600 sequence position (NetPhos 2.0 server [204]).

\subsubsection{Rapamycin enhanced the mRNA decapping activity}

After observing the rapamycin induced decrease in Edc4 interaction with raptor as well as total serine phosphorylated Edc4, we hypothesized that mTORC1 inhibition may lead to increase mRNA decapping activity. To evaluate this, $T$ lymphocytes were treated with rapamycin and 5 '-capped mRNA was specifically isolated and quantified. A significant decrease in the total amount of 5 capped mRNA was observed following rapamycin treatment as compared to control, indicating that decapping activity was increased as a result of rapamycin induced mTORC1 inhibition (Fig. 4.7). 
A

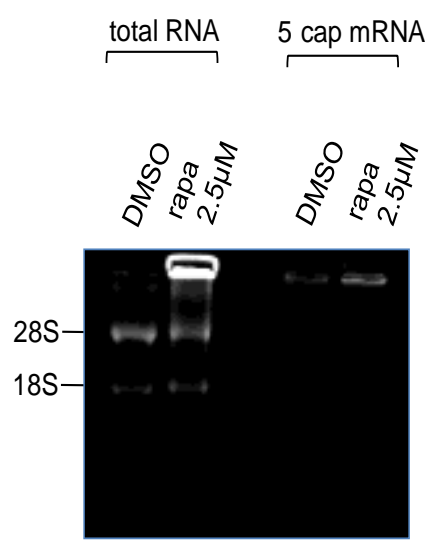

B

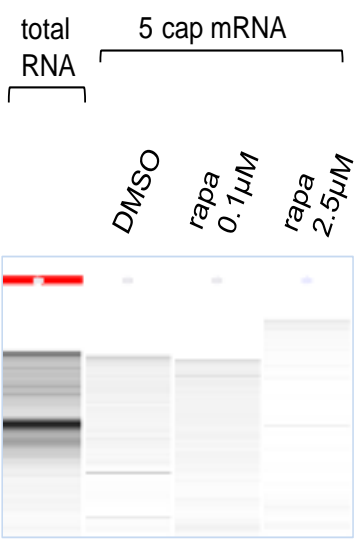

C

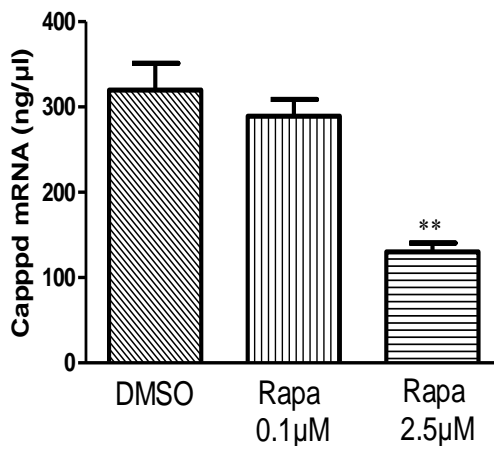

Figure 4.7: Rapamycin enhances the mRNA decapping activity.

CCRF-CEM cells were treated with either rapamycin or vehicle control for one hour and $(A)$ total RNA was extracted from the cells by chloroform/isopropanol precipitation method. Capped mRNAs were specifically isolated from total RNA using terminator exonuclease and lithium chloride precipitation. The removal of $18 \mathrm{~S}$ and $28 \mathrm{~S}$ rRNA from $5^{\prime}$-capped mRNA content was confirmed by $1.5 \%$ agarose gel electrophoresis. (B) After confirmation of $5^{\prime}$-capped mRNA purity, the total $5^{\prime}$ capped mRNA was run on the microchip gel and quantified by Agilent 2100 Bioanalyzer. (C) Bar diagram showed representation of five independent experiments (mean \pm SEM), while significance was determined by Student's $t$-test $\left({ }^{* *}=p<0.005\right)$. 


\subsection{Discussion}

In an attempt to identify novel interacting partners of mTORC1, we identified Edc4 protein as a new interacting partner of mTORC1. Edc4 is an important member of the mRNA decapping enzyme complex and has a suggested role in miRNA-mediated translational repression [146,149]. Edc4 is an essential constituent of $\mathrm{P}$ bodies and accelerates the mRNA decay process [148]. In human cells Edc4 exists as a multimeric protein having multiple WD40 (Trp-Asp) repeats at the $\mathrm{N}$-terminus [148]. These repeats are known as protein-protein interaction domain and serve as a scaffold for building protein complexes [92]. In some cases they play a role in recruiting phosphorylated proteins to the enzyme active sites [205]. The WD-40 repeat domains of raptor and G $\beta L$, which are the known interacting proteins of $\mathrm{mTORC} 1$, are likely to play important role in $\mathrm{mTORC} 1$ functions [32,33]. The existence of WD40 repeats in the Edc4 might be involved in its interaction with mTORC1. The C-terminus region of Edc4 is conserved and responsible for its localization in the $\mathrm{P}$ bodies [200]. Rapamycin, an mTORC1 specific inhibitor, modulates mRNA turnover by increasing the expression of decapping protein in $S$. Cerevisiae. This reflects the involvement of mTOR signaling in mRNA degradation [150]. In the present study, Edc4 was identified in the mTORC1 specific endogenous purification as well as in the myc-tag pulldown of mTORC1. The Edc4 signal was only detected in mTORC1 purification while it was absent from the mTORC2 specific purifications. Therefore, our experimental evidence suggests that Edc4 is associated with mTORC1 and might not interact with mTORC2 loop of mTOR signaling pathway.

We further found that the raptor component of mTORC1 co-localized with Edc4 in the cytoplasm and in the cytosolic $\mathrm{P}$ bodies. In $\mathrm{P}$ bodies, mRNAs are either degraded, or stored for return to translation [139]. Edc4 is the key component of $\mathrm{P}$ bodies and is even used as marker for $\mathrm{P}$ bodies localization $[148,200]$. A cap binding protein elF4E and 4E-transporter (4E-T), a negative regulator of elF4E, co-localized in the $P$ bodies [206]. elF4E is the potential target for 4E-BP1 inhibitory action. mTORC1 phosphorylates 4E-BP1, and prevents $4 \mathrm{E}$ BP1 elF4E binding to elF4E which allows elF4E to take part in the translation initiation process [29]. We hypothesize that the presence of $\mathrm{mTORC} 1$ within the $\mathrm{P}$ 
bodies might allow the transition of a stored mRNA to a translationally competent state or regulate mRNA decapping by interacting with Edc4 in the $\mathrm{P}$ bodies; however, this possibility needs further investigation. Quantitative co-localization of Edc4 with the raptor component of mTORC1 revealed a significant extent of cooccurrence between two different fluorescent labels with separate emission spectra. This suggests that the co-localized proteins are in very close proximity or it might even reside at the same physical location[201]. Co-localization of raptor (red pixels) and Edc4 (green pixels) in the scatter plots exhibited high colocalization between raptor component of mTORC1 and Edc4.

Furthermore, Pearson's correlation coefficients ( $r p$ ) were used to measure the extent of co-occurrence between two fluorescence channels. Pearson's coefficients range from -1 to 1 , with a value of -1 indicating a total lack of overlap between pixels from the two images, and a value of 1 representing perfect correlation [201]. The Pearson's correlation coefficients demonstrated a high colocalization between Edc4 and raptor counterpart of mTORC1. Mander's overlap coefficients $(R)$ were calculated which is insensitive to fluorochrome concentration fluctuations and photobleaching [201]. This coefficient ranges between 0 and 1 , with 1 being highly co-localized pixels and zero being the least co-localized pixels [203]. Mander's overlap coefficients confirmed a high degree of overlapping pixels between Edc4 and raptor protein. The Mander's co-localization coefficients for channel 1 (M1) and channel 2 (M2) were calculated to describe the contribution of both channels in the co-localization. Our results showed a high number of Edc4 pixels co-localize with raptor inside and outside the $\mathrm{P}$ bodies.

In order to elucidate the mechanism involved in the Edc4 and mTORC1 interaction, we used leucine, a known stimulator of mTORC1 mediated translation $[32,90]$. Nutrient starvation inhibits the mTOR signaling and causes an increased turnover of a subset of mRNA in yeast [150]. Leucine starvation increased mRNA and protein expression of transcription factors [207]. In our experiments, leucine starvation induced Edc4 expression as compared to leucine stimulated and complete medium supplementation. This indicates that regulation of mTORC1 kinase activity by leucine [32] increased Edc4 expression. 
To gain further insight into the mTORC1 involvement in the regulation of Edc4, rapamycin, a specific inhibitor of mTORC1 was employed. Rapamycin treatment, which should mimic the nutrient starved condition, also modulated Edc4 expression providing convincing evidence of mTORC1 involvement in the regulation of Edc4. These observations are in the line with previous studies where rapamycin was reported to increase the expression of decapping proteins and mRNA turnover $[150,208]$. We further demonstrated that the mTORC1 inhibition induced by rapamycin decreased $\mathrm{mTORC} 1$ interactions with Edc4. One possible explanation is that interaction of the raptor component of mTORC1 with Edc4 might be responsible for control of Edc4 activity in the mRNA decapping process. This mTORC1 interaction is decreased by rapamycin treatment and thus more Edc4 is available to take part in the mRNA decapping process.

The Edc4 is a phospho-protein with 86 serine, 11 threonine and 4 tyrosine predicted phosphorylation sites (NetPhos 2.0 server [204]. In total 29 phosphorylation sites including 19 phosphoserine, 3 phosphotyrosine, and 7 phosphothreonine (Phosphosite server [209] of yet unknown functional significance have been confirmed by mass spectrometric analysis. The mTOR is a well-characterized serine threonine kinase complex while Edc4 is a serine rich protein which has a stretch of 16 consecutive serine rich residues [148]. Thus Edc4 could be a target for various kinases including mTOR. To establish the involvement of mTORC1 in Edc4 regulation, we examined the effect of rapamycin treatment on the phosphorylation status of Edc4. A significant decrease was observed in total serine phosphorylated Edc4 protein signal after rapamycin treatment which indicated mTORC1 kinase role in Edc4 regulation. While investigating whether rapamycin had any effect on the total amount of $5^{\prime}$-capped mRNA in cell, we observed a substantial decrease in the $5^{\prime}$-capped mRNA associated with rapamycin treatment. These findings strongly suggest a regulatory role of mTORC1 in the total amount of 5 -capped mRNA in cells as a result of decreased cellular mRNA decapping activity. Based on these results, we attempt to speculate that mTORC1 interacts with Edc4 to keep its expression on basal levels by inactivating Edc4 through serine phosphorylation. We suggest that phosphorylated Edc4 would no longer be available for mRNA decapping activity. We hypothesize that $\mathrm{mTORC} 1$ inhibition by rapamycin results in an increased 
amount of dephosphorylated Edc4, and consequently higher cellular decapping activity and less total $5^{\prime}$-capped mRNA in the cell. Further studies might broaden our understanding about the mTORC1 interplay in the mRNA decapping.

\subsection{Conclusion}

In the present study Edc4 was identified as new interacting partner of mTORC1 using both endogenous purification and exogenous myc-tag purification strategies. mTORC1 inhibition by rapamycin, and co-localization analysis provided additional evidence for Edc4 and mTORC1 interactions. Modulation of Edc4 expression and mRNA decapping after rapamycin treatment suggests mTORC1 involvement in Edc4 regulation. Decreased in the phosphorylation of Edc4 after mTORC1 inhibition suggests a role for mTORC1 in the decapping process. These findings highlight the role of mTORC1 in the mRNA decapping via its interaction with Edc4. Further studies are required to provide a more complete understanding of the biological interplay between mTORC1 signaling and the mRNA decapping process. 


\section{Fetal calf serum heat inactivation and lipopolysaccharide contamination influence the human $T$ lymphoblast proteome and phosphoproteome}

Hazir Rahman ${ }^{1,2}$, Muhammad Qasim ${ }^{1,2}$, Michael Oellerich ${ }^{1}$, Abdul R Asif $^{1}$

1. Department of Clinical Chemistry, University Medical Centre, Goettingen, Germany.

2. Department of Microbiology, Kohat University of Science and Technology, Kohat, Pakistan.

As a pretext with mTORC1 proteomics in CCRF-CEM cells, this study was conducted to investigate the effect of FCS heat inactivation and lipopolysaccharide contamination on the proteome and phosphoproteome of CCRF-CEM cells. The findings of the present study were published in th journal of Proteome Science 2011, 9:71 doi:10.1186/1477-5956-9-71. 


\subsection{Abstract}

The effects of fetal calf serum (FCS) heat inactivation and bacterial lipopolysaccharide (LPS) contamination on cell physiology have been studied, but their effect on the proteome of cultured cells has yet to be described. This study was undertaken to investigate the effects of heat inactivation of FCS and LPS contamination on the human $T$ lymphoblast proteome. Human $T$ lymphoblastic leukaemia (CCRF-CEM) cells were grown in FCS, either non-heated, or heat inactivated, having low $(<1 \mathrm{EU} / \mathrm{mL}$ ) or regular ( $<30 \mathrm{EU} / \mathrm{mL}$ ) LPS concentrations. Protein lysates were resolved by 2-DE followed by phospho-specific and silver nitrate staining. Differentially regulated spots were identified by nano LC ESI QTOF MS/MS analysis.

A total of four proteins (EIF3M, PRS7, PSB4, and SNAPA) were up-regulated when CCRF-CEM cells were grown in media supplemented with heat inactivated FCS (HE) as compared to cells grown in media with non-heated FCS (NHE). Six proteins (TCPD, ACTA, NACA, TCTP, ACTB, and ICLN) displayed a differential phosphorylation pattern between the NHE and HE groups. Compared to the low concentration LPS group, regular levels of LPS resulted in the up-regulation of three proteins (SYBF, QCR1, and SUCB1).

The present study provides new information regarding the effect of FCS heat inactivation and change in FCS-LPS concentration on cellular protein expression, and post-translational modification in human $T$ lymphoblasts. Both heat inactivation and LPS contamination of FCS were shown to modulate the expression and phosphorylation of proteins involved in basic cellular functions, such as protein synthesis, cytoskeleton stability, oxidative stress regulation and apoptosis. Hence, the study emphasizes the need to consider both heat inactivation and LPS contamination of FCS as factors that can influence the T lymphoblast proteome. 


\subsection{Introduction}

Fetal calf serum (FCS) is a complex nutritional supplement that is routinely used in cell culture media $[210,211]$. Along with the growth factors, FCS contains several complement proteins [212-214]. Proteins of the complement system play a central role in innate immunity [215] and when present in cell culture media, they can influence immunological assays $[216,217]$. Heat inactivation of serum at $56^{\circ} \mathrm{C}$ for 30 minutes is used to inhibit the haemolytic activity of serum by decreasing the titer of heat labile complement proteins [218]. There are conflicting reports regarding the significance of FCS heat inactivation before its use in cell culture medium. Several studies have reported that heat inactivation of serum modifies growth factor content and increases cell proliferation $[219,220]$. However, Leshem and co-workers reported that heat inactivation of serum did not influence lymphocyte functions at least in in vitro studies [221].

Bacterial lipopolysaccharide (LPS) is an inevitable contaminant of serum used in cell culture medium. LPS acts via the Toll-like receptor (TLR) complex, which transduces the LPS signal across the plasma membrane and triggers downstream signaling, leading to the secretion of pro-inflammatory cytokines and induction of complement pathways [222-224]. Protein phosphorylation is crucial for gene regulation, cell growth and homeostasis [225,226]. LPS influences proteins by altering their phosphorylation status through activation of various kinases e.g., p70 S6 kinase [4]. The p70 S6 kinase is the downstream effector of the mammalian target of rapamycin complex 1 (mTORC1), an important regulator of cell growth, proliferation, protein synthesis and cell survival [227,228]. Analogous to the effects of FCS heat inactivation, there are contradictory findings regarding the effect of LPS concentrations on the physiology of cultured cells. Some research groups have reported a direct influence of LPS on cellular physiology [229-231], while others have not found any detectable effect on the growth of various cell lines including WI-38, 3T3 and CHO even after using LPS concentrations up to $100 \mathrm{EU} / \mathrm{mL}$ [224,232-234]. The heat inactivation procedure itself exerts no deactivating effect on LPS [235]. 
Cell cultures are routinely used to conduct important biological studies. Often, studies have used varying culture conditions with respect to FCS heat inactivation, or poorly documented LPS concentrations in cell cultures, while not acknowledging their possible effects on the proteome of the cultured cells. The present study was designed to determine the effect of FCS heat inactivation and the concentration of LPS in serum on cultured human T lymphoblastic leukaemia cells employing a proteomic and phosphoproteomic approach.

\subsection{Methods}

\subsubsection{Reagents}

RPMI-1640, FCS containing LPS concentrations of either $<1 \mathrm{EU} / \mathrm{mL}(<0.1$ to $0.2 \mathrm{ng} / \mathrm{mL}$ ) or $<30 \mathrm{EU} / \mathrm{mL}$ ( $<3$ to $6 \mathrm{ng} / \mathrm{mL}$ ), Dulbecco's phosphate buffer saline (PBS), penicillin and streptomycin were obtained from PAA Laboratories, Colbe, Germany. Urea, thiourea, dithiothreitol (DTT), trypsin, triflouroacetic acid (TFA), acitonitrile (ACN) and ammonium bicarbonate (AMBIC) were from Sigma-Aldrich, Steinheim, Germany. CHAPS buffer was from AppliChem, Darmstadt, Germany, and ampholeytes, protein assay reagents, Immobilized $\mathrm{pH}$ gradient strips (IPG strips) were provided by Bio-Rad, Munich, Germany. Protease and phosphatase inhibitor cocktail were from Roche, Mannheim, Germany. Bromophenol blue and Tris base were from Carl Roth, Karlsruhe, Germany, and sodium dodecyl sulfate (SDS) was from Serva, Heidelberg, Germany. Glycerin, potassium ferricynaide and sodium thiosulfate were from Merck, Darmstadt, Germany and formic acid from BASF, Ludwigshafen, Germany. Superoxide dismutase 2 (SOD2) antibodies was a gift from Dr. Dihazi, UMG, Goettingen, Germany. $\beta$-tubulin antibody was from BioVendor, Heidelberg, Germany and antibodies to HRP labelled anti-mouse secondary antibodies were from Bio-Rad, Munich, Germany.

\subsubsection{Cell cultures}

Human T lymphoblastic leukaemia cells (CCRF-CEM) were purchased from DSMZ (German collection of microorganisms and cell cultures, Braunschweig, Germany). Cells were grown in $75 \mathrm{~cm}^{2}$ culture flasks (Sarstedt, Numberecht, Germany) in RPMI-1640 medium containing L-glutamine, 10\% FCS, 
$100,000 \mathrm{U} / \mathrm{L}$ penicillin and $100 \mu \mathrm{g} / \mathrm{L}$ streptomycin, in $95 \%$ humidity and $5 \% \mathrm{CO}_{2}$ conditions at $37^{\circ} \mathrm{C}$.

\subsubsection{Heat inactivation and LPS treatment of cultured cells}

FCS was heated at $56^{\circ} \mathrm{C}$ for 30 minutes before adding it to the RPMI- 1640 medium. CCRF-CEM cells were grown in RPMI-1640 medium supplemented either with (a) FCS without heat inactivation and a normal concentration of LPS (NHE), (b) FCS with heat inactivation containing a normal concentration of LPS $(\mathrm{HE}),(\mathrm{c})$ FCS without heat inactivation having a low concentration of LPS (NHL), or (d) heated FCS with low concentration of LPS (HL). The cells were adapted in RPMI-1640 medium supplemented with four different FCS concentrations for at least five passages before starting the first harvest. The cells were grown to a density of $0.25 \times 10^{6}$ cells $/ \mathrm{mL}$ under recommended conditions i.e., $37^{\circ} \mathrm{C}, 95 \%$ humidity, $20 \% \mathrm{O}_{2}, 5 \% \mathrm{CO}_{2}$ and the medium was changed every second day. All experiments were repeated six times.

\subsubsection{Cell lysis and protein estimation}

Cells were washed with ice cold PBS and lysed in lysis buffer (7 M urea, 2 M thiourea, 4\% CHAPS, 2\% ampholytes [pH 3-10], 1\% DTT, 1\% protease inhibitor and $1 \%$ phosphatase inhibitor cocktail). Protein concentration was measured as described by Bradford (1976) using serum albumin as a standard [236].

\subsubsection{Sample preparation and two-dimensional gel electrophoresis (2-DE)}

2-DE was performed as described by Gorg et al [237]. Briefly, a $160 \mu \mathrm{g}$ protein sample was diluted in rehydration buffer $(7 \mathrm{M}$ urea, $2 \mathrm{M}$ thiourea, $4 \%$ CHAPS, 0.2 ampholytes [pH 3-10], $0.2 \%$ DTT and $0.25 \%$ bromophenol blue) were applied on immobilized pH gradient strip (IPG strip, $17 \mathrm{~cm}$ ) with a non-linear $\mathrm{pH}$ range of 3-10 at room temperature overnight for passive rehydration. Isoelectric focusing was performed with a Bio-Rad Protean electrophoresis apparatus set to final 32000 Volts hour. The IPG strip was then equilibrated for 20 minutes in 
equilibration buffer (6 M urea, 30\% glycerol, $2 \%$ SDS, and $50 \mathrm{mM}$ Tris- $\mathrm{HCl}[\mathrm{pH}$ 8.8]) containing DTT (10 g/L) and then subsequently immersed for 20 minutes in fresh equilibration buffer containing iodoacetamide $(40 \mathrm{~g} / \mathrm{L})$. Following equilibration, proteins were separated by SDS-PAGE at a constant voltage of 100 Volts using a $12.5 \%$ polyacrylamide separation gel at $4{ }^{\circ} \mathrm{C}$ [238].

\subsubsection{Phospho-specific staining of 2-DE gels}

The gels were fixed twice in solution containing 50\% methanol and $10 \%$ acetic acid for 45 minutes and washed three times in double distilled water for 15 minutes each. Gels were incubated in Pro-Q Diamond phospho-stain (Invitrogen, Paisley, UK) overnight in the dark at room temperature, destained three times for 30 minutes in $20 \%$ ACN and $50 \mathrm{mM}$ sodium acetate, followed by three washes in double distilled water for five minutes each. Gels were scanned using an imaging instrument (FLA -5100 Fuji photo film, Dusseldorf, Germany) at a wavelength of $532 \mathrm{~nm}$.

\subsubsection{Visualization of proteins and densitometric analysis}

Proteins were visualized by silver staining, as described by Blum et al [239], immersed in a fixative solution (50\% methanol and $12 \%$ acetic acid) for one hour and washed in 50\% and 30\% ethanol for 20 minutes each. Gels were sensitized in $0.02 \%$ sodium thiosulfate for 60 seconds and washed three times in water. Staining was done in silver solution $(0.2 \%$ silver nitrate, $0.026 \%$ formaldehyde) for 20 minutes, followed by three washings in water. All gels were developed in a solution containing $6 \%$ sodium carbonate, $0.0185 \%$ formaldehyde and $6 \%$ sodium thiosulfate until spots appeared and the reaction was stopped by adding the stop solution ( $50 \%$ methanol and $12 \%$ acetic acid). Gels were scanned (CanoScan 8400F, Canon, Krefeld, Germany) dried (Gel Drier, Bio-Rad, Munich, Germany), and subjected to densitometric analysis using the Delta2D software version 4.0 (DECODON, Greifswald, Germany). 


\subsubsection{Tryptic digestion}

Differentially expressed spots were excised and in-gel digested according to the method described by Shevchenko and colleagues [240]. Briefly, sliced gel spots were destained with $30 \mathrm{mM}$ potassium ferricyanide and $100 \mathrm{mM}$ sodium thiosulfate; followed by washing with $50 \% \mathrm{ACN}$ and $100 \mathrm{mM} \mathrm{AMBIC}$, which was then removed and dried in a vacuum centrifuge (UNIVAPO, uniEquip, Matinsried, Germany). The gel pieces were digested with trypsin digestion buffer $(0.1 \mu \mathrm{g} / \mu \mathrm{l}$ trypsin, $1 \mathrm{M}$ calcium chloride, and $1 \mathrm{M} \mathrm{AMBIC)}$ for 45 minutes on ice and then incubated overnight in digestion buffer without trypsin at $37^{\circ} \mathrm{C}$. The peptides were extracted with increasing concentrations of $A C N$ and TFA in several rounds and the extracted peptides were dried by vacuum centrifugation. Peptides were reconstituted in $0.1 \%$ FA for injection into a nano-flow HPLC.

\subsubsection{Peptide sequence analysis using nano LC ESI Q-TOF MS/M and database search}

Peptide samples $(1 \mu \mathrm{l})$ were introduced onto two consecutive C18-reversed phase chromatography columns (C18 pepMap: $300 \mu \mathrm{m} \times 5 \mathrm{~mm}$; $5 \mu \mathrm{m}$ particle size, and C18 pepMap100 nanoanalytical column: $75 \mu \mathrm{m} \times 15 \mathrm{~cm}$; $3 \mu \mathrm{m}$ particle size; LC Packings, Germering, Germany) using a nano-flow CapLC autosampler (Waters, Eschborn, Germany). Peptides were eluted with an increasing gradient of ACN and analyzed on a Q-TOF Ultima Global mass spectrometer (Micromass, Manchester, UK) equipped with a nanoflow ESI Z-spray source in the positive ion mode, as previously described [241]. The data were analyzed with the MassLynx (version 4.0) software. The peaklists were searched using the online MASCOT search engine (http://www.matrixscience.com) against the UniProt/SwissProt database release 15.15 (515203 entries, 181334896 elements). The data were searched against the database with following parameters: trypsin as enzyme for digestion; up to a maximum of one missed cleavage site allowed; monoisotopic mass value and with unrestricted protein mass; peptide tolerance $\pm 0.5 \mathrm{Da}$ and MS/MS tolerance $\pm 0.5 \mathrm{Da}$. Proteins were identified on the basis of two or more 
peptides, whose ions score, exceeded the threshold, $p<0.05$ which reflects the $95 \%$ confidence level for the matched peptides.

\subsubsection{SDS-PAGE and Western blotting}

Samples were resolved on 12.5\% SDS-PAGE and electro-transferred using a semi-dry transblot system (SD transblot, Bio-Rad, Munich, Germany) onto PVDF membrane (Millipore, Schwalbach, Germany) at 17 Volts in a transfer buffer (192 mM glycine, 10\% methanol, and $25 \mathrm{mM}$ Tris- $\mathrm{HCl}[\mathrm{pH}$ 8.3]) for 30 minutes. The membrane was blocked with $5 \%$ skimmed milk powder prepared in TBS-T buffer (50 mM Tris- $\mathrm{HCl}$ [pH 7.5], $200 \mathrm{mM} \mathrm{NaCl}$, and 0.05\% Tween 20) for one hour at room temperature and washed three times with TBS-T buffer. Membrane was incubated with Anti-SOD2, or anti- $\beta$ tubulin antibody prepared in $5 \%$ skimmed milk powder for overnight at $4^{\circ} \mathrm{C}$. After three washes in TBS-T for five minutes each, the membrane was incubated in HRP labelled anti-mouse secondary antibody for one hour at room temperature. Followed by subsequent washes, the signal on the blot was detected using an enhanced chemiluminescent (ECL) reagent (GE Healthcare, Munich, Germany) and developed on Amersham Hyperfilm (GE Healthcare, Munich, Germany). Signal intensities from each immunoblot were quantified using Lab Image software version 2.71 (Kapelan, Leipzig, Germany).

\subsubsection{Statistical analysis}

Densitometric analysis of protein spots from silver and phospho-stained gel were performed using Delta2D software. Protein spots, which showed $\geq 1.5$ fold change in phosphorylation signal and consistently statistically significant $(p<$ 0.05 ) using the Student's $t$-test in at least six independent 2-DE experiments, were selected for in-gel digestion and identified using ESI Q-TOF MS/MS analysis. Error bars in results represent mean \pm SD. Immunoblot intensities were quantified using Lablmage software (Kapelan, Leipzig, Germany). Immunoblotting was repeated at least three times and results were expressed as mean $\pm S D$ with significance measured using the Student's $t$-test $(p<0.05)$. 


\subsection{Results}

Human T lymphoblastic cells were grown in RPMI-1640 medium supplemented either with (a) non-heat inactivated FCS with normal concentrations of LPS (NHE), (b) heat inactivated FCS containing normal concentrations of LPS (HE), (c) non-heat inactivated FCS with low concentrations of LPS (NHL), or (d) heat inactivated FCS with low concentrations of LPS (HL). The cells were grown for at least five passages, harvested and used for 2-DE. The 2-DE gels were silver stained followed by phospho specific staining, and differentially regulated spots were excised, digested, and identified by nano LC QTOF MS/MS analysis.

\subsubsection{Cells grown in medium with heat inactivated FCS}

Initially, we compared human T lymphoblastic cells grown in NHE and HE medium. Four protein spots (numbers 4, 6, 7 and 10 in Table 5.1) were upregulated in the HE group. These were identified as eukaryotic translation initiation factor 3 subunit M (EIF3M), 26S protease regulatory subunit 7 (PRS7), proteasome subunit beta type-4 (PSB4) and alpha-soluble NSF attachment protein (SNAPA) respectively. Fig. 5.1A shows a representative silver stained gel with these differentially regulated spots marked, while figure 5.1B shows six replicates of two regulated spots (spots 8 and 10). Fig. 5.2A \&B showed graphical display of regulated spots in silver stained gels

Densitometric analysis of phospho-stained gels was performed to check the proteins exhibiting significant changes in phosphorylation signals by after heat inactivation of FCS. Fig. 5.3 shows a representative phospho-stained gel (Figure 5.3A) and six replications (Fig. 5.3B) of two differentially phosphorylated proteins (TCTP, spot 16) and (ACTB, spot 17).In the HE group, six protein spots 12, 13, $15,16,17$ and 18 displayed higher phosphorylation signals, identified as Tcomplex protein 1 subunit delta (TCPD), actin aortic smooth muscle (ACTA), nascent polypeptide-associated complex subunit alpha (NACA), translationally- 
controlled tumor protein (TCTP), actin cytoplasmic 1 (ACTB) and methylosome subunit pICln (ICLN) respectively (Table 5.2, Fig. 5.4) 
A

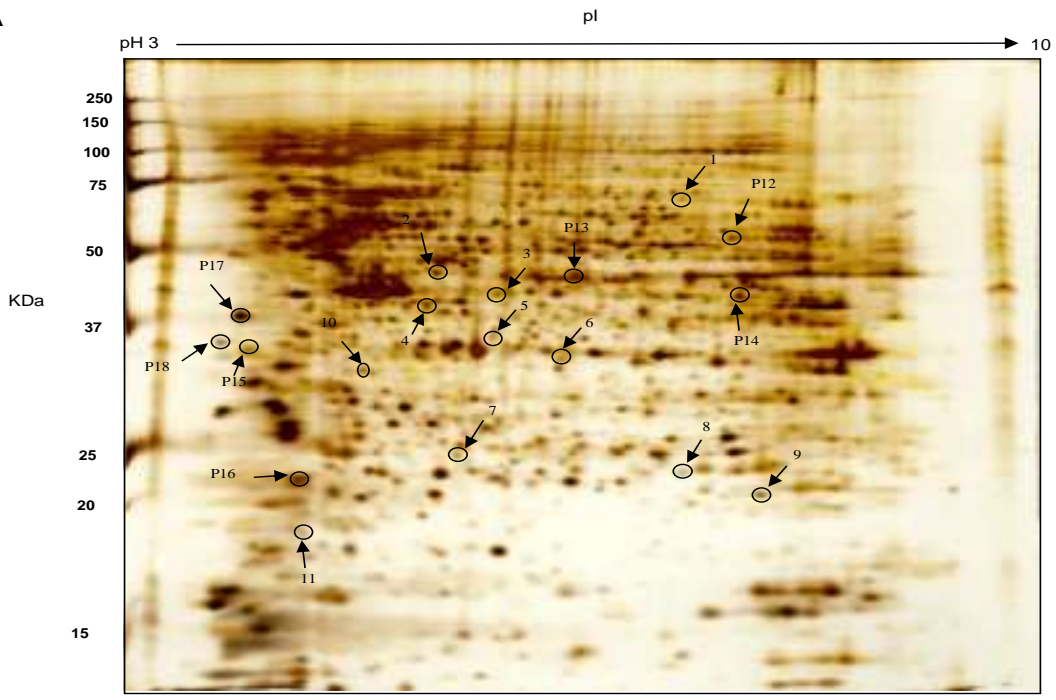

B

Spot 8 (MOBKL1A)
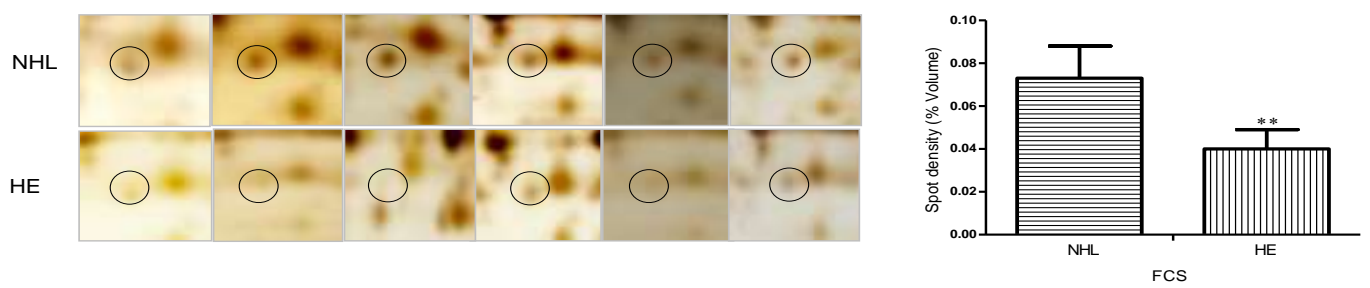

Spot 10 (SNAPA)
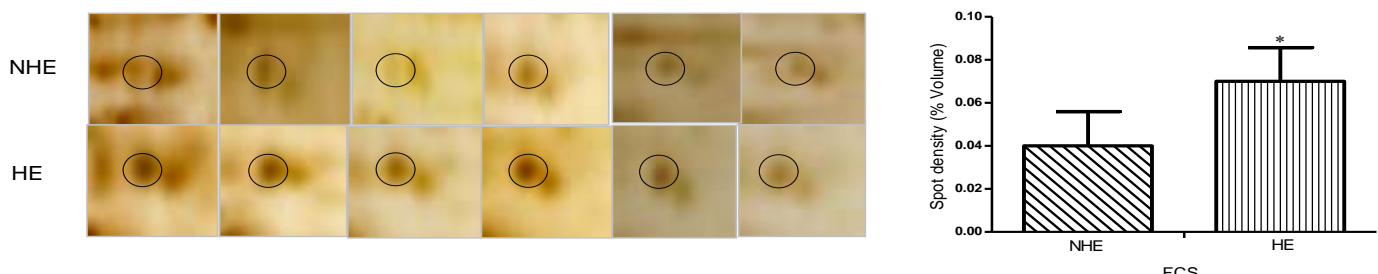

Figure 5.1: Silver nitrate stained 2-DE gel.

(A) Proteins $(160 \mu \mathrm{g})$ were separated in the first dimension using non-linear $\mathrm{pH}$ 3-10 gradient IPG strips (17cm, Bio-Rad), followed by second dimension on 12.5\% SDS-PAGE. Consistently regulated spots were excised from silver stained gel after densitometric analysis for identification by Q-TOF MS/MS analysis. Spots marked on the gel showed differentially regulated proteins. Note: "P" refers to phospho protein spots also shown in figure 5.2

(B) Two representative differentially regulated 2-DE spots (MOBKL1A, spot 8; SNAPA, spot 10) in non-heated FCS with low LPS (NHL) and in heated FCS with normal LPS concentration (HE) respectively. The spot IDs correspond to the listing in Table 5.1. The error bars represent mean \pm $\operatorname{SD}\left({ }^{*}=p<0.05,{ }^{* *}=p<0.005\right)$ of six independent experiments. 

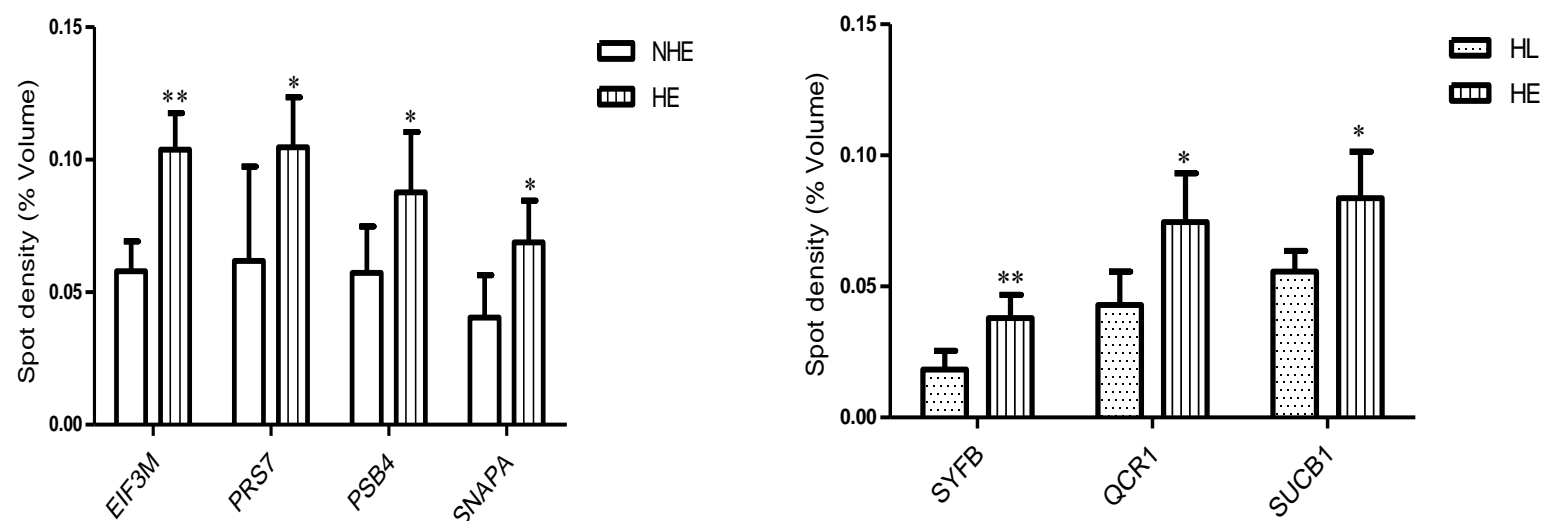

Figure 5.2: Graphical display of selected proteins significantly regulated in CCRF-CEM cells in silver stained 2-DE gel.

CCRF-CEM cell lysates were resolved on 2-DE and gels were stained with silver nitrate. Significantly regulated protein spots by densitometric analysis were identified my Q-TOF MS/MS analysis. (A) Bar graphs represent mean spot density for four proteins which were up-regulated in $\mathrm{HE}$ (heat inactivation with regular LPS) group as compared to NHE (No heat inactivation with regular LPS) control group. (B) Three proteins were up-regulated in HE (heat inactivation with regular LPS) as compared to $\mathrm{HL}$ (heat inactivation with low LPS) group. Bar charts illustrate mean spot density. The error bars represent $\pm \mathrm{SD}\left({ }^{*}=p<0.05,{ }^{* *}=p<0.005\right)$ of six independent experiments. 
A

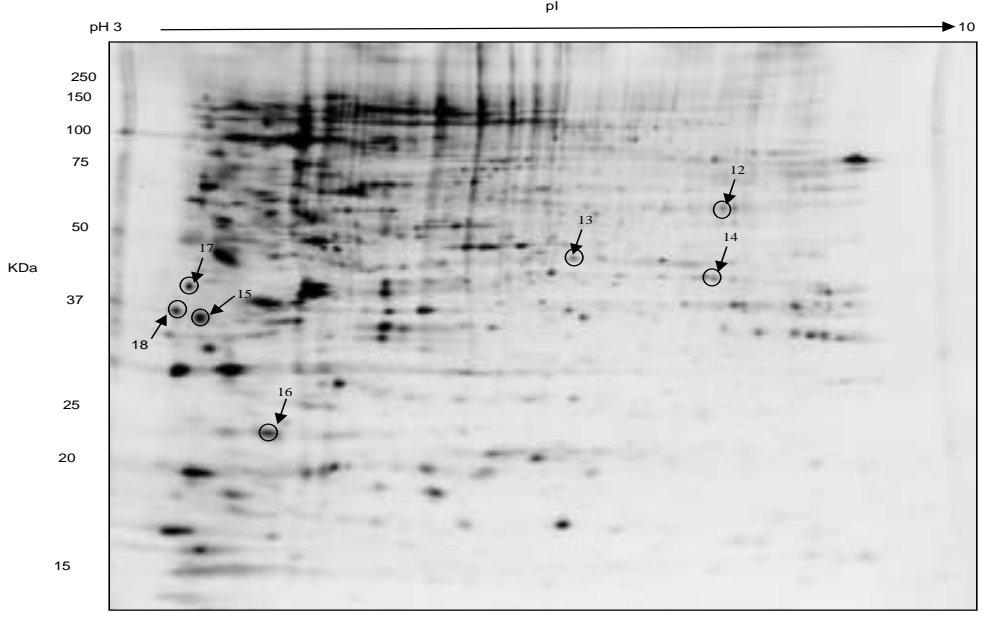

B

Spot 16 (TCTP)
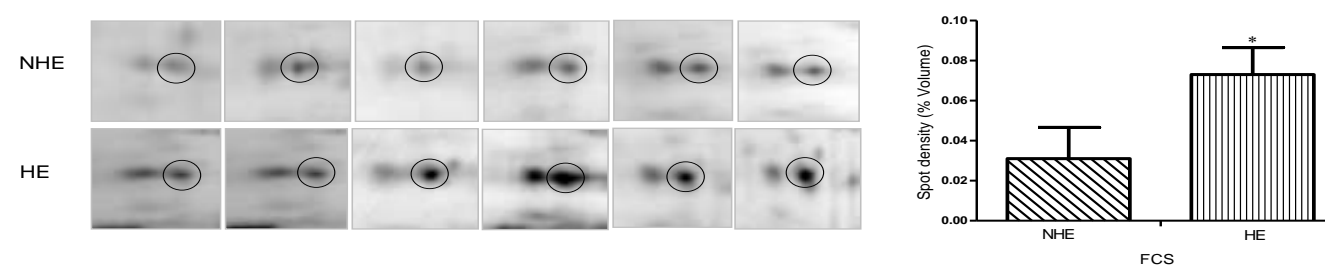

Spot 17 (ACTB)
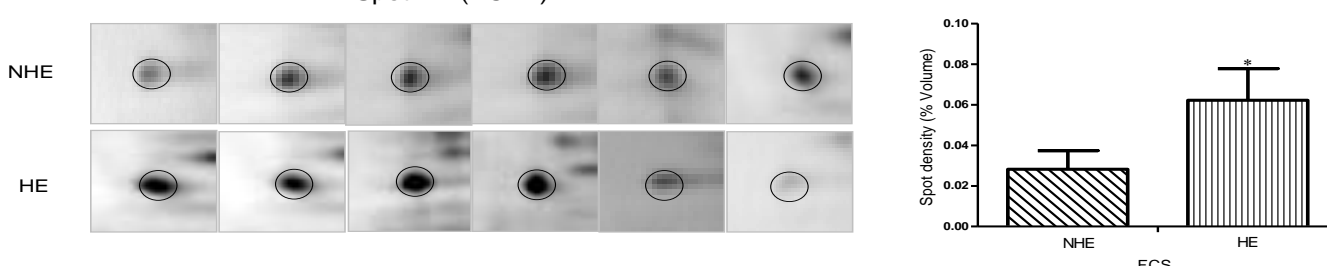

Figure 5.3: Phospho-specific florescence stained 2-DE.

(A) Proteins were resolved on 2-DE and gels were stained by Pro-Q Diamond phospho-stain (Invitrogen) and then scanned (FLA -5100). The spots showing significant regulation after densitometry analysis were marked and identified by $\mathrm{Q}-\mathrm{TOF}$ MS/MS analysis.

(B) Illustration of two representative 2-DE spots (TCTP, spot 16; ACTB; spot 17) in non-heated FCS with normal LPS (NHE) and in heated FCS with normal LPS (HE). The error bars represent mean $\pm \mathrm{SD}\left({ }^{*}=p<0.05\right)$ of six independent experiments. 


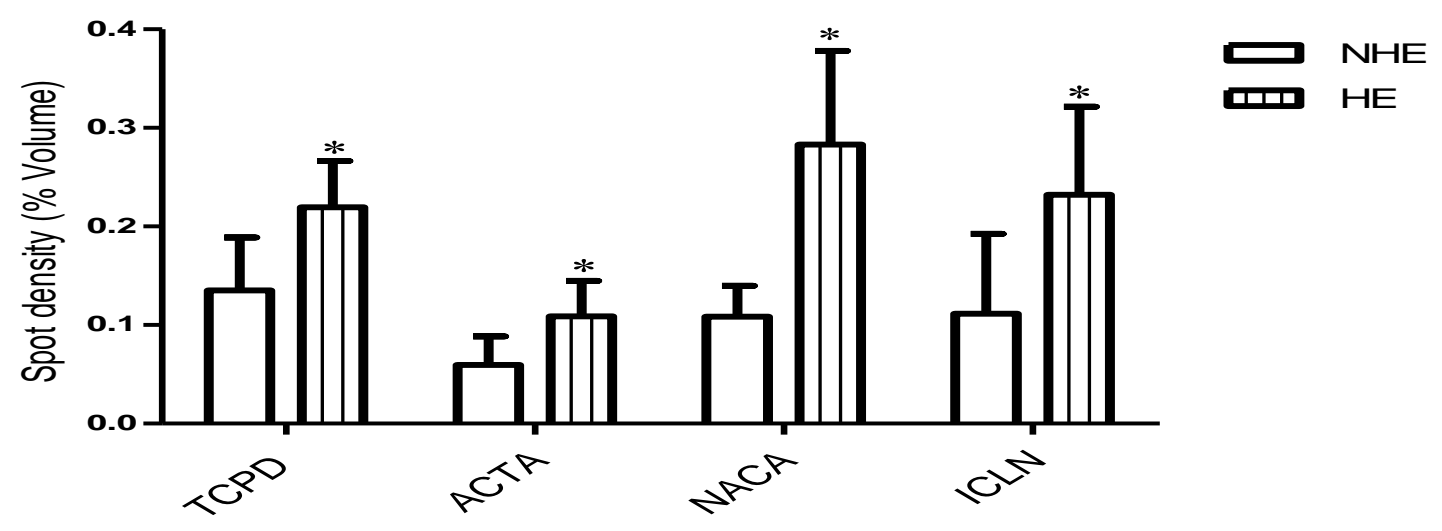

Figure 5.4: Proteins significantly regulated in CCRF-CEM cells in phosphospecific stained 2-DE gel.

CCRF-CEM cell lysates were separated on 2-DE and gels were stained with phospho-specific stain. Differentially regulated protein spots by densitometric analysis were identified by Q-TOF MS/MS analysis. Bar graphs show mean spot density for four proteins which were up-regulated in HE (heat inactivation with regular LPS) group as compared to NHE (No heat inactivation with regular LPS) control group. The error bars represent $\pm \mathrm{SD}\left({ }^{*}=p<0.05\right)$ of six independent experiments.

\subsubsection{Proteins with altered expression as a function of FCS-LPS concentrations}

We investigated the influence of LPS concentrations on the cell proteome by comparing the NHL with NHE groups, one protein, phenylalanyl tRNA synthetase beta chain (SYFB, spot 1), was down-regulated. In the HE compared to the HL group, three protein spots (spot 1,2 and 3), identified as SYFB, cytochrome b-c1complex subunit 1-mitochondrial (QCR1) and succinyl-CoA ligase subunit beta-mitochondrial (SUCB1), were up-regulated (Table 5.1, Fig. 5.2). In phospho-stained gels only one protein, alcohol dehydrogenase class-3 (ADHX, spot 14), was down-regulated in the HE compared to the HL group (Table 5.2). 


\subsubsection{Proteins regulated by both LPS concentration and heat treatment of FCS}

The HL group compared to the NHE demonstrated two up-regulated proteins (spot 5 and 11) identified as N-acetyl-D-glucosamine kinase (NAGK) and Diablo homolog mitochondrial (DBLOH). By comparing the NHL and HE groups, one protein (spot 8) Mps one binder kinase activator-like 1A (MOBKL1A) was upregulated (Fig. 5.1B), whereas another protein (spot 9) identified as superoxide dismutase 2 (SOD2) was down-regulated. Regulation of SOD2 expression was further confirmed by immunoblot analysis (Fig. 5.5). The MS/MS spectra for all differentially regulated proteins in silver and phospho-stained gels are provided in Appendix Table 2 \&3.

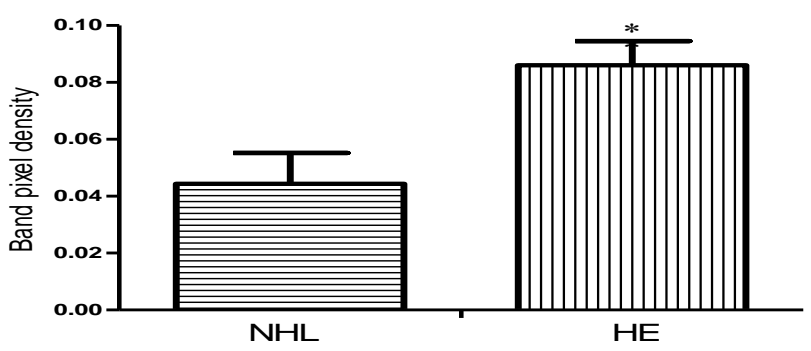

SOD2

B.Tubulin

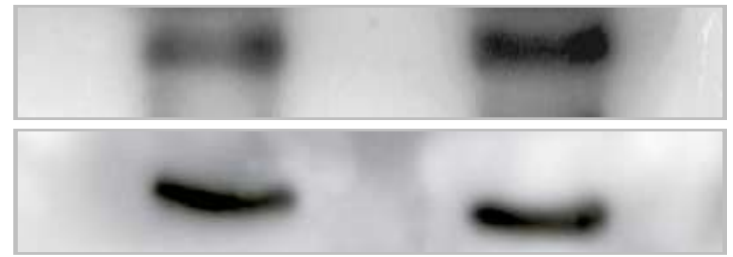

Figure 5.5: Immunoblot analysis of superoxide dismutase 2 (SOD2) expression.

CCRF-CEM lysate treated with non-heated FCS with low LPS (NHL) and in heated FCS with normal LPS (HE), were resolved on 1DE and immunoblotted with antibody against SOD2. Densitometric analyses were done using Lab Image version 2.71 software. $\beta$-tubulin was used as a loading control. The error bars represent mean $\pm \mathrm{SD}\left({ }^{*}=p<0.05\right)$ of three independent experimen 
Table 5.1: Differentially regulated proteins by LPS and heat inactivation of FCS.

\begin{tabular}{|c|c|c|c|c|c|c|c|c|c|}
\hline \multirow{2}{*}{$\begin{array}{l}\text { Spot } \\
\text { ID }\end{array}$} & \multirow[t]{2}{*}{ Abb. } & \multirow{2}{*}{$\begin{array}{l}\text { Protein } \\
\text { name }^{a}\end{array}$} & \multirow[t]{2}{*}{ Acc. No. } & \multirow{2}{*}{$\begin{array}{l}\text { Mass } \\
(\mathrm{kDa})\end{array}$} & \multicolumn{5}{|c|}{ Fold change (Mean \pm SD) } \\
\hline & & & & & HE/NHE & NHL/NHE & HL/NHE & NHL/HE & HL/HE \\
\hline 1 & SYFB & $\begin{array}{l}\text { Phenylalan } \\
\text { yltRNA } \\
\text { synthetase } \\
\text { beta chain }\end{array}$ & Q9NSD9 & 66.1 & NS & $\begin{array}{c}* 2.35 \downarrow(0.019 \\
\pm 0.01 / 0.04 \pm \\
0.02)\end{array}$ & NS & NS & $\begin{array}{c}* 2.07 \downarrow \\
(0.018 \pm \\
0.007 / \\
0.037 \pm \\
0.008)\end{array}$ \\
\hline 2 & QCR1 & $\begin{array}{l}\text { Cytochrome } \\
\text { b-c1 } \\
\text { complex } \\
\text { subunit } 1\end{array}$ & P31930 & 52.6 & NS & NS & NS & NS & $\begin{array}{c}* 1.73 \downarrow \\
(0.042 \pm \\
0.012 / \\
0.074 \pm \\
0.018)\end{array}$ \\
\hline 3 & SUCB1 & $\begin{array}{l}\text { Succinyl- } \\
\text { CoA ligase } \\
\text { subunit } \\
\text { beta }\end{array}$ & Q9P2R7 & 50.3 & NS & NS & NS & NS & $\begin{array}{c}* 1.50 \downarrow(0.55 \\
\pm 0.007 / \\
0.083 \pm \\
0.017)\end{array}$ \\
\hline 4 & EIF3M & $\begin{array}{l}\text { Eukaryotic } \\
\text { translation } \\
\text { initiation } \\
\text { factor } 3 \\
\text { subunit M }\end{array}$ & Q7L2H7 & 42.5 & $\begin{array}{c}* * 1.79 \uparrow \\
(0.103 \pm \\
0.013 / \\
0.057 \pm \\
0.011)\end{array}$ & NS & NS & NS & NS \\
\hline 5 & NAGK & $\begin{array}{l}\mathrm{N} \text {-acetyl-D- } \\
\text { glucosamin } \\
\text { e kinase }\end{array}$ & Q9UJ70 & 37.3 & NS & NS & $\begin{array}{l}* 1.60 \uparrow \\
(0.064 \pm \\
0.024 / \\
0.04 \pm \\
0.007)\end{array}$ & NS & NS \\
\hline 6 & PRS7 & $\begin{array}{l}26 \mathrm{~S} \\
\text { protease } \\
\text { regulatory } \\
\text { subunit } 7\end{array}$ & P35998 & 48.6 & $\begin{array}{l}* 1.69 \uparrow \\
(0.104 \pm \\
0.018 / \\
0.061 \pm \\
0.035)\end{array}$ & NS & NS & NS & NS \\
\hline 7 & PSB4 & $\begin{array}{l}\text { Proteasome } \\
\text { subunit } \\
\text { beta type-4 }\end{array}$ & P28070 & 29.2 & $\begin{array}{l}* 1.53 \uparrow \\
(0.087 \pm \\
0.022 / \\
0.057 \pm \\
0.017)\end{array}$ & NS & NS & NS & NS \\
\hline 8 & $\begin{array}{l}\text { MOBKL } \\
1 \mathrm{~A}\end{array}$ & $\begin{array}{l}\text { Mps one } \\
\text { binder } \\
\text { kinase } \\
\text { activator A1 }\end{array}$ & Q7L9L4 & 25.0 & NS & NS & NS & $\begin{array}{c}* * 1.85 \uparrow \\
(0.076 \pm \\
0.0150 / \\
0.04 \pm \\
0.009)\end{array}$ & NS \\
\hline 9 & SOD2 & $\begin{array}{l}\text { Superoxide } \\
\text { dismutase } \\
\text { [Mn], } \\
\text { mitochondri } \\
\text { al }\end{array}$ & P04179 & 24.7 & NS & NS & NS & $\begin{array}{c}* 1.68 \downarrow \\
(0.08 \pm \\
0.037 / \\
0.135 \pm \\
0.028)\end{array}$ & NS \\
\hline 10 & SNAPA & $\begin{array}{l}\text { Alpha- } \\
\text { soluble } \\
\text { NSF } \\
\text { attachment } \\
\text { protein }\end{array}$ & P54920 & 33.2 & $\begin{array}{c}{ }^{*} 1.70 \uparrow \\
(0.068 \pm \\
0.015 / \\
0.04 \pm 0.015)\end{array}$ & NS & NS & NS & NS \\
\hline 11 & DBLOH & $\begin{array}{l}\text { Diablo } \\
\text { homolog, } \\
\text { mitochondri } \\
\text { al }\end{array}$ & Q9NR28 & 7.1 & NS & NS & $\begin{array}{c}\star 2.02 \uparrow \\
(0.074 \pm \\
0.008 / \\
0.033 \pm \\
0.019) \\
\end{array}$ & NS & NS \\
\hline
\end{tabular}

Abb: Abbreviation; Acc. No: Accession number; Mass: Molecular mass of the protein observed in a Mascot search (www.matrixscience.com); ${ }^{2}$ Proteins identified by Q-TOF MS/MS analysis and database search against Swissprot; $\uparrow$ : Upregulated, $\downarrow$ : Down-regulated, NS: Non-significant change; ${ }^{*}=p<0.05,{ }^{* *}=p<0.005$. 
Table 5.2: Differentially phosphorylated proteins by LPS and heat inactivation of FCS.

\begin{tabular}{|c|c|c|c|c|c|c|c|c|c|}
\hline \multirow{2}{*}{$\begin{array}{l}\text { Spot } \\
\text { ID }\end{array}$} & \multirow[t]{2}{*}{ Abb. } & \multirow{2}{*}{$\begin{array}{l}\text { Protein } \\
\text { name }^{a}\end{array}$} & \multirow{2}{*}{$\begin{array}{l}\text { Acc. } \\
\text { No. }\end{array}$} & \multirow{2}{*}{$\begin{array}{l}\text { Mass } \\
(k D a)\end{array}$} & \multicolumn{5}{|c|}{ Fold change (Mean \pm SD) } \\
\hline & & & & & HE/NHE & NHL/NHE & HL/NHE & NHL/HE & HL/HE \\
\hline 12 & TCPD & $\begin{array}{l}\text { T-complex } \\
\text { protein } 1 \\
\text { subunit } \\
\text { delta }\end{array}$ & P50991 & 57.8 & $\begin{array}{c}{ }^{*} 1.62 \uparrow \\
(0.219 \pm \\
0.047 / 0.135 \\
\pm 0.053)\end{array}$ & NS & NS & $\begin{array}{c}{ }^{*} 1.68 \downarrow \\
(0.130 \pm \\
0.068 / 0.219 \\
\pm 0.046)\end{array}$ & NS \\
\hline 13 & ACTA & $\begin{array}{l}\text { Actin, aortic } \\
\text { smooth } \\
\text { muscle }\end{array}$ & P62736 & 41.9 & $\begin{array}{c}{ }^{*} 1.83 \uparrow \\
(0.108 \pm \\
0.036 / 0.059 \\
\pm 0.029)\end{array}$ & NS & NS & NS & NS \\
\hline 14 & ADHX & $\begin{array}{l}\text { Alcohol } \\
\text { dehydrogen } \\
\text { ase class-3 }\end{array}$ & P11766 & 39.6 & NS & NS & NS & NS & $\begin{array}{c}* 1.75 \uparrow \\
(0.226 \pm \\
0.08 / 0.129 \\
\pm 0.046)\end{array}$ \\
\hline 15 & NACA & $\begin{array}{l}\text { Nascent } \\
\text { polypeptide } \\
\text {-associated } \\
\text { complex } \\
\text { subunit } \\
\text { alpha }\end{array}$ & Q13765 & 23.3 & $\begin{array}{c}* 2.60 \uparrow \\
(0.283 \pm \\
0.095 / 0.108 \\
\pm 0.031)\end{array}$ & NS & NS & $\begin{array}{c}* 1.74 \downarrow \\
(0.162 \pm \\
0.044 / 0.283 \\
\pm 0.095)\end{array}$ & NS \\
\hline 16 & TCTP & $\begin{array}{l}\text { Translation } \\
\text { ally- } \\
\text { controlled } \\
\text { tumor } \\
\text { protein }\end{array}$ & P13693 & 19.5 & $\begin{array}{c}* 2.30 \uparrow \\
(0.073 \pm \\
0.013 / 0.031 \\
\pm 0.015)\end{array}$ & NS & NS & NS & NS \\
\hline 17 & ACTB & $\begin{array}{l}\text { Actin, } \\
\text { cytoplasmic } \\
1\end{array}$ & $\begin{array}{l}\text { Q96HG } \\
5\end{array}$ & 41.7 & $\begin{array}{c}* 2.20 \uparrow \\
(0.062 \pm \\
0.015 / 0.028 \\
\pm 0.009)\end{array}$ & NS & NS & $\begin{array}{c}* 2.37 \downarrow \\
(0.018 \pm \\
0.011 / 0.043 \\
\pm 0.015)\end{array}$ & NS \\
\hline 18 & ICLN & $\begin{array}{l}\text { Methylosom } \\
\text { e subunit } \\
\text { plCln }\end{array}$ & P54105 & 26.1 & $\begin{array}{c}{ }^{*} 2.08 \uparrow \\
(0.232 \pm \\
0.089 / 0.111 \\
\pm 0.081)\end{array}$ & NS & NS & $\begin{array}{c}* 1.80 \downarrow \\
(0.283 \pm \\
0.117 / 0.510 \\
\pm 0.113)\end{array}$ & NS \\
\hline
\end{tabular}

Abb: Abbreviation; Acc. No: Accession number; Mass: Molecular mass of the protein observed in MASCOT search; ${ }^{\mathrm{a}}$ Phosphoproteins identified by Q-TOF MS/MS analysis and database search against Swissprot; $\uparrow:$ Up-regulated, $\downarrow$ : Down-regulated, NS: Non-significant change; ${ }^{*}=p<0.05,{ }^{* *}=p<0.005$. 


\subsection{Discussion}

Cell culture media are supplemented with FCS as a source of growth factors necessary for cell survival and cell proliferation [211,242,243]. Besides growth factors, FCS also contains complement proteins and growth inhibitory factors $[212,244]$. Heat inactivation of FCS is considered a mandatory step in cell culture to inactivate serum inhibitory factors $[218,245]$; however, such heat treatment has no effect on the activity of LPS [235]. Recently E. Manor reported an enhancement of cell proliferation by human plasma as compared to human serum [246]; however others prefer the use of serum to supplement cell culture medium $[247,248]$. There are at least 18 different factors including 11 chemokines which are reported to be more abundant in serum as compared to plasma; these are likely to be released by platelets during the coagulation cascade [249]. FCS is believed to be more effective in stimulating cell proliferation than human serum (HS) or rabbit serum $[219,250]$. Depending on the cancerous cell type, the LPS may have varied effects on cell physiology [230,231,251-253]. The present study used a proteomics approach to investigate whether heat treatment and LPS concentration exert any detectable changes on the global proteome expression and phosphoproteome in cultured human T cells. It is important to stress that we examined both heat inactivated and non-heat inactivated FCS each with regular and low LPS concentrations. Most commercially available FCS has less than 30 $\mathrm{EU} / \mathrm{mL}$ of LPS. To mimic practices commonly used in the laboratories, we used regular and low LPS containing FCS.

\subsubsection{Impact of heat inactivation of FCS on protein regulation}

In the present study, four proteins displayed increased levels in the heat inactivated LPS group, as compared to non-treated group (Table 5.1). EIF3M (spot 4), an important regulator of protein turnover [254] was up-regulated. This finding correlates with a previous study investigating the influence of serum heat inactivation on cell protein content in osteoblast progenitor cells [219]. However, LPS concentration (NHL compared to NHE) had no significant influence on EIF3M expression. Two proteins (PRS7 "spot 6" and PSB4 "spot 7"), which are members of a multiprotein complex involved in cellular protein degradation [255] were up- 
regulated by heat inactivation of FCS. The expression of both proteins remained unchanged at both low and normal LPS concentrations in FCS. This is in line with the previous observation that at least $\geq 100 \mathrm{ng} / \mathrm{mL}$ of LPS was required to influence the expression of PRS7 [256]. FCS heat inactivation influenced the intensity of the phosphorylation signal of six proteins (TCTP, TCPD, NACA, ACTA, ACTB and ICLN). TCTP (spot 16) is a cytoskeletal related protein involved in cell growth, survival and protection against various stress conditions [257]. Cells grown in heat inactivated FCS supplemented medium showed increased TCTP phosphorylation as compared to non-heat inactivated group (Fig. 5.3B). The phosphorylation of TCTP is linked to a decrease in microtubule stabilization and could potentially affect microtubule dynamics, resulting in compromised structural integrity of cells [258]. TCPD protein showed increased phosphorylation in the heat inactivated FCS group. TCPD is a member of the chaperone containing Tcomplex polypeptide 1 (CCT) that is involved in both protein folding and cytoskeleton network regulation [259]. This protein also helps in dopamine mediated neuronal apoptosis [260]. Another protein, NACA (spot 15) was upregulated in the heat inactivated FCS group. NACA is a transcriptional co-activator that modulates C-Jun-mediated transcription [261]. Two cytoskeletal proteins ACTA and ACTB (spot 13 and 17 respectively) displayed increase phosphorylation signals in the HE group, as compared to NHE group. These proteins are ubiquitously expressed in eukaryotic cells, are involved in the cytoskeletal architecture of the cell [262], and they are modified by phosphorylation during stressful conditions [263]. The ICLN protein (spot 18) participates in the regulation of small nuclear ribonucleoproteins, (snRNP) biogenesis, and is an essential component of spliceosomes [264]. It showed an altered phosphorylation signal in the presence of FCS heat inactivation.

\subsubsection{Impact of LPS contamination in FCS on protein regulation}

Three proteins, SYFB (spot 1 involved in protein biosynthesis [265]). QCR1 (spot 2, a mitochondrial respiratory chain protein [266] and SUCB1 (spot 3, which is the mitochondrial matrix enzyme involved in the ATP synthesis [267] were significantly up-regulated when grown in medium containing normal (ie "regular") as compared to low LPS concentrations. This implies that increased LPS concentrations may have stimulatory effects on protein synthesis. These findings 
are consistent with observations made by Hamilton and colleagues, who reported increased protein synthesis in murine peritoneal macrophages cultured at 10 $\mathrm{ng} / \mathrm{ml}$ LPS concentration [268]. LPS has been reported to induce protein synthesis in B lymphocytes [269,270], and enhance T lymphocytes proliferation [271] by an unknown molecular mechanism.

\subsubsection{Protein regulation by combined changes in LPS concentrations and heat treatment of FCS}

Two proteins, NAGK (spot 5, which converts $\mathrm{N}$-acetylglucosamine into GlcNAc 6-phosphate [272]) and DBLOH (spot 11, which is a pro-apoptotic protein [273]) were up-regulated in the HL as compared to the NHE group. Cells grown in medium containing non-heated FCS with low LPS had significantly increased expression of MOBKL1A (spot 8, a cell division associated protein [274]). SOD2 (spot 9 is a mitochondrial anti-oxidant enzyme essential for cell survival [275]) that protects $T$ lymphocytes against free oxygen radicals that are generated in these cells to kill microorganisms [276]. In the NHL group SOD2 expression was downregulated as compared to $\mathrm{HE}$, both in the 2-DE and immunoblot analysis (Fig. 5.5). This suggests that commonly used (ie. "regular") LPS concentrations and serum heat inactivation might produce oxidative challenge to the cells. Previous reports have also described a similar modulation in the SOD2 expression by LPS in human monocytes [277]. Such cellular proteome regulation reflects a survival strategy of the cells allowing them to respond to external factors through alterations in metabolic activity.

\subsection{Conclusion}

These results suggest that the heat inactivation and LPS concentrations in FCS are indeed able to alter the expression and phosphorylation of proteins involved in important cellular functions of cultured human $\mathrm{T}$ cells. The study emphasizes the importance of considering the effects of FCS heat treatment, or LPS concentrations used in the cell cultures, on phosphorylation and cellular proteome of $\mathrm{T}$ cells. This work also demonstrates the ability of a proteomic approach to demonstrate the complex picture of cellular responses to selected cell 
culture conditions. The exact mechanism(s) by which serum heat inactivation and LPS regulate cellular protein expression and post-translational modification is not yet clear and needs further investigation. 


\section{Summary}

The mammalian target of rapamycin (mTOR) is an intracellular protein kinase that plays a key role in the control of cell growth, differentiation, cell survival, and cell proliferation. In humans, mTOR deregulation is implicated in parasitic, fungal, bacterial and viral infections, immune disorders, diabetes, obesity, cardiac diseases, renal abnormalities, and various cancers. mTOR was first identified as TOR in Saccharomyces cerevisiae. It exists in two structurally and functionally distinct complexes, mTOR complex 1 (mTORC1), and mTOR complex 2 (mTORC2). mTORC1, a rapamycin sensitive protein complex, senses the availability of growth factors, nutrients, cellular energy levels, and is actively involved in cellular transcription and translation processes. mTORC1 performs a range of biological functions with the help of its interacting proteins. These interacting proteins act as scaffolds and recruit substrates and regulatory proteins required for mTOR kinase function. The present study was undertaken to identify novel interacting partners of mTORC1 that specifically interact with mTORC1 to enable this crucial cell signaling hub to carry out its biological functions.

Human T cells (CCRF-CEM) and human embryonic kidney (HEK293) cell lines were used to identify novel interacting partners of mTORC1. Endogenous mTORC1 along with its interacting proteins were purified using raptor monoclonal antibodies and immunoblotted to confirm the mTORC1 specific purification. Following confirmation of mTORC1 specific purification by immunoblotting, the remaining IP elutes were resolved on SDS-PAGE and stained with silver nitrate. Protein bands from the gel were excised, processed by in-gel digestion and identified by nano-LC ESI Q-TOF MS/MS analysis. The mass spectrometric identification of endogenous $\mathrm{mTORC} 1$ interacting proteins was further validated by expressing the myc-tag raptor pRK5 vector in CCRF-CEM and HEK293 cells. Myc-tag raptor component of mTORC1 was isolated by pulled-down from the cell lysate using an affinity column and conjugated monoclonal myc-tag antibodies using agarose beads. The co-purified elutes were resolved on SDS-PAGE and mTORC1 specific purification was first confirmed by immunoblotting, and later identified by nano-LC ESI Q-TOF MS/MS analysis. A total of 10 novel interacting proteins (hnRNP A2/B1, SRSF7, RP-P0, NCL, DNM2, GAPDH, 2-OADH, 
GLT25D1, PHB2, Edc4) were identified in both endogenous and myc-tag mTORC1 purifications. Functional annotation analysis demonstrated that these ten proteins are involved in important biological functions. Three proteins, hnRNP A2/B1, SRSF7, and Edc4, are important for mRNA processing while two proteins, RP-PO and NCL, were involved in transcription and translation. One protein, DNM2, identified in mTORC1 specific purifications, is associated with intracellular trafficking, while two proteins, GAPDH and 2-OADH, are involved in carbohydrate metabolism. Moreover, two proteins, GLT25D1 and PHB2, are involved in posttranslation modification, protein turnover and chaperone functions. The mass spectrometric identification of Edc4, DNM2, and hnRNP A2/B1 proteins were further confirmed by immunoblotting using protein specific antibodies.

Enhancer of mRNA decapping protein 4 (Edc4) was consistently identified as a new interacting protein with mTORC1 in both the endogenous and myc-tag raptor component of $\mathrm{mTORC1.} \mathrm{Edc4} \mathrm{has} \mathrm{a} \mathrm{suggested} \mathrm{role} \mathrm{in} \mathrm{mRNA} \mathrm{decapping}$ and repression of miRNA mediated translation. The potential interaction of Edc4 with mTORC1 was further confirmed using reverse co-immunoprecipitation. Quantitative co-localization using confocal microscopy demonstrated a high degree of pixel overlapping between Edc4 protein with raptor component of mTORC1 both inside and outside of $P$ bodies. Incubation of cells under leucine starved conditions increased the total expression of Edc4. Leucine is an essential amino acid which is a positive regulator of mTORC1 kinase activity, providing evidence that $\mathrm{mTORC} 1$ may be involved in the regulation of Edc4. Furthermore, rapamycin increased total Edc4 protein expression but at the same time decreased the Edc4 interaction with mTORC1, further evidence of mTORC1 involvement in Edc4 regulation. We further examined the effects of rapamycin on Edc4 phosphorylation status. Rapamycin treatment resulted in a significant decrease in total serine phosphorylated Edc4 protein signal, suggesting the involvemnt of $\mathrm{mTORC} 1$ kinase activity in the regulation of Edc4. In addition, we observed that rapamycin significantly decreased the total $5^{\prime}$-capped mRNA. These findings suggest that $\mathrm{mTORC1}$, by interacting with Edc4, inactivates the Edc4 through serine phosphorylation, and regulates its expression. This results in hyper-phosphorylated Edc4 which is then no longer available for mRNA decapping activity. The inhibition of $\mathrm{mTORC} 1$ by rapamycin results in an 
increased amount of dephosphorylated Edc4, and consequently higher cellular decapping activity, and less total $5^{\prime}$-capped mRNA in the cell (Fig 6.1). These findings provide the first evidence for the pivotal role of mTORC1 in Edc4 regulation. Further in-depth studies are required to get a complete understanding of the biological interplay of mTORC1 signaling in the mRNA decapping process. Functional characterization of these novel interacting proteins may be helpful in understanding the complexity of the mTORC1 network and may offer new targets for therapeutic interventions in human diseases associated with deregulated mTORC1 signaling. 


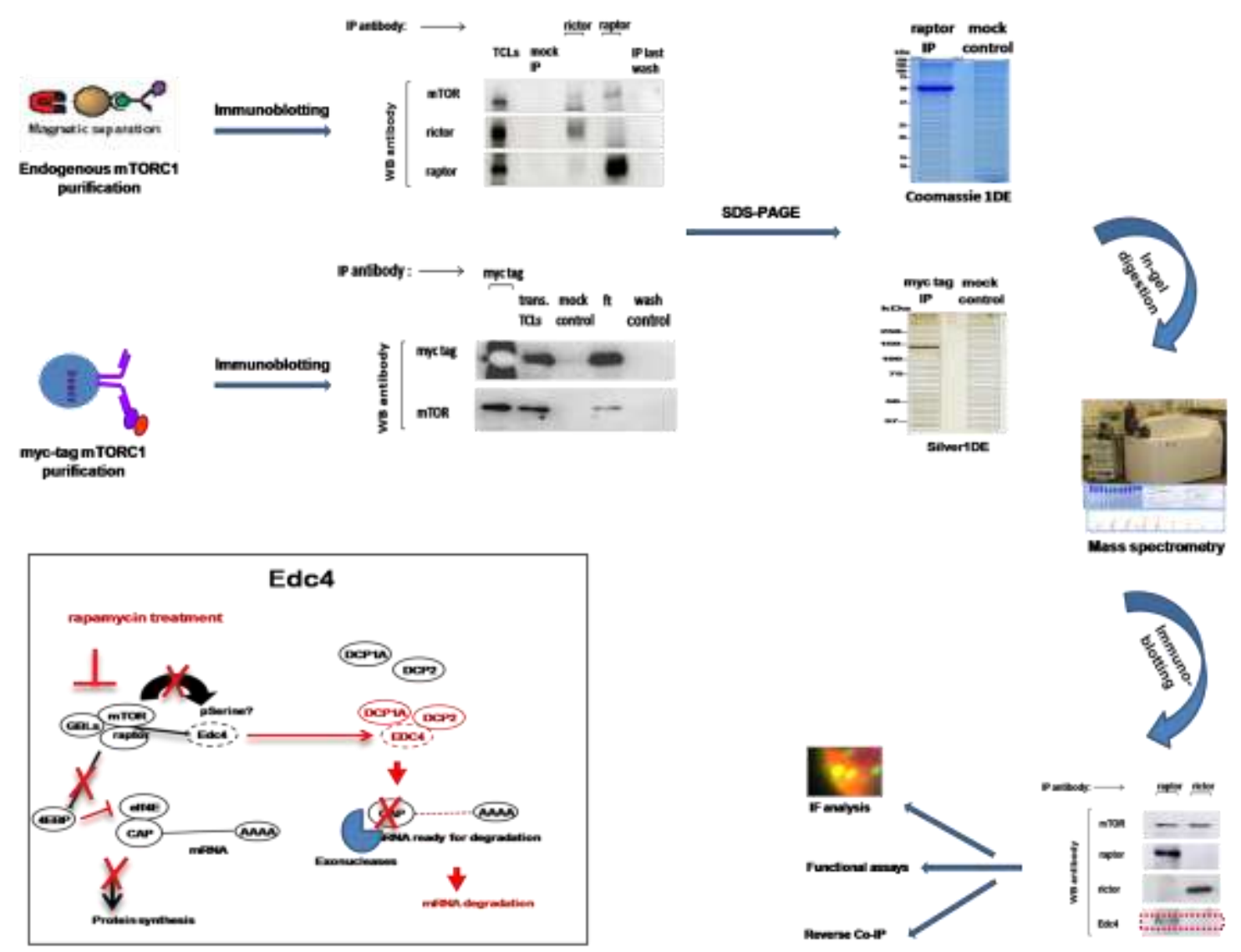

Figure 6.1: mTORC1 interactomics; mTORC1 interplay in mRNA decapping through interaction with Edc4.

CCRF-CEM or HEK293 cells were grown for 48 hours in complete medium, lysed, and endogenous mTOR complexes were immunopurified using raptor or rictor antibodies. In parallel, cells were transfected with myc-tagged raptor and purified with myc-tag antibody. After resolving the purified elute on 1-DE SDS-PAGE, the integrity of mTOR complexes were checked by detecting the mTOR signal in both the raptor and rictor IP elutes. To confirm the absence of mTORC2 contamination in the mTORC1 purified material, the elutes were immunoblotted using rictor antibody. After confirmation of successful mTORC1 purification, the elutes were separated on 1-DE and stained with silver or Coomssie. Whole lane of protein bands from the raptor IP and mock IP were excised and tryptic digested for nano-LC ESI Q-TOF MS/MS analysis. The schematic diagram (Edc4 box) shows that mTORC1 interacts with Edc4 to keep its expression at the basal level by inhibiting Edc4 through serine phosphorylation (black bold arrow). This hyperphosphorylated Edc4 is then no longer available for mRNA decapping activity in the mRNA decay process. Treatment of cells with rapamycin leads to the inhibition of mTORC1 kinase activity, resulting in the Edc4 dephosphorylation. This dephosphorylated Edc4 probably leads to activation of the decapping machinery and increased mRNA degradation. 


\section{References}

1. Guertin DA, Stevens DM, Thoreen CC, Burds AA, Kalaany NY, Moffat J et al.: Ablation in mice of the mTORC components raptor, rictor, or $\mathrm{mLST} 8$ reveals that mTORC2 is required for signaling to Akt-FOXO and PKCalpha, but not S6K1. Dev Cell 2006, 11: 859-871.

2. Wullschleger $S$, Loewith $R$, Hall $M N$ : TOR signaling in growth and metabolism. Cell 2006, 124: 471-484.

3. Zoncu R, Efeyan A, Sabatini DM: mTOR: from growth signal integration to cancer, diabetes and ageing. Nat Rev Mol Cell Biol 2011, 12: 21-35.

4. Yecies JL, Manning BD: Transcriptional control of cellular metabolism by mTOR signaling. Cancer Res 2011, 71: 2815-2820.

5. Ma XM, Blenis J: Molecular mechanisms of mTOR-mediated translational control. Nat Rev Mol Cell Biol 2009, 10: 307-318.

6. Wang X, Proud CG: mTORC1 signaling: what we still don't know. J Mol Cell Biol 2010, 3(4): 206-220.

7. Mayer C, Grummt I: Ribosome biogenesis and cell growth: mTOR coordinates transcription by all three classes of nuclear RNA polymerases. Oncogene 2006, 25: 6384-6391.

8. Edinger AL, Thompson CB: Akt maintains cell size and survival by increasing mTOR-dependent nutrient uptake. Mol Biol Cell 2002, 13: $2276-$ 2288.

9. Laplante M, Sabatini DM: An emerging role of mTOR in lipid biosynthesis. Curr Biol 2009, 19: 1046-1052.

10. Jung $\mathrm{CH}, \mathrm{Ro} \mathrm{SH}, \mathrm{Cao} \mathrm{J}$, Otto NM, Kim DH: mTOR regulation of autophagy. FEBS Lett 2010, 584: 1287-1295.

11. Sarbassov DD, Ali SM, Kim DH, Guertin DA, Latek RR, ErdjumentBromage $\mathrm{H}$ et al:: Rictor, a novel binding partner of mTOR, defines a rapamycin-insensitive and raptor-independent pathway that regulates the cytoskeleton. Curr Biol 2004, 14: 1296-1302.

12. Cheekatla SS, Aggarwal A, Naik S: mTOR signaling pathway regulates the IL-12/IL-10 axis in Leishmania donovani infection. Med Microbiol Immunol 2011, 201(1): 37-46.

13. Bonifazi P, D'Angelo $\mathrm{C}$, Zagarella $\mathrm{S}$, Zelante $\mathrm{T}$, Bozza $\mathrm{S}$, De LA et al:: Intranasally delivered siRNA targeting PI3K/Akt/mTOR inflammatory pathways protects from aspergillosis. Mucosal Immunol 2010, 3: 193-205. 
14. Ferrer IR, Wagener ME, Robertson JM, Turner AP, Araki K, Ahmed R et al.: Cutting edge: Rapamycin augments pathogen-specific but not graftreactive CD8+ T cell responses. J Immunol 2010, 185: 2004-2008.

15. Peng L, Liang D, Tong W, Li J, Yuan Z: Hepatitis C virus NS5A activates the mammalian target of rapamycin (mTOR) pathway, contributing to cell survival by disrupting the interaction between FK506-binding protein 38 (FKBP38) and mTOR. J Biol Chem 2010, 285: 20870-20881.

16. Kudchodkar SB, Yu Y, Maguire TG, Alwine JC: Human cytomegalovirus infection induces rapamycin-insensitive phosphorylation of downstream effectors of mTOR kinase. J Virol 2004, 78: 11030-11039.

17. Kudchodkar SB, Yu Y, Maguire TG, Alwine JC: Human cytomegalovirus infection alters the substrate specificities and rapamycin sensitivities of raptor- and rictor-containing complexes. Proc Natl Acad Sci U S A 2006, 103: $14182-14187$.

18. Thomson AW, Turnquist HR, Raimondi G: Immunoregulatory functions of mTOR inhibition. Nat Rev Immunol 2009, 9: 324-337.

19. Pierdominici M, Vacirca D, Delunardo F, Ortona E: mTOR Signaling and Metabolic Regulation of T Cells: New Potential Therapeutic Targets in Autoimmune Diseases. Curr Pharm Des 2011, 17(35): 3888-3897.

20. Inoki K, Mori H, Wang J, Suzuki T, Hong S, Yoshida S et al:: mTORC1 activation in podocytes is a critical step in the development of diabetic nephropathy in mice. J Clin Invest 2011, 121: 2181-2196.

21. Fraenkel M, Ketzinel-Gilad M, Ariav Y, Pappo O, Karaca M, Castel J et al:: mTOR inhibition by rapamycin prevents beta-cell adaptation to hyperglycemia and exacerbates the metabolic state in type 2 diabetes. Diabetes 2008, 57: 945-957.

22. Williamson DL: Normalizing a hyperactive mTOR initiates muscle growth during obesity. Aging (Albany NY) 2011, 3: 83-84.

23. Jaworski J, Sheng M: The growing role of mTOR in neuronal development and plasticity. Mol Neurobiol 2006, 34: 205-219.

24. Pei JJ, Hugon J: mTOR-dependent signalling in Alzheimer's disease. $J$ Cell Mol Med 2008, 12: 2525-2532.

25. Warner JR: The economics of ribosome biosynthesis in yeast. Trends Biochem Sci 1999, 24: 437-440.

26. Dazert E, Hall MN: mTOR signaling in disease. Curr Opin Cell Biol 2011, 23(6): 744-755.

27. Shen WH, Chen Z, Shi S, Chen H, Zhu W, Penner A et al:: Cardiac restricted overexpression of kinase-dead mammalian target of rapamycin 
(mTOR) mutant impairs the mTOR-mediated signaling and cardiac function. J Biol Chem 2008, 283: 13842-13849.

28. Ibraghimov-Beskrovnaya $O$, Natoli TA: mTOR signaling in polycystic kidney disease. Trends Mol Med 2011, 17(11): 625-633.

29. Guertin DA, Sabatini DM: Defining the role of mTOR in cancer. Cancer Cell 2007, 12: 9-22.

30. Emerling BM, Akcakanat A: Targeting PI3K/mTOR Signaling in Cancer. Cancer Res 2011, 71(24): 7351-7359.

31. Hara K, Maruki Y, Long X, Yoshino K, Oshiro N, Hidayat S et al:: Raptor, a binding partner of target of rapamycin (TOR), mediates TOR action. Cell 2002, 110: 177-189.

32. Kim DH, Sarbassov DD, Ali SM, King JE, Latek RR, Erdjument-Bromage H et al:: mTOR interacts with raptor to form a nutrient-sensitive complex that signals to the cell growth machinery. Cell 2002, 110: 163-175.

33. Kim DH, Sarbassov DD, Ali SM, Latek RR, Guntur KV, Erdjument-Bromage $\mathrm{H}$ et al.: GbetaL, a positive regulator of the rapamycin-sensitive pathway required for the nutrient-sensitive interaction between raptor and mTOR. Mol Cell 2003, 11: 895-904.

34. Saci A, Cantley LC, Carpenter CL: Rac1 regulates the activity of mTORC1 and mTORC2 and controls cellular size. Mol Cell 2011, 42: 50-61.

35. Sancak $Y$, Thoreen CC, Peterson TR, Lindquist RA, Kang SA, Spooner E et al:: PRAS40 is an insulin-regulated inhibitor of the mTORC1 protein kinase. Mol Cell 2007, 25: 903-915.

36. Sancak Y, Bar-Peled L, Zoncu R, Markhard AL, Nada S, Sabatini DM: Ragulator-Rag complex targets mTORC1 to the lysosomal surface and is necessary for its activation by amino acids. Cell 2010, 141: 290-303.

37. Caron E, Ghosh S, Matsuoka Y, Ashton-Beaucage D, Therrien M, Lemieux $S$ et al.: A comprehensive map of the mTOR signaling network. Mol Syst Biol 2010, 6: 453.

38. Yang Q, Guan KL: Expanding mTOR signaling. Cell Res 2007, 17: 666681.

39. Polak P, Hall MN: mTOR and the control of whole body metabolism. Curr Opin Cell Biol 2009, 21: 209-218.

40. Goberdhan DC, Boyd CA: mTOR: dissecting regulation and mechanism of action to understand human disease. Biochem Soc Trans 2009, 37: 213216. 
41. Brown EJ, Albers MW, Shin TB, Ichikawa K, Keith CT, Lane WS et al.: A mammalian protein targeted by $\mathrm{G} 1$-arresting rapamycin-receptor complex. Nature 1994, 369: 756-758.

42. Chen J, Zheng XF, Brown EJ, Schreiber SL: Identification of an 11-kDa FKBP12-rapamycin-binding domain within the 289-kDa FKBP12rapamycin-associated protein and characterization of a critical serine residue. Proc Natl Acad Sci U S A 1995, 92: 4947-4951.

43. Sabatini DM, Erdjument-Bromage H, Lui M, Tempst P, Snyder SH: RAFT1: a mammalian protein that binds to FKBP12 in a rapamycin-dependent fashion and is homologous to yeast TORs. Cell 1994, 78: 35-43.

44. Heitman J, Movva NR, Hall MN: Targets for cell cycle arrest by the immunosuppressant rapamycin in yeast. Science 1991, 253: 905-909.

45. Cafferkey R, Young PR, McLaughlin MM, Bergsma DJ, Koltin Y, Sathe GM et al: Dominant missense mutations in a novel yeast protein related to mammalian phosphatidylinositol 3-kinase and VPS34 abrogate rapamycin cytotoxicity. Mol Cell Biol 1993, 13: 6012-6023.

46. Abraham RT: Mammalian target of rapamycin: immunosuppressive drugs uncover a novel pathway of cytokine receptor signaling. Curr Opin Immunol 1998, 10: 330-336.

47. Hay N, Sonenberg N: Upstream and downstream of mTOR. Genes Dev 2004, 18: 1926-1945.

48. Fingar DC, Blenis J: Target of rapamycin (TOR): an integrator of nutrient and growth factor signals and coordinator of cell growth and cell cycle progression. Oncogene 2004, 23: 3151-3171.

49. Andrade MA, Bork P: HEAT repeats in the Huntington's disease protein. Nat Genet 1995, 11: 115-116.

50. Lee JW, Park S, Takahashi Y, Wang HG: The association of AMPK with ULK1 regulates autophagy. PLoS One 2010, 5: e15394.

51. Carriere A, Romeo Y, Acosta-Jaquez HA, Moreau J, Bonneil E, Thibault P et al:: ERK1/2 phosphorylate Raptor to promote Ras-dependent activation of mTOR complex 1 (mTORC1). J Biol Chem 2011, 286: 567-577.

52. Holz MK, Blenis J: Identification of S6 kinase 1 as a novel mammalian target of rapamycin (mTOR)-phosphorylating kinase. J Biol Chem 2005, 280: 26089-26093.

53. Pullen N, Thomas G: The modular phosphorylation and activation of p70s6k. FEBS Lett 1997, 410: 78-82.

54. Oshiro N, Takahashi R, Yoshino K, Tanimura K, Nakashima A, Eguchi S et al.: The proline-rich Akt substrate of $40 \mathrm{kDa}$ (PRAS40) is a physiological 
substrate of mammalian target of rapamycin complex 1. J Biol Chem 2007, 282: 20329-20339.

55. Kovacina KS, Park GY, Bae SS, Guzzetta AW, Schaefer E, Birnbaum MJ et al.: Identification of a proline-rich Akt substrate as a 14-3-3 binding partner. J Biol Chem 2003, 278: 10189-10194.

56. Vander HE, Lee SI, Bandhakavi S, Griffin TJ, Kim DH: Insulin signalling to mTOR mediated by the Akt/PKB substrate PRAS40. Nat Cell Biol 2007, 9: 316-323.

57. Thedieck K, Polak P, Kim ML, Molle KD, Cohen A, Jeno P et al.: PRAS40 and PRR5-like protein are new mTOR interactors that regulate apoptosis. PLoS One 2007, 2: e1217.

58. Kazi AA, Lang $\mathrm{CH}$ : PRAS40 regulates protein synthesis and cell cycle in C2C12 myoblasts. Mol Med 2010, 16: 359-371.

59. Caccamo A, Maldonado MA, Majumder S, Medina DX, Holbein W, Magri A et al: Naturally secreted amyloid-beta increases mammalian target of rapamycin (mTOR) activity via a PRAS40-mediated mechanism. J Biol Chem 2011, 286: 8924-8932.

60. Peterson TR, Laplante M, Thoreen CC, Sancak Y, Kang SA, Kuehl WM et al.: DEPTOR is an mTOR inhibitor frequently overexpressed in multiple myeloma cells and required for their survival. Cell 2009, 137: 873-886.

61. Liu M, Wilk SA, Wang A, Zhou L, Wang RH, Ogawa W et al.: Resveratrol inhibits mTOR signaling by promoting the interaction between mTOR and DEPTOR. J Biol Chem 2010, 285: 36387-36394.

62. Kazi AA, Hong-Brown L, Lang SM, Lang CH: Deptor knockdown enhances mTOR activity and protein synthesis in myocytes and ameliorates disuse muscle atrophy. Mol Med 2011, 17(9-10): 925-936.

63. Sancak Y, Sabatini DM: Rag proteins regulate amino-acid-induced mTORC1 signalling. Biochem Soc Trans 2009, 37: 289-290.

64. Watanabe R, Wei L, Huang J: mTOR signaling, function, novel inhibitors, and therapeutic targets. J Nucl Med 2011, 52: 497-500.

65. Vezina C, Kudelski A, Sehgal SN: Rapamycin (AY-22,989), a new antifungal antibiotic. I. Taxonomy of the producing streptomycete and isolation of the active principle. J Antibiot (Tokyo) 1975, 28: 721-726.

66. Sehgal SN, Czerkawski H, Kudelski A, Pandev K, Saucier R, Vezina C: Ravidomycin (AY-25,545), a new antitumor antibiotic. J Antibiot (Tokyo) 1983, 36: 355-361.

67. Kelly PA, Gruber SA, Behbod F, Kahan BD: Sirolimus, a new, potent immunosuppressive agent. Pharmacotherapy 1997, 17: 1148-1156. 
68. Dumont FJ, Su Q: Mechanism of action of the immunosuppressant rapamycin. Life Sci 1996, 58: 373-395.

69. Kay JE, Kromwel L, Doe SE, Denyer M: Inhibition of T and B lymphocyte proliferation by rapamycin. Immunology 1991, 72: 544-549.

70. Bove J, Martinez-Vicente M, Vila M: Fighting neurodegeneration with rapamycin: mechanistic insights. Nat Rev Neurosci 2011, 12: 437-452.

71. Thuret R, Maurin C, Sun M, Perrotte P, Karakiewicz PI: [Treatment of metastatic renal cell carcinoma]. Prog Urol 2011, 21: 233-244.

72. Chen HL, Liu K, Meng XY, Wen XD, You QS: Local application of rapamycin inhibits vein graft restenosis in rabbits. Transplant Proc 2011, 43: 2017-2021.

73. Carpenter CL, Cantley LC: Phosphoinositide 3-kinase and the regulation of cell growth. Biochim Biophys Acta 1996, 1288: M11-M16.

74. Leavens KF, Birnbaum MJ: Insulin signaling to hepatic lipid metabolism in health and disease. Crit Rev Biochem Mol Biol 2011, 46: 200-215.

75. Cantley LC: The phosphoinositide 3-kinase pathway. Science 2002, 296: 1655-1657.

76. Maag D, Maxwell MJ, Hardesty DA, Boucher KL, Choudhari N, Hanno AG et al.: Inositol polyphosphate multikinase is a physiologic PI3-kinase that activates Akt/PKB. Proc Natl Acad Sci U S A 2011, 108: 1391-1396.

77. Sarbassov DD, Ali SM, Sengupta S, Sheen JH, Hsu PP, Bagley AF et al:: Prolonged rapamycin treatment inhibits mTORC2 assembly and Akt/PKB. Mol Cell 2006, 22: 159-168.

78. Toker A, Newton AC: Cellular signaling: pivoting around PDK-1. Cell 2000, 103: $185-188$.

79. Vanhaesebroeck B, Alessi DR: The PI3K-PDK1 connection: more than just a road to PKB. Biochem J 2000, 346 Pt 3: 561-576.

80. Vasudevan KM, Garraway LA: AKT signaling in physiology and disease. Curr Top Microbiol Immunol 2010, 347: 105-133.

81. Dan HC, Adli M, Baldwin AS: Regulation of mammalian target of rapamycin activity in PTEN-inactive prostate cancer cells by I kappa B kinase alpha. Cancer Res 2007, 67: 6263-6269.

82. Manning BD, Cantley LC: Rheb fills a GAP between TSC and TOR. Trends Biochem Sci 2003, 28: 573-576.

83. Tee AR, Fingar DC, Manning BD, Kwiatkowski DJ, Cantley LC, Blenis J: Tuberous sclerosis complex-1 and -2 gene products function together to 
inhibit mammalian target of rapamycin (mTOR)-mediated downstream signaling. Proc Natl Acad Sci U S A 2002, 99: 13571-13576.

84. Tee AR, Manning BD, Roux PP, Cantley LC, Blenis J: Tuberous sclerosis complex gene products, Tuberin and Hamartin, control mTOR signaling by acting as a GTPase-activating protein complex toward Rheb. Curr Biol 2003, 13: 1259-1268.

85. Chong-Kopera H, Inoki K, Li Y, Zhu T, Garcia-Gonzalo FR, Rosa JL et al.: TSC1 stabilizes TSC2 by inhibiting the interaction between TSC2 and the HERC1 ubiquitin ligase. J Biol Chem 2006, 281: 8313-8316.

86. Findlay GM, Harrington LS, Lamb RF: TSC1-2 tumour suppressor and regulation of mTOR signalling: linking cell growth and proliferation? Curr Opin Genet Dev 2005, 15: 69-76.

87. Tzatsos A: Raptor binds the SAIN (Shc and IRS-1 NPXY binding) domain of insulin receptor substrate-1 (IRS-1) and regulates the phosphorylation of IRS-1 at Ser-636/639 by mTOR. J Biol Chem 2009, 284: 22525-22534.

88. O'Reilly KE, Rojo F, She QB, Solit D, Mills GB, Smith D et al:: mTOR inhibition induces upstream receptor tyrosine kinase signaling and activates Akt. Cancer Res 2006, 66: 1500-1508.

89. Harrington LS, Findlay GM, Lamb RF: Restraining PI3K: mTOR signalling goes back to the membrane. Trends Biochem Sci 2005, 30: 35-42.

90. Kim J, Guan KL: Amino Acid Signaling in TOR Activation. Annu Rev Biochem 2011, 80: 1001-1032.

91. Avruch J, Long X, Ortiz-Vega S, Rapley J, Papageorgiou A, Dai N: Amino acid regulation of TOR complex 1. Am J Physiol Endocrinol Metab 2009, 296: E592-E602.

92. Smith TF, Gaitatzes C, Saxena K, Neer EJ: The WD repeat: a common architecture for diverse functions. Trends Biochem Sci 1999, 24: 181-185.

93. Inoki K, Zhu T, Guan KL: TSC2 mediates cellular energy response to control cell growth and survival. Cell 2003, 115: 577-590.

94. Inoki $\mathrm{K}$, Ouyang $\mathrm{H}$, Zhu $\mathrm{T}$, Lindvall $\mathrm{C}$, Wang $\mathrm{Y}$, Zhang $\mathrm{X}$ et al.: TSC2 integrates Wnt and energy signals via a coordinated phosphorylation by AMPK and GSK3 to regulate cell growth. Cell 2006, 126: 955-968.

95. Gwinn DM, Shackelford DB, Egan DF, Mihaylova MM, Mery A, Vasquez DS et al:: AMPK phosphorylation of raptor mediates a metabolic checkpoint. Mol Cell 2008, 30: 214-226.

96. Kalender A, Selvaraj A, Kim SY, Gulati P, Brule S, Viollet B et al:: Metformin, independent of AMPK, inhibits mTORC1 in a rag GTPasedependent manner. Cell Metab 2010, 11: 390-401. 
97. Brugarolas J, Lei K, Hurley RL, Manning BD, Reiling JH, Hafen E et al:: Regulation of mTOR function in response to hypoxia by REDD1 and the TSC1/TSC2 tumor suppressor complex. Genes Dev 2004, 18: 2893-2904.

98. DeYoung MP, Horak P, Sofer A, Sgroi D, Ellisen LW: Hypoxia regulates TSC1/2-mTOR signaling and tumor suppression through REDD1-mediated 14-3-3 shuttling. Genes Dev 2008, 22: 239-251.

99. Budanov AV, Karin M: p53 target genes sestrin1 and sestrin2 connect genotoxic stress and mTOR signaling. Cell 2008, 134: 451-460.

100. Vousden KH, Ryan KM: p53 and metabolism. Nat Rev Cancer 2009, 9: 691-700.

101. Zhang XD, Qin ZH, Wang J: The role of $\mathrm{p} 53$ in cell metabolism. Acta Pharmacol Sin 2010, 31: 1208-1212.

102. Ellisen LW, Ramsayer KD, Johannessen CM, Yang A, Beppu H, Minda $\mathrm{K}$ et al.: REDD1, a developmentally regulated transcriptional target of p63 and p53, links p63 to regulation of reactive oxygen species. Mol Cell 2002, 10: 995-1005.

103. Feng Z: p53 regulation of the IGF-1/AKT/mTOR pathways and the endosomal compartment. Cold Spring Harb Perspect Biol 2010, 2: a001057.

104. Sarbassov DD, Sabatini DM: Redox regulation of the nutrient-sensitive raptor-mTOR pathway and complex. J Biol Chem 2005, 280: 39505-39509.

105. Yoshida S, Hong S, Suzuki T, Nada S, Mannan AM, Wang J et al:: Redox regulates mTORC1 activity by modulating the TSC1/TSC2-Rheb pathway. J Biol Chem 2011.

106. Schalm SS, Blenis J: Identification of a conserved motif required for mTOR signaling. Curr Biol 2002, 12: 632-639.

107. Bai X, Jiang Y: Key factors in mTOR regulation. Cell Mol Life Sci 2010, 67: 239-253.

108. Zhang J, Gao Z, Yin J, Quon MJ, Ye J: S6K directly phosphorylates IRS-1 on Ser-270 to promote insulin resistance in response to TNF-(alpha) signaling through IKK2. J Biol Chem 2008, 283: 35375-35382.

109. Tremblay F, Brule S, Hee US, Li Y, Masuda K, Roden M et al:: Identification of IRS-1 Ser-1101 as a target of S6K1 in nutrient- and obesity-induced insulin resistance. Proc Natl Acad Sci U S A 2007, 104: 14056-14061.

110. Veilleux A, Houde VP, Bellmann K, Marette A: Chronic inhibition of the mTORC1/S6K1 pathway increases insulin-induced PI3K activity but inhibits Akt2 and glucose transport stimulation in 3T3-L1 adipocytes. Mol Endocrinol 2010, 24: 766-778. 
111. Julien LA, Carriere A, Moreau J, Roux PP: mTORC1-activated S6K1 phosphorylates Rictor on threonine 1135 and regulates mTORC2 signaling. Mol Cell Biol 2010, 30: 908-921.

112. Lai KP, Leong WF, Chau JF, Jia D, Zeng L, Liu $\mathrm{H}$ et al.: S6K1 is a multifaceted regulator of Mdm2 that connects nutrient status and DNA damage response. EMBO J 2010, 29: 2994-3006.

113. Chao SK, Horwitz SB, McDaid HM: Insights into 4E-BP1 and p53 mediated regulation of accelerated cell senescence. Oncotarget 2011, 2: 89-98.

114. Brunn GJ, Hudson CC, Sekulic A, Williams JM, Hosoi H, Houghton PJ et al.: Phosphorylation of the translational repressor PHAS-I by the mammalian target of rapamycin. Science 1997, 277: 99-101.

115. Gingras AC, Gygi SP, Raught B, Polakiewicz RD, Abraham RT, Hoekstra MF et al.: Regulation of 4E-BP1 phosphorylation: a novel two-step mechanism. Genes Dev 1999, 13: 1422-1437.

116. Hosokawa N, Hara T, Kaizuka T, Kishi C, Takamura A, Miura $Y$ et al.: Nutrient-dependent mTORC1 association with the ULK1-Atg13-FIP200 complex required for autophagy. Mol Biol Cell 2009, 20: 1981-1991.

117. Neufeld TP: TOR-dependent control of autophagy: biting the hand that feeds. Curr Opin Cell Biol 2010, 22: 157-168.

118. Yang Z, Klionsky DJ: Mammalian autophagy: core molecular machinery and signaling regulation. Curr Opin Cell Biol 2010, 22: 124-131.

119. Chan EY: mTORC1 phosphorylates the ULK1-mAtg13-FIP200 autophagy regulatory complex. Sci Signal 2009, 2: e51.

120. Hannan KM, Brandenburger $Y$, Jenkins A, Sharkey K, Cavanaugh A, Rothblum $\mathrm{L}$ et al.: mTOR-dependent regulation of ribosomal gene transcription requires S6K1 and is mediated by phosphorylation of the carboxy-terminal activation domain of the nucleolar transcription factor UBF. Mol Cell Biol 2003, 23: 8862-8877.

121. Grummt I: Life on a planet of its own: regulation of RNA polymerase I transcription in the nucleolus. Genes Dev 2003, 17: 1691-1702.

122. Zaragoza D, Ghavidel A, Heitman J, Schultz MC: Rapamycin induces the G0 program of transcriptional repression in yeast by interfering with the TOR signaling pathway. Mol Cell Biol 1998, 18: 4463-4470.

123. Preiss T, Baron-Benhamou J, Ansorge W, Hentze MW: Homodirectional changes in transcriptome composition and mRNA translation induced by rapamycin and heat shock. Nat Struct Biol 2003, 10: 1039-1047.

124. Gu Y, Lindner J, Kumar A, Yuan W, Magnuson MA: Rictor/mTORC2 is essential for maintaining a balance between beta-cell proliferation and cell size. Diabetes 2011, 60: 827-837. 
125. Jacinto E, Facchinetti V, Liu D, Soto N, Wei S, Jung SY et al:: SIN1/MIP1 maintains rictor-mTOR complex integrity and regulates Akt phosphorylation and substrate specificity. Cell 2006, 127: 125-137.

126. Pearce LR, Sommer EM, Sakamoto K, Wullschleger S, Alessi DR: Protor-1 is required for efficient mTORC2-mediated activation of SGK1 in the kidney. Biochem J 2011, 436: 169-179.

127. Goncharova EA, Goncharov DA, Li H, Pimtong W, Lu S, Khavin I et al.: mTORC2 Is Required for Proliferation and Survival of TSC2-Null Cells. Mol Cell Biol 2011, 31: 2484-2498.

128. Frias MA, Thoreen CC, Jaffe JD, Schroder W, Sculley T, Carr SA et al:: $\mathrm{mSin} 1$ is necessary for Akt/PKB phosphorylation, and its isoforms define three distinct mTORC2s. Curr Biol 2006, 16: 1865-1870.

129. Frias MA, Thoreen CC, Jaffe JD, Schroder W, Sculley T, Carr SA et al:: mSin1 is necessary for Akt/PKB phosphorylation, and its isoforms define three distinct mTORC2s. Curr Biol 2006, 16: 1865-1870.

130. Yang Q, Inoki K, Ikenoue T, Guan KL: Identification of Sin1 as an essential TORC2 component required for complex formation and kinase activity. Genes Dev 2006, 20: 2820-2832.

131. Pearce LR, Huang X, Boudeau J, Pawlowski R, Wullschleger S, Deak M et al.: Identification of Protor as a novel Rictor-binding component of mTOR complex-2. Biochem J 2007, 405: 513-522.

132. Woo SY, Kim DH, Jun CB, Kim YM, Haar EV, Lee SI et al.: PRR5, a novel component of mTOR complex 2, regulates platelet-derived growth factor receptor beta expression and signaling. J Biol Chem 2007, 282: 2560425612.

133. Shatkin AJ: Capping of eucaryotic mRNAs. Cell 1976, 9: 645-653.

134. Filipowicz W: Functions of the 5,-terminal m7G cap in eukaryotic mRNA. FEBS Lett 1978, 96: 1-11.

135. Coller J, Parker R: General translational repression by activators of mRNA decapping. Cell 2005, 122: 875-886.

136. Matsuo H, Li H, McGuire AM, Fletcher CM, Gingras AC, Sonenberg N et al.: Structure of translation factor elF4E bound to m7GDP and interaction with 4E-binding protein. Nat Struct Biol 1997, 4: 717-724.

137. Nojima H, Tokunaga C, Eguchi S, Oshiro N, Hidayat S, Yoshino $\mathrm{K}$ et al:: The mammalian target of rapamycin (mTOR) partner, raptor, binds the mTOR substrates p70 S6 kinase and 4E-BP1 through their TOR signaling (TOS) motif. J Biol Chem 2003, 278: 15461-15464. 
138. Pause A, Belsham GJ, Gingras AC, Donze O, Lin TA, Lawrence JC, Jr. et al.: Insulin-dependent stimulation of protein synthesis by phosphorylation of a regulator of 5'-cap function. Nature 1994, 371: 762-767.

139. Parker R, Sheth U: P bodies and the control of mRNA translation and degradation. Mol Cell 2007, 25: 635-646.

140. Eulalio A, Behm-Ansmant I, Izaurralde E: P bodies: at the crossroads of post-transcriptional pathways. Nat Rev Mol Cell Biol 2007, 8: 9-22.

141. Huang L, Mollet S, Souquere S, Le RF, Ernoult-Lange M, Pierron G et al.: Mitochondria Associate with P-bodies and Modulate MicroRNA-mediated RNA Interference. J Biol Chem 2011, 286: 24219-24230.

142. Eulalio A, Behm-Ansmant I, Schweizer D, Izaurralde E: P-body formation is a consequence, not the cause, of RNA-mediated gene silencing. Mol Cell Biol 2007, 27: 3970-3981.

143. Franks TM, Lykke-Andersen J: The control of mRNA decapping and Pbody formation. Mol Cell 2008, 32: 605-615.

144. Aizer A, Brody Y, Ler LW, Sonenberg N, Singer RH, Shav-Tal Y: The dynamics of mammalian $\mathrm{P}$ body transport, assembly, and disassembly in vivo. Mol Biol Cell 2008, 19: 4154-4166.

145. She M, Decker CJ, Svergun DI, Round A, Chen N, Muhlrad D et al:: Structural basis of dcp2 recognition and activation by dcp1. Mol Cell 2008, 29: 337-349.

146. Fenger-Gron M, Fillman C, Norrild B, Lykke-Andersen J: Multiple processing body factors and the ARE binding protein TTP activate mRNA decapping. Mol Cell 2005, 20: 905-915.

147. Xu J, Yang JY, Niu QW, Chua NH: Arabidopsis DCP2, DCP1, and VARICOSE form a decapping complex required for postembryonic development. Plant Cell 2006, 18: 3386-3398.

148. Yu JH, Yang WH, Gulick T, Bloch KD, Bloch DB: Ge-1 is a central component of the mammalian cytoplasmic mRNA processing body. RNA 2005, 11: 1795-1802.

149. Brodersen $P$, Sakvarelidze-Achard L, Bruun-Rasmussen M, Dunoyer $P$, Yamamoto $\mathrm{YY}$, Sieburth $\mathrm{L}$ et al.: Widespread translational inhibition by plant miRNAs and siRNAs. Science 2008, 320: 1185-1190.

150. Albig AR, Decker CJ: The target of rapamycin signaling pathway regulates mRNA turnover in the yeast Saccharomyces cerevisiae. Mol Biol Cell 2001, 12: 3428-3438.

151. Blum H, Beier H, Gross HJ: Improved silver staining of plant-proteins, RNA and DNA in polyacrylamide gels. Electrophoresis 1987, 8: 93-99. 
152. Asif AR, Armstrong VW, Voland A, Wieland E, Oellerich M, Shipkova M: Proteins identified as targets of the acyl glucuronide metabolite of mycophenolic acid in kidney tissue from mycophenolate mofetil treated rats. Biochimie 2007, 89: 393-402.

153. Apweiler R, Bairoch A, Wu CH, Barker WC, Boeckmann B, Ferro S et al.: UniProt: the Universal Protein knowledgebase. Nucleic Acids Res 2004, 32: 115-119.

154. Tatusov RL, Fedorova ND, Jackson JD, Jacobs AR, Kiryutin B, Koonin EV et al:: The COG database: an updated version includes eukaryotes. $B M C$ Bioinformatics 2003, 4: 41.

155. Warde-Farley D, Donaldson SL, Comes O, Zuberi K, Badrawi R, Chao P et al.: The GeneMANIA prediction server: biological network integration for gene prioritization and predicting gene function. Nucleic Acids Res 2010, 38: 214-220.

156. Trotta E, D'Ambrosio E, Ravagnan G, Paci M: Evidence for DAPI intercalation in CG sites of DNA oligomer [d(CGACGTCG)]2: a 1H NMR study. Nucleic Acids Res 1995, 23: 1333-1340.

157. Du M, Shen QW, Zhu MJ, Ford SP: Leucine stimulates mammalian target of rapamycin signaling in $\mathrm{C} 2 \mathrm{C} 12$ myoblasts in part through inhibition of adenosine monophosphate-activated protein kinase. J Anim Sci 2007, 85: 919-927.

158. Schultze FC, Petrova DT, Oellerich M, Armstrong VW, Asif AR: Differential proteome and phosphoproteome signatures in human T-lymphoblast cells induced by sirolimus. Cell Prolif 2010, 43: 396-404.

159. Chomczynski P: A reagent for the single-step simultaneous isolation of RNA, DNA and proteins from cell and tissue samples. Biotechniques 1993, 15: 532-537.

160. Zhou H, Huang S: mTOR signaling in cancer cell motility and tumor metastasis. Crit Rev Eukaryot Gene Expr 2010, 20: 1-16.

161. Heitman J, Koller A, Kunz J, Henriquez R, Schmidt A, Movva NR et al.: The immunosuppressant FK506 inhibits amino acid import in Saccharomyces cerevisiae. Mol Cell Biol 1993, 13: 5010-5019.

162. Laplante M, Sabatini DM: mTOR signaling at a glance. J Cell Sci 2009, 122: 3589-3594.

163. Goberdhan DC, Ogmundsdottir MH, Kazi S, Reynolds B, Visvalingam SM, Wilson $\mathrm{C}$ et al:: Amino acid sensing and mTOR regulation: inside or out? Biochem Soc Trans 2009, 37: 248-252.

164. Goberdhan DC: Intracellular amino acid sensing and mTORC1-regulated growth: new ways to block an old target? Curr Opin Investig Drugs 2010, 11: 1360-1367. 
165. Bonetta L: Protein-protein interactions: Interactome under construction. Nature 2010, 468: 851-854.

166. Lamond AI, Mann M: Cell biology and the genome projects a concerted strategy for characterizing multiprotein complexes by using mass spectrometry. Trends Cell Biol 1997, 7: 139-142.

167. Zhou J, Allred DC, Avis I, Martinez A, Vos MD, Smith L et al.: Differential expression of the early lung cancer detection marker, heterogeneous nuclear ribonucleoprotein-A2/B1 (hnRNP-A2/B1) in normal breast and neoplastic breast cancer. Breast Cancer Res Treat 2001, 66: 217-224.

168. Shyu $A B$, Wilkinson MF: The double lives of shuttling mRNA binding proteins. Cell 2000, 102: 135-138.

169. Goh ET, Pardo OE, Michael N, Niewiarowski A, Totty N, Volkova D et al:: Involvement of heterogeneous ribonucleoprotein $\mathrm{F}$ in the regulation of cell proliferation via the mammalian target of rapamycin/S6 kinase 2 pathway. $J$ Biol Chem 2010, 285: 17065-17076.

170. Popielarz M, Cavaloc Y, Mattei MG, Gattoni R, Stevenin J: The gene encoding human splicing factor 9G8. Structure, chromosomal localization, and expression of alternatively processed transcripts. J Biol Chem 1995, 270: $17830-17835$.

171. Michlewski G, Sanford JR, Caceres JF: The splicing factor SF2/ASF regulates translation initiation by enhancing phosphorylation of 4E-BP1. Mol Cell 2008, 30: 179-189.

172. Rodriguez-Gabriel MA, Remacha M, Ballesta JP: Phosphorylation of ribosomal protein $\mathrm{PO}$ is not essential for ribosome function but can affect translation. Biochemistry 1998, 37: 16620-16626.

173. Zinzalla V, Stracka D, Oppliger W, Hall MN: Activation of mTORC2 by association with the ribosome. Cell 2011, 144: 757-768.

174. Sengupta S, Peterson TR, Sabatini DM: Regulation of the mTOR complex 1 pathway by nutrients, growth factors, and stress. Mol Cell 2010, 40: 310322.

175. Srivastava M, Pollard HB: Molecular dissection of nucleolin's role in growth and cell proliferation: new insights. FASEB J 1999, 13: 1911-1922.

176. Bouvet P, Diaz JJ, Kindbeiter K, Madjar JJ, Amalric F: Nucleolin interacts with several ribosomal proteins through its RGG domain. $J$ Biol Chem 1998, 273: 19025-19029.

177. Jin YJ, Burakoff SJ: The 25-kDa FK506-binding protein is localized in the nucleus and associates with casein kinase II and nucleolin. Proc Natl Acad Sci U S A 1993, 90: 7769-7773. 
178. Csermely P, Schnaider T, Cheatham B, Olson MO, Kahn CR: Insulin induces the phosphorylation of nucleolin. A possible mechanism of insulininduced RNA efflux from nuclei. J Biol Chem 1993, 268: 9747-9752.

179. Heymann JA, Hinshaw JE: Dynamins at a glance. J Cell Sci 2009, 122: 3427-3431.

180. Durieux AC, Prudhon B, Guicheney P, Bitoun M: Dynamin 2 and human diseases. J Mol Med (Berl) 2010, 88: 339-350.

181. Drenan RM, Liu X, Bertram PG, Zheng XF: FKBP12-rapamycin-associated protein or mammalian target of rapamycin (FRAP/mTOR) localization in the endoplasmic reticulum and the Golgi apparatus. J Biol Chem 2004, 279: 772-778.

182. Pelkmans L, Fava E, Grabner H, Hannus M, Habermann B, Krausz E et al.: Genome-wide analysis of human kinases in clathrin- and caveolae/raftmediated endocytosis. Nature 2005, 436: 78-86.

183. Hennig KM, Colombani J, Neufeld TP: TOR coordinates bulk and targeted endocytosis in the Drosophila melanogaster fat body to regulate cell growth. J Cell Biol 2006, 173: 963-974.

184. Liu X, Zheng XF: Endoplasmic reticulum and Golgi localization sequences for mammalian target of rapamycin. Mol Biol Cell 2007, 18: 1073-1082.

185. Hassan BH, Cronan JE: Protein-protein interactions in assembly of lipoic acid on the 2-oxoacid dehydrogenases of aerobic metabolism. $J$ Biol Chem 2011, 286: 8263-8276.

186. Sirover MA: New insights into an old protein: the functional diversity of mammalian glyceraldehyde-3-phosphate dehydrogenase. Biochim Biophys Acta 1999, 1432: 159-184.

187. Colell A, Green DR, Ricci JE: Novel roles for GAPDH in cell death and carcinogenesis. Cell Death Differ 2009, 16: 1573-1581.

188. Tisdale EJ: Glyceraldehyde-3-phosphate dehydrogenase is required for vesicular transport in the early secretory pathway. J Biol Chem 2001, 276: 2480-2486.

189. Lee MN, Ha SH, Kim J, Koh A, Lee CS, Kim JH et al:: Glycolytic flux signals to mTOR through glyceraldehyde-3-phosphate dehydrogenasemediated regulation of Rheb. Mol Cell Biol 2009, 29: 3991-4001.

190. Liefhebber JM, Punt S, Spaan WJ, van Leeuwen HC: The human collagen beta(1-O)galactosyltransferase, GLT25D1, is a soluble endoplasmic reticulum localized protein. BMC Cell Biol 2010, 11: 33.

191. Takahashi M, Tsuda T, Ikeda Y, Honke K, Taniguchi N: Role of N-glycans in growth factor signaling. Glycoconj J 2004, 20: 207-212. 
192. Scott KL, Kabbarah O, Liang MC, Ivanova E, Anagnostou V, Wu J et al.: GOLPH3 modulates mTOR signalling and rapamycin sensitivity in cancer. Nature 2009, 459: 1085-1090.

193. Mishra S, Ande SR, Nyomba BL: The role of prohibitin in cell signaling. FEBS J 2010, 277: 3937-3946.

194. Wang S, Nath N, Fusaro G, Chellappan S: Rb and prohibitin target distinct regions of E2F1 for repression and respond to different upstream signals. Mol Cell Biol 1999, 19: 7447-7460.

195. Wang S, Nath N, Adlam M, Chellappan S: Prohibitin, a potential tumor suppressor, interacts with RB and regulates E2F function. Oncogene 1999, 18: 3501-3510.

196. Sun L, Liu L, Yang XJ, Wu Z: Akt binds prohibitin 2 and relieves its repression of MyoD and muscle differentiation. J Cell Sci 2004, 117: 30213029.

197. Kim DH, Sabatini DM: Raptor and mTOR: subunits of a nutrient-sensitive complex. Curr Top Microbiol Immunol 2004, 279: 259-270.

198. Bloch DB, Rabkina D, Quertermous T, Bloch KD: The immunoreactive region in a novel autoantigen contains a nuclear localization sequence. Clin Immunol Immunopathol 1994, 72: 380-389.

199. Fan SJ, Marchand V, Ephrussi A: Drosophila Ge-1 Promotes P Body Formation and oskar mRNA Localization. PLoS One 2011, 6: e20612.

200. Jinek M, Eulalio A, Lingel A, Helms S, Conti E, Izaurralde E: The C-terminal region of Ge-1 presents conserved structural features required for P-body localization. RNA 2008, 14: 1991-1998.

201. Adler J, Parmryd I: Quantifying colocalization by correlation: the Pearson correlation coefficient is superior to the Mander's overlap coefficient. Cytometry A 2010, 77: 733-742.

202. Zafar S, von AN, Oellerich M, Zerr I, Schulz-Schaeffer WJ, Armstrong VW et al:: Proteomics approach to identify the interacting partners of cellular prion protein and characterization of Rab7a interaction in neuronal cells. $J$ Proteome Res 2011, 10: 3123-3135.

203. Manders EMM, Verbeek FJ, Aten JA: Measurement of co-localization of objects in dualcolor confocal images. Journal of Microscopy 1993, 169: 375-382.

204. Blom N, Gammeltoft S, Brunak S: Sequence and structure-based prediction of eukaryotic protein phosphorylation sites. J Mol Biol 1999, 294: 13511362.

205. Yaffe MB, Elia AE: Phosphoserine/threonine-binding domains. Curr Opin Cell Biol 2001, 13: 131-138. 
206. Sheth U, Parker R: Decapping and decay of messenger RNA occur in cytoplasmic processing bodies. Science 2003, 300: 805-808.

207. Bruhat A, Jousse C, Carraro V, Reimold AM, Ferrara M, Fafournoux P: Amino acids control mammalian gene transcription: activating transcription factor 2 is essential for the amino acid responsiveness of the CHOP promoter. Mol Cell Biol 2000, 20: 7192-7204.

208. Ikari A, Sanada A, Sawada H, Okude C, Tonegawa C, Sugatani J: Decrease in transient receptor potential melastatin 6 mRNA stability caused by rapamycin in renal tubular epithelial cells. Biochim Biophys Acta 2011, 1808: 1502-1508.

209. Hornbeck PV, Chabra I, Kornhauser JM, Skrzypek E, Zhang B: PhosphoSite: A bioinformatics resource dedicated to physiological protein phosphorylation. Proteomics 2004, 4: 1551-1561.

210. Goustin AS, Leof EB, Shipley GD, Moses HL: Growth factors and cancer. Cancer Res 1986, 46: 1015-1029.

211. Morgan JF, Morton HJ, Parker RC: Nutrition of animal cells in tissue culture; initial studies on a synthetic medium. Proc Soc Exp Biol Med 1950, 73: 1-8.

212. Barta O, Nelson RA, Jr., Kuo CY: Separation of six bovine complement components and one inactivator (1, 2). Immunol Commun 1976, 5: 75-86.

213. Kimura T, Miyazaki K, Mashima K, Yamashita J, Horio T, Kakuno T: Purification and properties of growth inhibitor from normal rabbit serum. $J$ Biochem 1991, 110: 423-428.

214. Otsuka $\mathrm{H}$ : An inhibitor present in calf serum which prevents growth of BHK21 cells in suspension culture. J Cell Sci 1972, 10: 137-152.

215. Tulamo R, Frosen J, Junnikkala S, Paetau A, Kangasniemi M, Pelaez J et al.: Complement system becomes activated by the classical pathway in intracranial aneurysm walls. Lab Invest 2010, 90: 168-179.

216. Shen Y, Halperin JA, Benzaquen L, Lee CM: Characterization of neuronal cell death induced by complement activation. Brain Res Brain Res Protoc 1997, 1: 186-194.

217. Soltis RD, Hasz D, Morris MJ, Wilson ID: The effect of heat inactivation of serum on aggregation of immunoglobulins. Immunology 1979, 36: 37-45.

218. Triglia RP, Linscott WD: Titers of nine complement components, conglutinin and C3b-inactivator in adult and fetal bovine sera. Mol Immunol 1980, 17: 741-748.

219. Bruinink A, Tobler U, Halg M, Grunert J: Effects of serum and serum heatinactivation on human bone derived osteoblast progenitor cells. J Mater Sci Mater Med 2004, 15: 497-501. 
220. Huang FP, Stott DI: Dual inhibitory and stimulatory activities in serum from SLE patients and lupus mice that regulate the proliferation of an IL-2dependent T cell line. Lupus 1995, 4: 297-303.

221. Leshem B, Yogev D, Fiorentini D: Heat inactivation of fetal calf serum is not required for in vitro measurement of lymphocyte functions. J Immunol Methods 1999, 223: 249-254.

222. Khan KN, Kitajima M, Hiraki K, Fujishita A, Sekine I, Ishimaru T et al.: Tolllike receptors in innate immunity: role of bacterial endotoxin and toll-like receptor 4 in endometrium and endometriosis. Gynecol Obstet Invest 2009, 68: $40-52$.

223. Raetz CR, Whitfield C: Lipopolysaccharide endotoxins. Annu Rev Biochem 2002, 71: 635-700.

224. Xu D, Komai-Koma M, Liew FY: Expression and function of Toll-like receptor on T cells. Cell Immunol 2005, 233: 85-89.

225. Hunter T, Plowman GD: The protein kinases of budding yeast: six score and more. Trends Biochem Sci 1997, 22: 18-22.

226. Nicholson-Weller A, Halperin JA: Membrane signaling by complement C5b9, the membrane attack complex. Immunol Res 1993, 12: 244-257.

227. Dos SS, Delattre Al, De LF, Bult H, Raes M: Gene expression profiling of LPS-stimulated murine macrophages and role of the NF-kappaB and PI3K/mTOR signaling pathways. Ann N Y Acad Sci 2007, 1096: 70-77.

228. Su SC, Hua KF, Lee H, Chao LK, Tan SK, Lee $H$ et al:: LTA and LPS mediated activation of protein kinases in the regulation of inflammatory cytokines expression in macrophages. Clin Chim Acta 2006, 374: 106-115.

229. Zanin-Zhorov A, Tal-Lapidot G, Cahalon L, Cohen-Sfady M, PevsnerFischer $\mathrm{M}$, Lider $\mathrm{O}$ et al:: Cutting edge: $\mathrm{T}$ cells respond to lipopolysaccharide innately via TLR4 signaling. J Immunol 2007, 179: 4144.

230. Case Gould MG: Endotoxin in Vertebrate Cell Culture: Its Measurement and Significance. In Uses and Standardization of Vertebrate Cell Lines. Tissue CultureAssociation, Gaithersburg, MD 1984, 125-136.

231. Sibley $\mathrm{CH}$, Terry $\mathrm{A}$, Raetz $\mathrm{CR}$ : Induction of kappa light chain synthesis in 70Z/3 B lymphoma cells by chemically defined lipid A precursors. J Biol Chem 1988, 263: 5098-5103.

232. Epstein J, Lee MM, Kelly CE, Donahoe PK: Effect of E. coli endotoxin on mammalian cell growth and recombinant protein production. In Vitro Cell Dev Biol 1990, 26: 1121-1122. 
233. Sutmuller RP, den Brok MH, Kramer M, Bennink EJ, Toonen LW, Kullberg BJ et al:: Toll-like receptor 2 controls expansion and function of regulatory $T$ cells. J Clin Invest 2006, 116: 485-494.

234. Wille JJ, Park J, Elgavish A: Effects of growth factors, hormones, bacterial lipopolysaccharides, and lipotechoic acids on the clonal growth of normal ureteral epithelial cells in serum-free culture. J Cell Physiol 1992, 150: $52-$ 58.

235. Gorbet MB, Sefton MV: Endotoxin: the uninvited guest. Biomaterials 2005, 26: 6811-6817.

236. Bradford MM: $A$ rapid and sensitive method for the quantitation of microgram quantities of protein utilizing the principle of protein-dye binding. Anal Biochem 1976, 72: 248-254.

237. Gorg A, Obermaier C, Boguth G, Harder A, Scheibe B, Wildgruber R et al:: The current state of two-dimensional electrophoresis with immobilized $\mathrm{pH}$ gradients. Electrophoresis 2000, 21: 1037-1053.

238. Laemmli UK: Cleavage of structural proteins during the assembly of the head of bacteriophage T4. Nature 1970, 227: 680-685.

239. Blum H. BHGHJ: Improved silver staining of plant-proteins, RNA and DNA in polyacrylamide gels. Electrophoresis 1987, 8: 93-99.

240. Shevchenko A, Wilm M, Vorm O, Mann M: Mass spectrometric sequencing of proteins silver-stained polyacrylamide gels. Anal Chem 1996, 68: 850858.

241. Asif AR, Oellerich M, Amstrong VW, Riemenschneider B, Monod M, Reichard U: Proteome of conidial surface associated proteins of Aspergillus fumigatus reflecting potential vaccine candidates and allergens. J Proteome Res 2006, 5: 954-962.

242. Gerharz CD, Gabbert HE, Biesalski HK, Engers R, Luley C: Fetal calf serum and retinoic acid affect proliferation and terminal differentiation of a rat rhabdomyosarcoma cell line (BA-HAN-1C). Br J Cancer 1989, 59: 6167.

243. Freshney RI: Culture of animal cells. A manual of basic technique. WileyLiss, New York 1994, 190-191.

244. Li QG, Blacher R, Esch F, Congote LF: Isolation from fetal bovine serum of an apolipoprotein-H-like protein which inhibits thymidine incorporation in fetal calf erythroid cells. Biochem J 1990, 267: 261-264.

245. Kabat EA, Mayer MM: Expeimental Immunochemsitry. Charles $C$ Thomas, Springfield, Illinois 1961.

246. Manor E: Human plasma accelerates immortalization of B lymphocytes by Epstein-Barr virus. Cell Prolif 2008, 41: 292-298. 
247. Tuyaerts S, Noppe SM, Corthals J, Breckpot K, Heirman C, de GC et al:: Generation of large numbers of dendritic cells in a closed system using Cell Factories. J Immunol Methods 2002, 264: 135-151.

248. Bollard CM, Aguilar L, Straathof KC, Gahn B, Huls MH, Rousseau A et al:: Cytotoxic T lymphocyte therapy for Epstein-Barr virus+ Hodgkin's disease. J Exp Med 2004, 200: 1623-1633.

249. Ayache S, Panelli MC, Byrne KM, Slezak S, Leitman SF, Marincola FM et al.: Comparison of proteomic profiles of serum, plasma, and modified media supplements used for cell culture and expansion. J Transl Med 2006, 4: 40.

250. Kuznetsov SA, Mankani MH, Robey PG: Effect of serum on human bone marrow stromal cells: ex vivo expansion and in vivo bone formation. Transplantation 2000, 70: 1780-1787.

251. Liu X, Liang J, Li G: Lipopolysaccharide promotes adhesion and invasion of hepatoma cell lines HepG2 and HepG2.2.15. Mol Biol Rep 2010, 37: 22352239.

252. Hsu RY, Chan CH, Spicer JD, Rousseau MC, Giannias B, Rousseau S et al.: LPS-induced TLR4 signaling in human colorectal cancer cells increases beta1 integrin-mediated cell adhesion and liver metastasis. Cancer Res 2011, 71: 1989-1998.

253. He W, Liu Q, Wang L, Chen W, Li N, Cao X: TLR4 signaling promotes immune escape of human lung cancer cells by inducing immunosuppressive cytokines and apoptosis resistance. Mol Immunol 2007, 44: 2850-2859.

254. Kolupaeva VG, Unbehaun A, Lomakin IB, Hellen CU, Pestova TV: Binding of eukaryotic initiation factor 3 to ribosomal $40 S$ subunits and its role in ribosomal dissociation and anti-association. RNA 2005, 11: 470-486.

255. Turk B: Targeting proteases: successes, failures and future prospects. Nat Rev Drug Discov 2006, 5: 785-799.

256. Dhungana S, Merrick BA, Tomer KB, Fessler MB: Quantitative proteomics analysis of macrophage rafts reveals compartmentalized activation of the proteasome and of proteasome-mediated ERK activation in response to lipopolysaccharide. Mol Cell Proteomics 2009, 8: 201-213.

257. Bommer UA, Thiele BJ: The translationally controlled tumour protein (TCTP). Int J Biochem Cell Biol 2004, 36: 379-385.

258. Yarm FR: Plk phosphorylation regulates the microtubule-stabilizing protein TCTP. Mol Cell Biol 2002, 22: 6209-6221.

259. Blitvich BJ, Rayms-Keller A, Blair CD, Beaty BJ: Complete cDNA and deduced amino acid sequence of the chaperonin containing T-complex 
polypeptide 1 (CCT) delta subunit from Aedes triseriatus mosquitoes. DNA Seq 2001, 12: 203-208.

260. Zilkha-Falb R, Barzilai A, Djaldeti R, Ziv I, Melamed E, Shirvan A: Involvement of T-complex protein-1delta in dopamine triggered apoptosis in chick embryo sympathetic neurons. J Biol Chem 2000, 275: 36380-36387.

261. Kim SH, Shim KS, Lubec G: Human brain nascent polypeptide-associated complex alpha subunit is decreased in patients with Alzheimer' $\mathrm{s}$ disease and Down syndrome. J Investig Med 2002, 50: 293-301.

262. Bursten SL, Stevenson F, Torrano F, Lovett DH: Mesangial cell activation by bacterial endotoxin. Induction of rapid cytoskeletal reorganization and gene expression. Am J Pathol 1991, 139: 371-382.

263. Shirai $Y$, Sasaki N, Kishi $Y$, Izumi A, Itoh K, Sameshima M et al:: Regulation of levels of actin threonine phosphorylation during life cycle of Physarum polycephalum. Cell Motil Cytoskeleton 2006, 63: 77-87.

264. Pu WT, Krapivinsky GB, Krapivinsky L, Clapham DE: pICln inhibits snRNP biogenesis by binding core spliceosomal proteins. Mol Cell Biol 1999, 19: 4113-4120.

265. Hagopian JC, Reis M, Kitajima JP, Bhattacharya D, de Oliveira MC: Comparative analysis of the complete plastid genome sequence of the red alga Gracilaria tenuistipitata var. liui provides insights into the evolution of rhodoplasts and their relationship to other plastids. J Mol Evol 2004, 59: 464-477.

266. Schagger H, Brandt U, Gencic S, von JG: Ubiquinol-cytochrome-c reductase from human and bovine mitochondria. Methods Enzymol 1995, 260: 82-96.

267. Ostergaard E: Disorders caused by deficiency of succinate-CoA ligase. Journal of Inherited Metabolic Disease 2008, 31: 226-229.

268. Hamilton TA, Jansen MM, Somers SD, Adams DO: Effects of bacterial lipopolysaccharide on protein synthesis in murine peritoneal macrophages: relationship to activation for macrophage tumoricidal function. J Cell Physiol 1986, 128: 9-17.

269. Stott DI, Williamson AR: Non-histone chromatin proteins of B lymphocytes stimulated by lipopolysaccharide. Biochim Biophys Acta 1978, 521: 726738.

270. Stott DI: Non-histone chromatin proteins of B lymphocytes stimulated by lipopolysaccharide. III. De novo synthesis. Biochim Biophys Acta 1980, 610: 371-383.

271. Vogel SN, Hilfiker ML, Caulfield MJ: Endotoxin-induced T lymphocyte proliferation. J Immunol 1983, 130: 1774-1779. 
272. Hinderlich S, Berger M, Schwarzkopf M, Effertz K, Reutter W: Molecular cloning and characterization of murine and human $\mathrm{N}$-acetylglucosamine kinase. Eur J Biochem 2000, 267: 3301-3308.

273. Srinivasula SM, Datta P, Fan XJ, Fernandes-Alnemri T, Huang Z, Alnemri ES: Molecular determinants of the caspase-promoting activity of Smac/DIABLO and its role in the death receptor pathway. $J$ Biol Chem 2000, 275: 36152-36157.

274. Devroe E, Erdjument-Bromage H, Tempst P, Silver PA: Human Mob proteins regulate the NDR1 and NDR2 serine-threonine kinases. J Biol Chem 2004, 279: 24444-24451.

275. MacMillan-Crow LA, Cruthirds DL: Invited review: manganese superoxide dismutase in disease. Free Radic Res 2001, 34: 325-336.

276. Grigolo B, Borzi RM, Mariani E, Monaco MC, Cattini L, Porstmann T et al:: Intracellular $\mathrm{Cu} / \mathrm{Zn}$ superoxide dismutase levels in $\mathrm{T}$ and non-T cells from normal aged subjects. Mech Ageing Dev 1994, 73: 27-37.

277. Tian L, White JE, Lin HY, Haran VS, Sacco J, Chikkappa G et al:: Induction of $\mathrm{Mn}$ SOD in human monocytes without inflammatory cytokine production by a mutant endotoxin. Am J Physiol 1998, 275: 740-747. 


\section{Appendices}

\section{Appendix Figure 1: SDS-PAGE anlalysis of mTORC1 interacting proteins.}

(A) Endogsnous mTORC1 specific purified elutes were prepared from CCRF-CEM cells lysate (as described in mthod section), resolved on SDS-PAGE, and stained with Coomassie blue. Mock IP (negative control) sample was also run on the gel. After staining, whole lane of protein bands were excised from the gel and tryptic digested for MS/MS analysis.

(B) Myc-tag mTORC1 specific purified elutes were prepared from HEK293 cells and separated on SDS-PAGE. Protein bands were visualized by using silver nitrate staining and tryptic digested for MS/MS analysis.

A

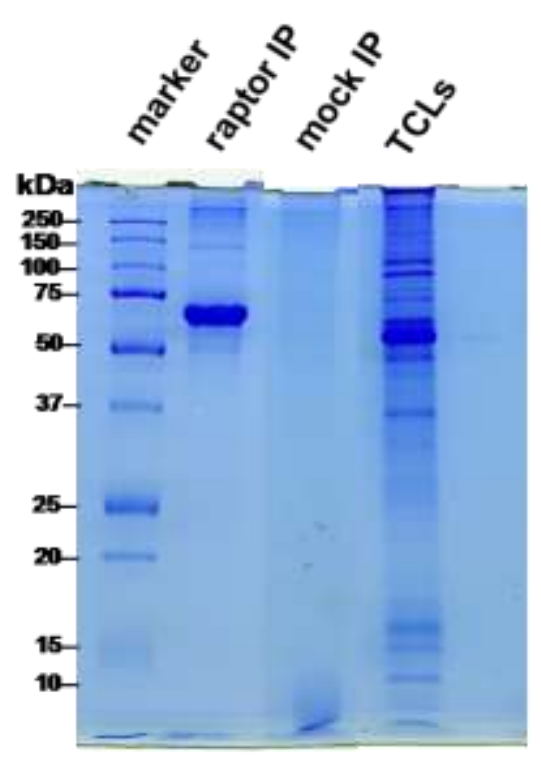

B

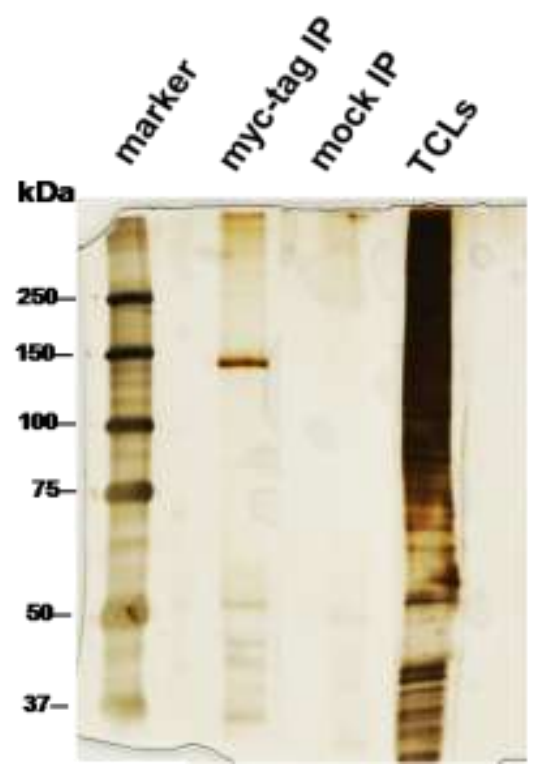




\section{Appendix Table 1: List of $\mathrm{mTORC} 1$ interacting proteins spectra identified by ESI Q-TOF MS/MS analysis.}

${ }^{a}$ Mascot score: $>42$ indicate identity or extensive homology $(\mathrm{p}<0.05)$; ${ }^{\mathrm{b}} \mathrm{pl}$ : isoelectric $\mathrm{pH}$; 'Peptides: number of peptides matched with protein in MS/MS query; MS/MS analysis: sequence of protein with identified peptide (bold) and exemplary MSMS spectra of the peptide with higher ion-score.

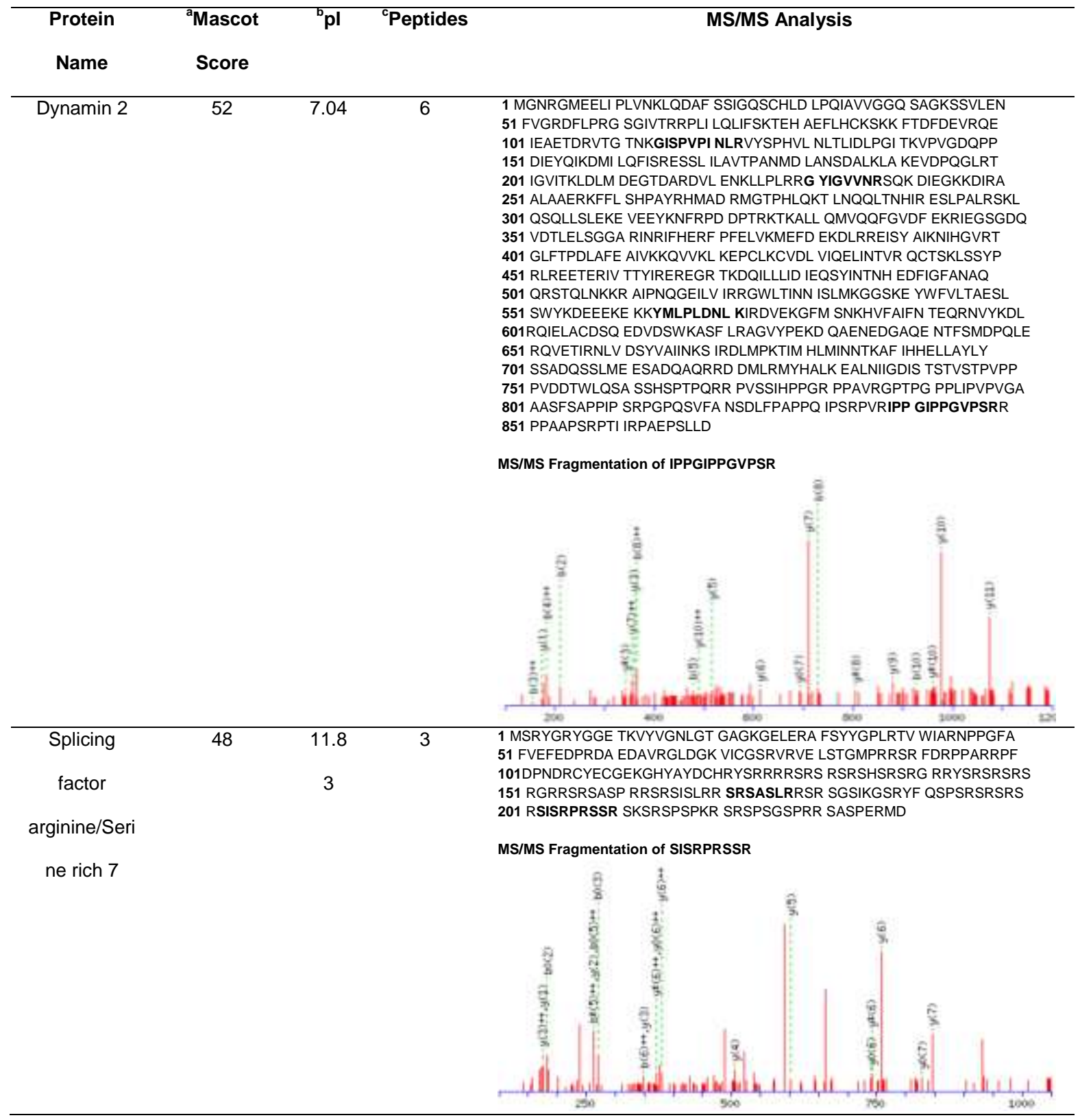




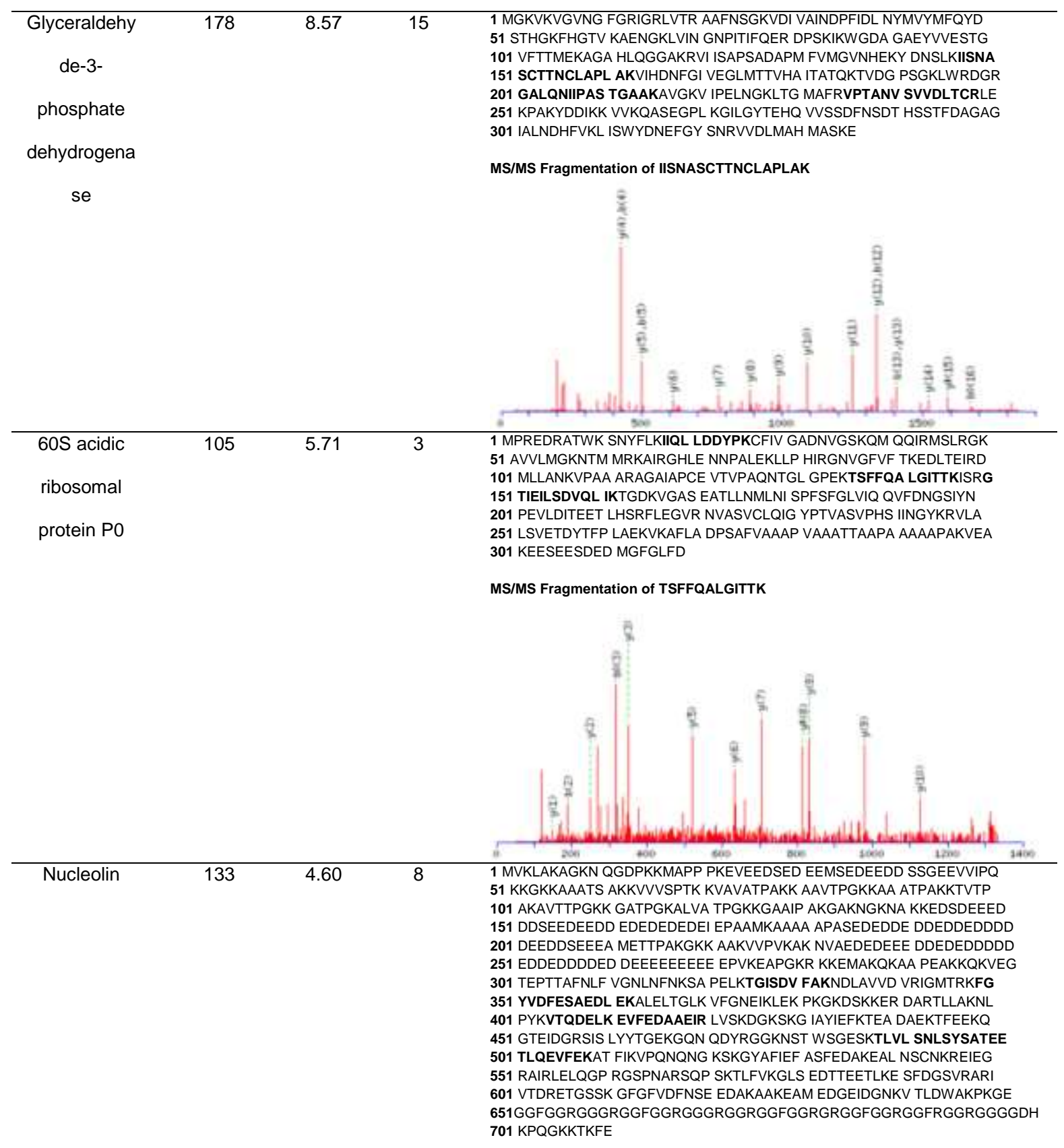

MS/MS Fragmentation of EVFEDAAEIR

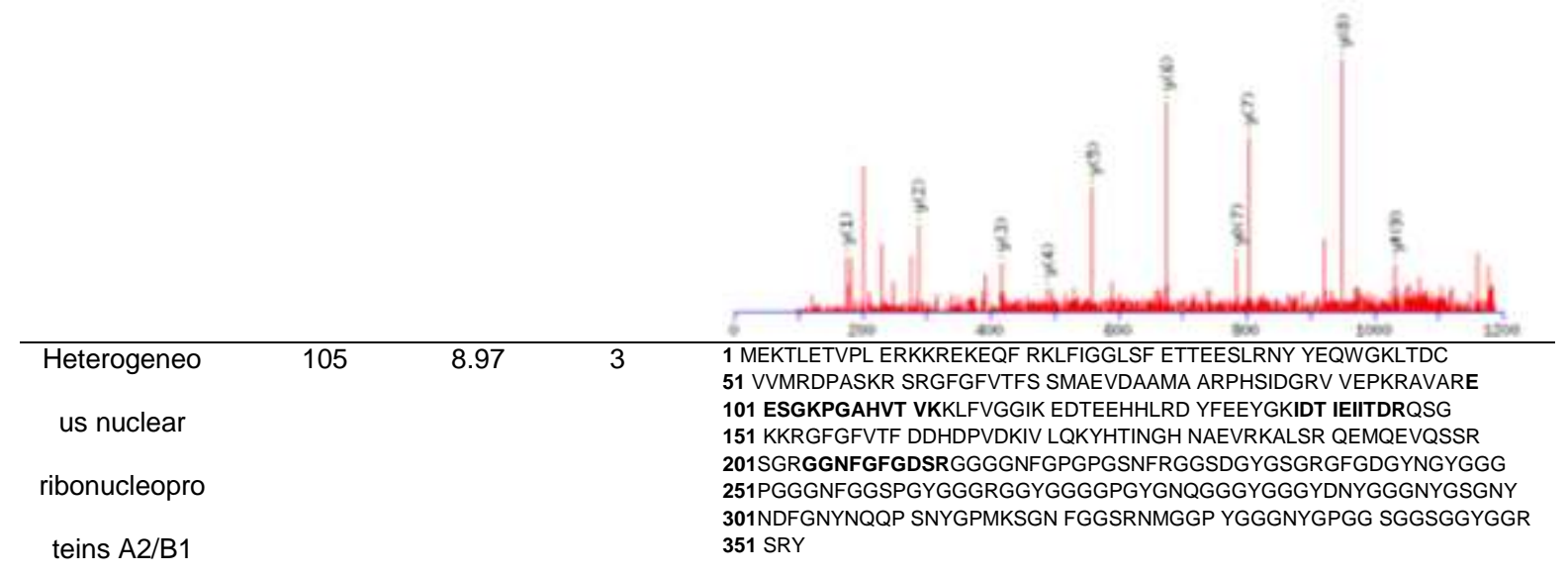

MS/MS Fragmentation of IDTIEIITDR 


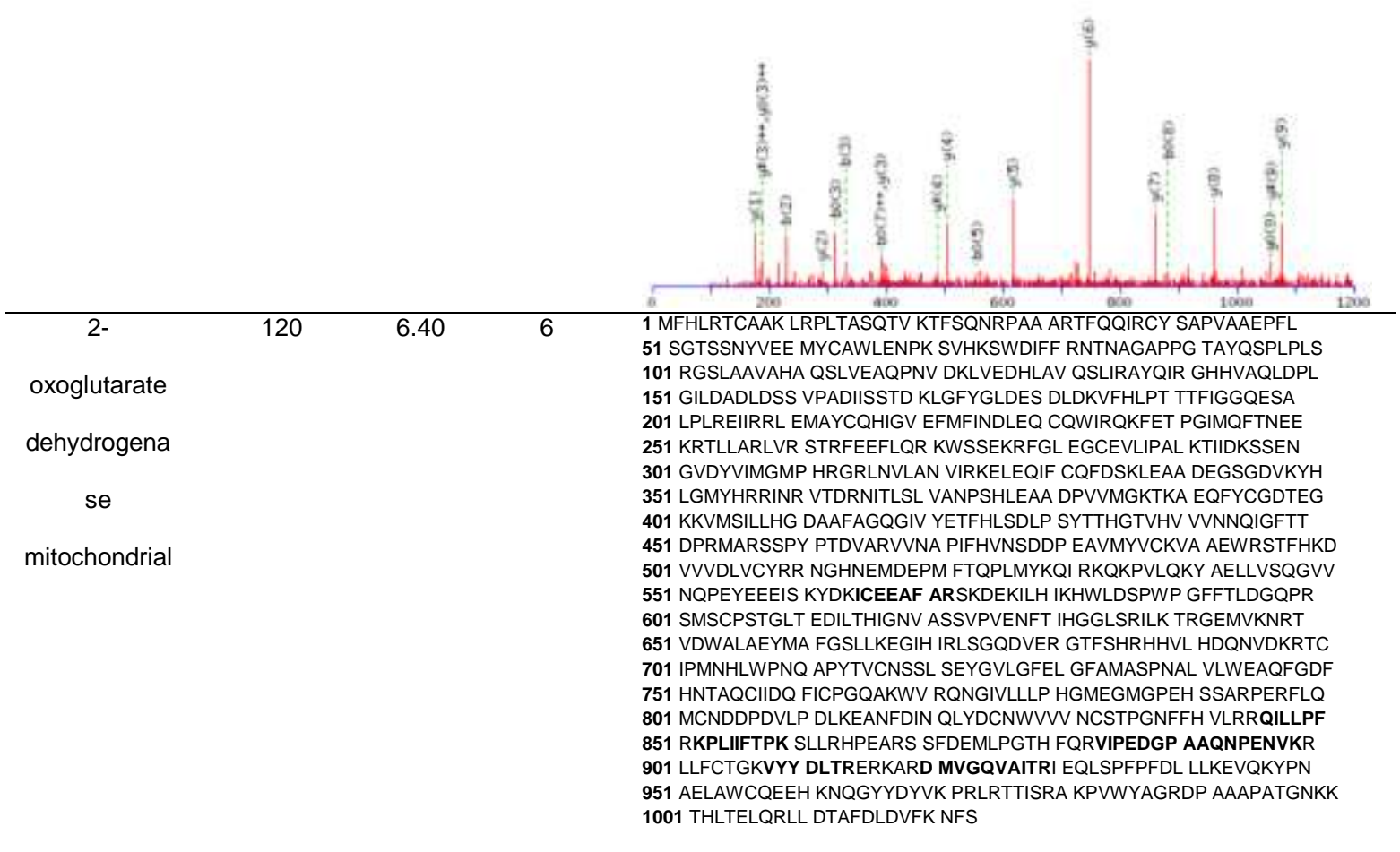

MS/MS Fragmentation of KPLIIFTPK

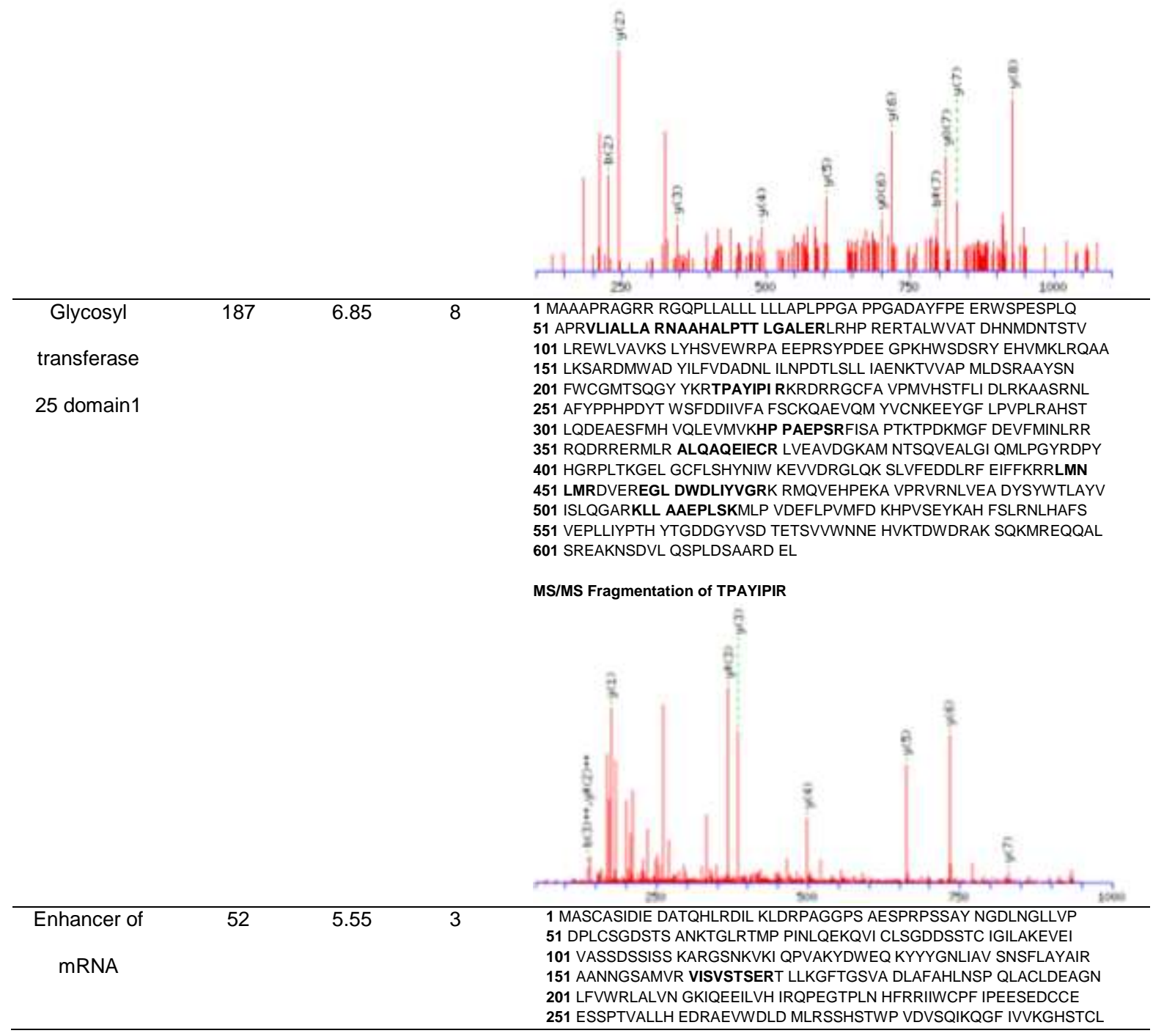


451 SEFLLTHPVL SFGIQVVSRC RLRHTEVLPA EEENDSLGAD GTHGAGAMES 501 AAGVLIKLFC VHTKALQDVQ IRFQPQLNPD VVAPLPTHTA HEDFTFGESR

551 PELGSEGLGS AAHGSQPDLR RIVELPAPAD FLSLSSETKP KLMTPDAFMT 601 PSASLQQITA SPSSSSSGSS SSSSSSSSSL TAVSAMSSTS AVDPSLTRPP 651 EELTLSPKLQ LDGSLTMSSS GSLQASPRGL LPGLLPAPAD KLTPKGPGQV 701 PTATSALSLE LQEVEPLGLP QASPSRTRSP DVISSASTAL SQDIPEIASE 751 ALSRGFGSSA PEGLEPDSMA SAASALHLLS PRPRPGPELG PQLGLDGGPG 801 DGDRHNTPSL LEAALTQEAS TPDSQVWPTA PDITRETCST LAESPRNGLQ 851 EKHKSLAFHR PPYHLLQQRD SQDASAEQSD HDDEVASLAS ASGGFGTKVP 901 APRLPAKDWK TKGSPRTSPK LKRKSKKDDG DAAMGSRLTE HQVAEPPEDW 951 PALIWQQQRE LAELRHSQEE LLQRLCTQLE GLQSTVTGHV ERALETRHEQ 1001 EQRRLERALA EGQQRGGQLQ EQLTQQLSQA LSSAVAGRLE RSIRDEIKKT 1051 VPPCVSRSLE PMAGQLSNSV ATKLTAVEGS MKENISKLLK SKNLTDAIAR 1101 AAADTLQGPM QAAYREAFQS VVLPAFEKSC QAMFQQINDS FRLGTQEYLQ 1151 QLESHMKSRK AREQEAREPV LAQLRGLVST LQSATEQMAA TVAGSVRAEV 1201 QHQLHVAVGS LQESILAQVQ RIVKGEVSVA LKEQQAAVTS SIMQAMRSAA 1251 GTPVPSAHLD CQAQQAHILQ LLQQGHLNQA FQQALTAADL NLVLYVCETV 1301 DPAQVFGQPP CPLSQPVLLS LIQQLASDLG TRTDLKLSYL EEAVMHLDHS 1351 DPITRDHMGS VMAQVRQKLF QFLQAEPHNS LGKAARRLSL MLHGLVTPSL $1401 \mathrm{P}$

MS/MS Fragmentation of VISVSTSER

3

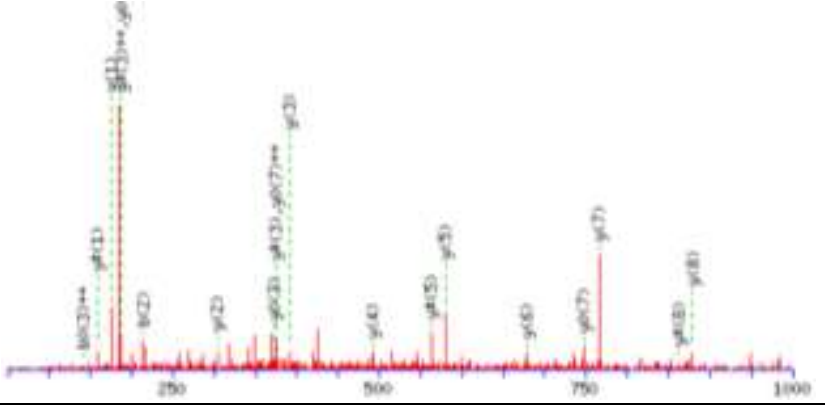

51 FFNRIGGVQQ DTILAEGLHF RIPWFOYPII YDIRARPRKI SSPTGSKDLQ 101 MVNISLRVLS RPNAQELPSM YQRLGLDYEE RVLPSIVNEV LKSVVAKFNA 151 SQLITQRAQV SLLIRRELTE RAKDFSLILD DVAITELSFS REYTAAVEAK 201 QVAQQEAQRA QFLVEKAKQE QRQKIVQAEG EAEAAKMLGE ALSKNPGYIK 251 LRKIRAAQNI SKTIATSQNR IYLTADNLVL NLQDESFTRG SDSLIKGKK

MS/MS Fragmentation of FNASQLITQR

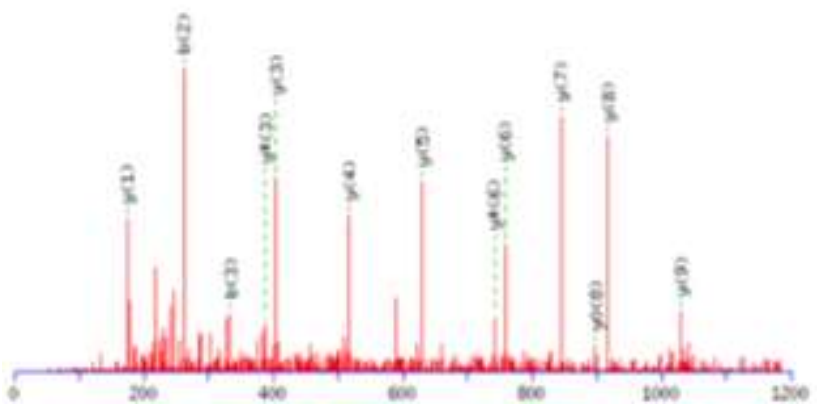




\section{Appendix Table 2: MS/MS spectral data of differentially regulated proteins identified by Q-TOF analysis.}

Spot ID: spot identification number on the 1DE gel; ${ }^{a} \mathrm{Abb}$.: abbreviation for protein name; ${ }^{\mathrm{b}}$ Mascot score: $>42$ indicate identity or extensive homology $(p<0.05)$; ${ }^{\mathrm{C}}$ Peptides: number of peptides matched with protein in MS/MS query; MS/MS analysis: sequence of protein with identified peptide (bold) and exemplary MSMS spectra of the peptide with higher ion-score.

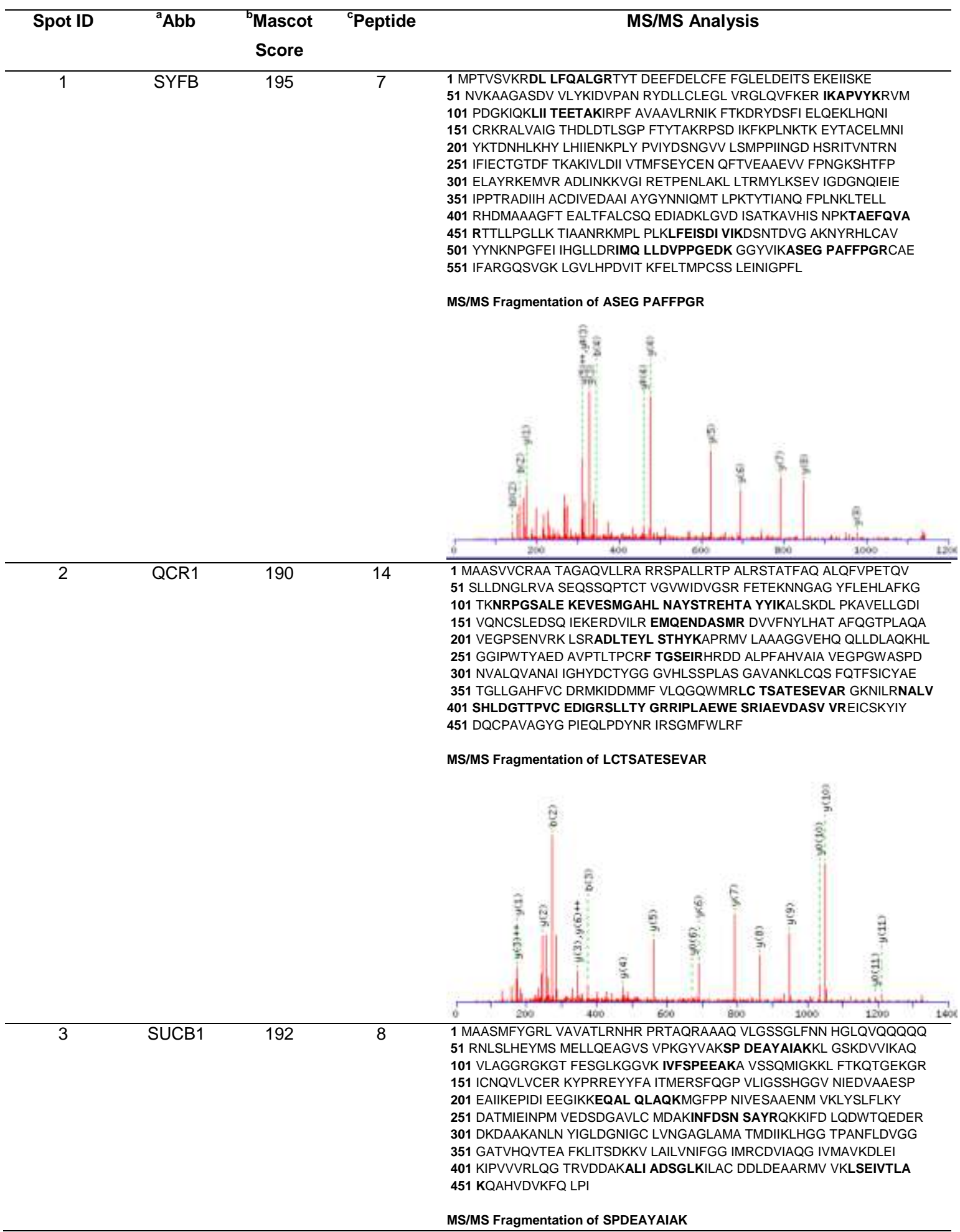




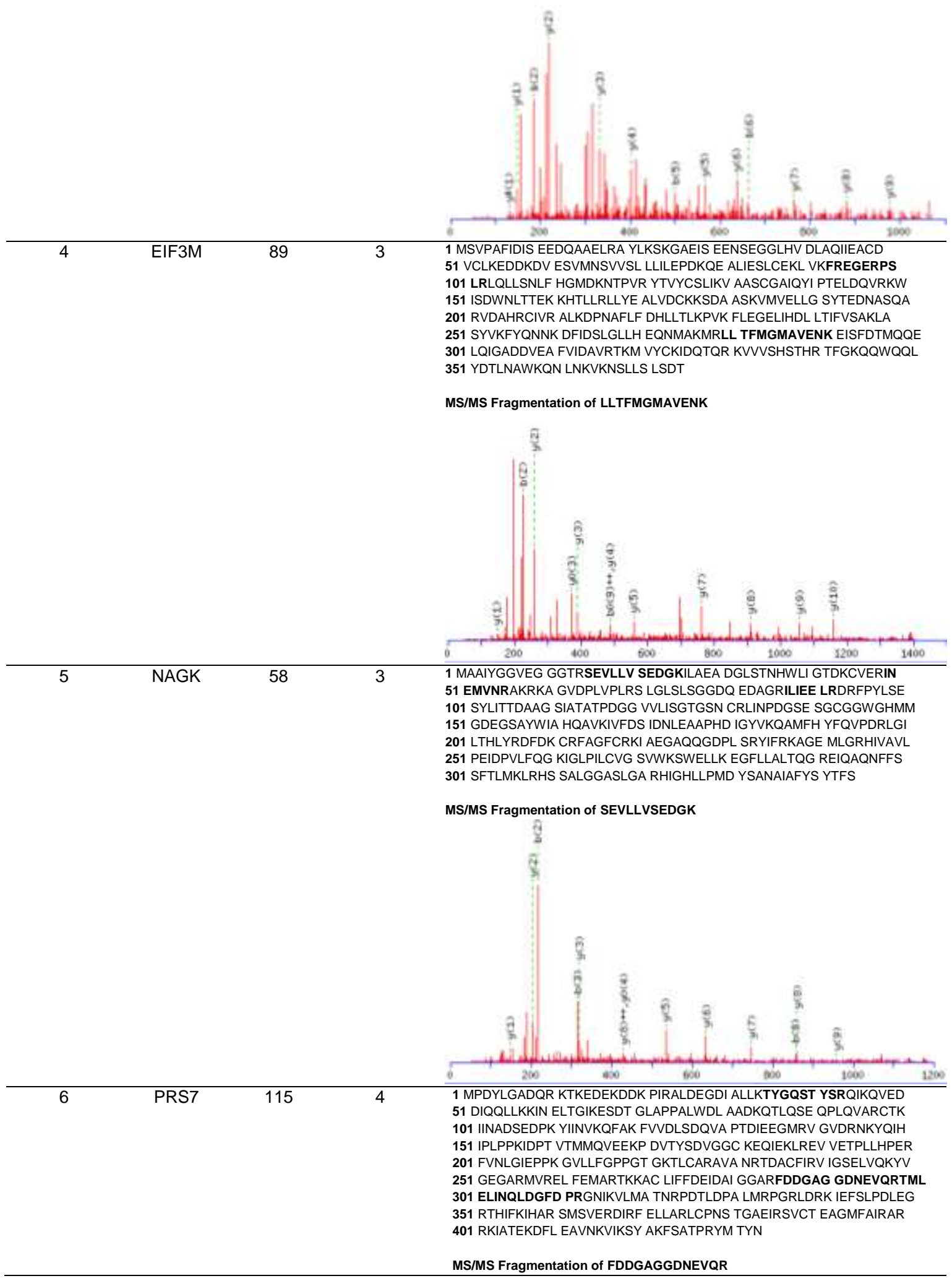




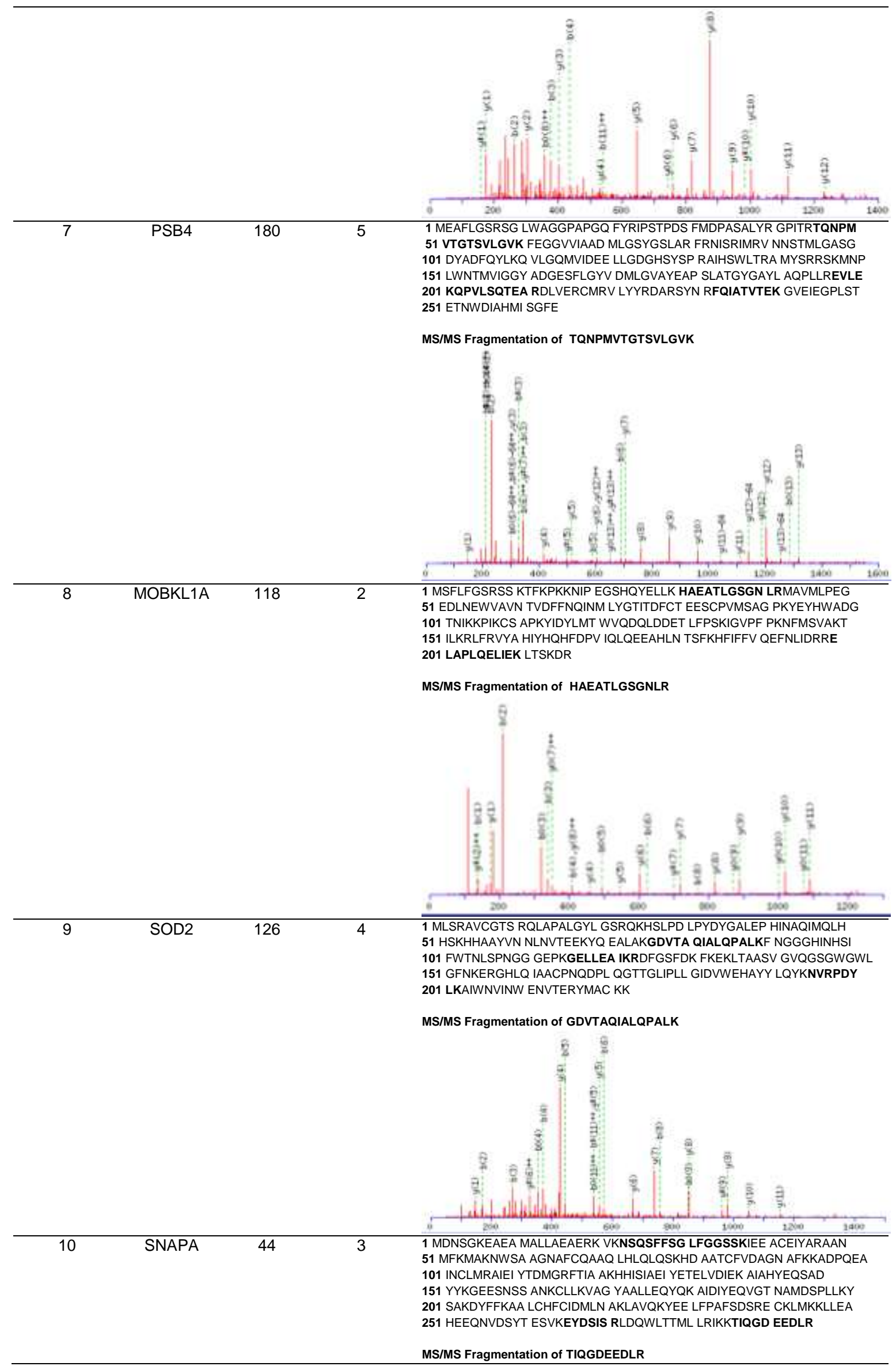




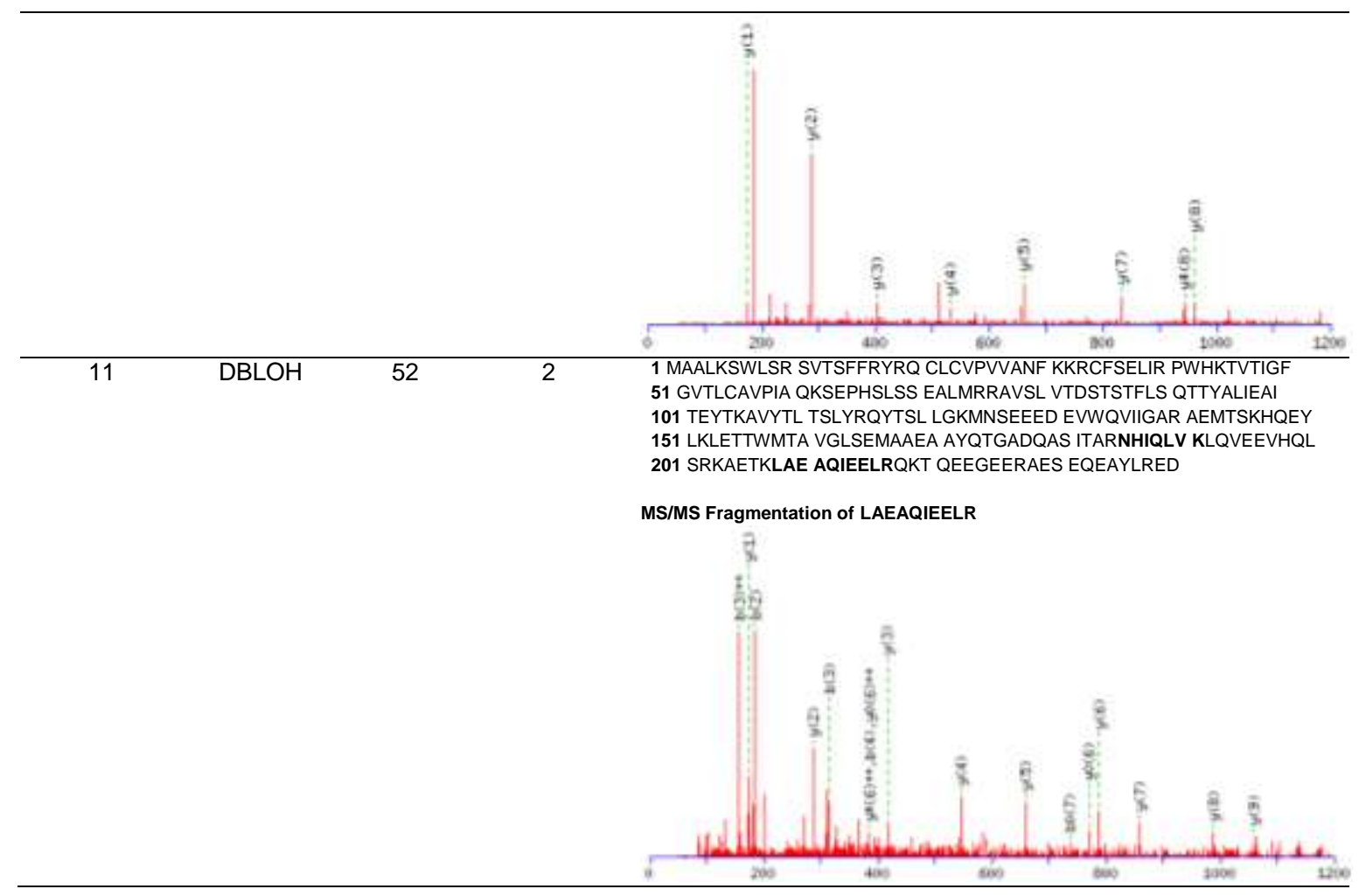

\section{Appendix Table 3: MS/MS analysis table for differentially regulated phospho- proteins identified by Q-TOF analysis.}

Spot ID: indicate spot identification number on the 1DE gel; ${ }^{a}$ Abbreviation for protein name; ${ }^{b}$ Mascot score: $>42$ indicate identity or extensive homology $(p<0.05)$; ${ }^{c}$ Peptides: number of peptides matched with protein in MS/MS query; MS/MS analysis: sequence of protein with identified peptide (bold) and exemplary MSMS spectra of the peptide with higher ion-score.

\begin{tabular}{|c|c|c|c|c|}
\hline Spot ID & ${ }^{\mathrm{a}} \mathrm{Abb}$ & $\begin{array}{l}\text { Mascot } \\
\text { Score }^{\text {b }}\end{array}$ & Peptides $^{c}$ & MS/MS Analysis \\
\hline 12 & TCPD & 152 & 6 & 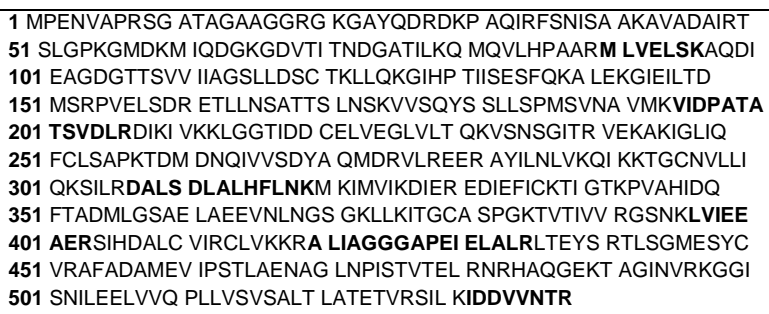 \\
\hline & & & & MS/MS Fragmentation of ALIAGGGAPEIELALR \\
\hline
\end{tabular}




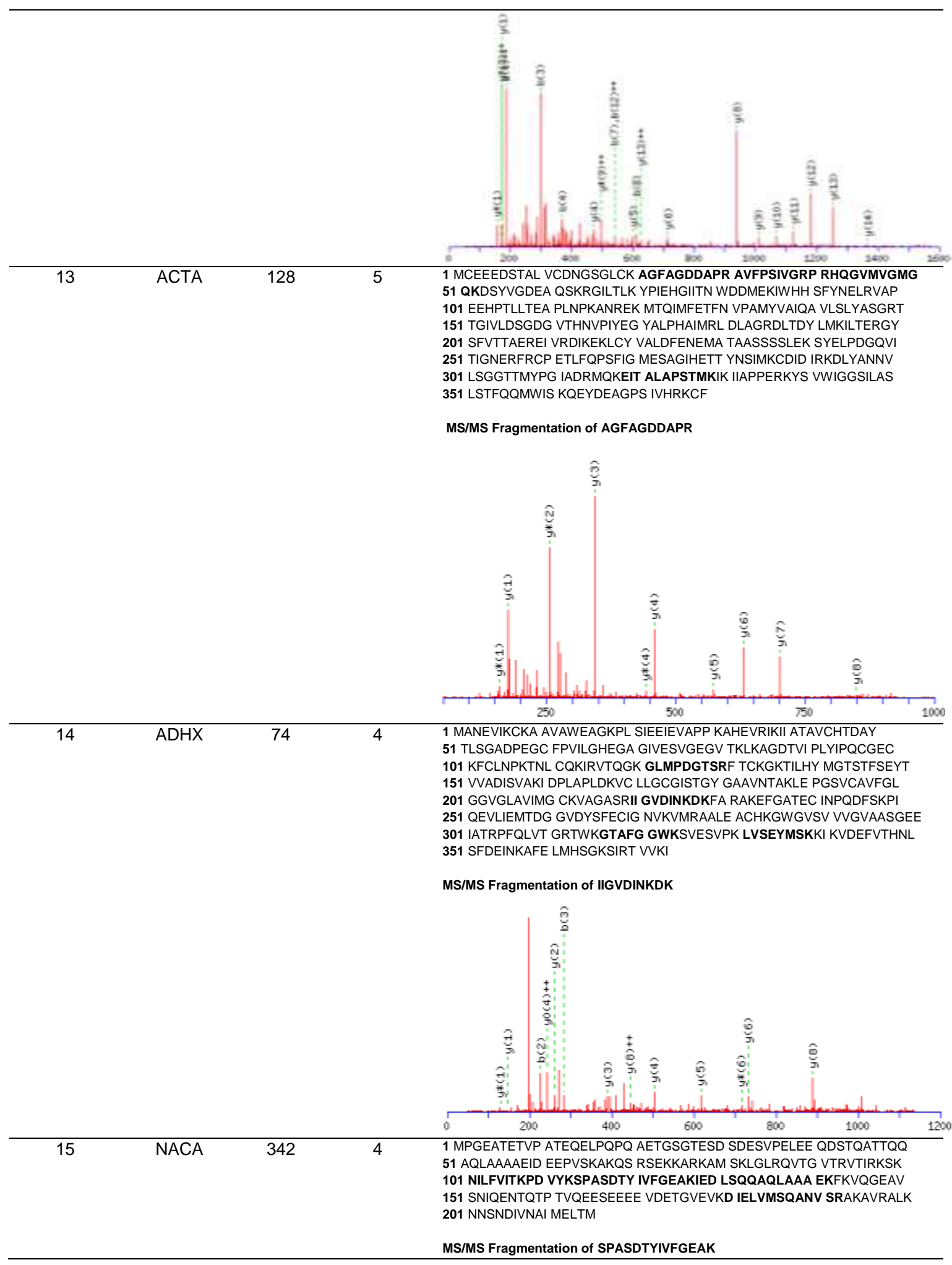




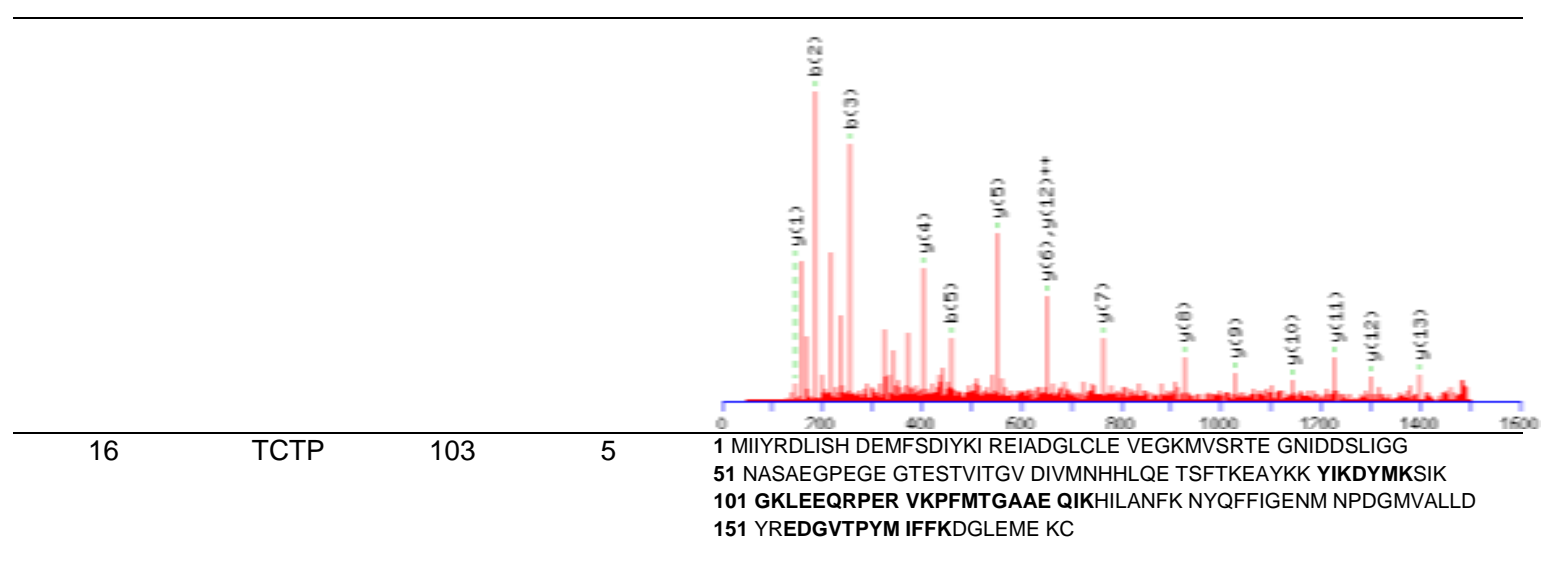

MS/MS Fragmentation of GKLEEQRPER

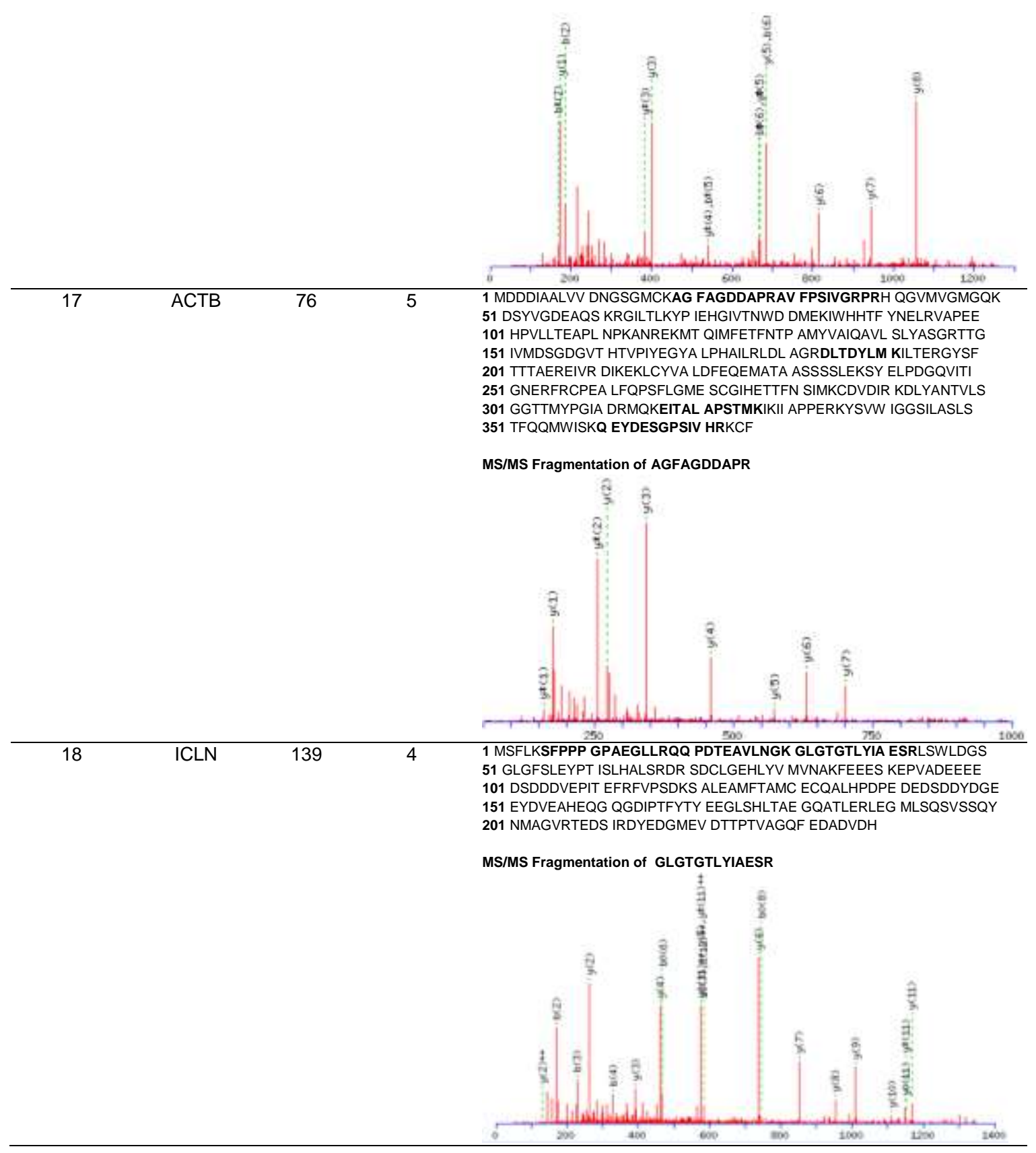




\section{Acknowledgements}

I am greatly indebted for my research and success to Merciful and Almighty "Allah" Who blessed me with the ability to achieve this milestone, and all respects are for the Holy Prophet, Hazrat Muhammad (PBUH).

I would like to express my profound gratitude and thank to Prof. Dr. Michael. Oellerich, Director of the Department of Clinical Chemistry, for his incessant cooperation, guidance, and for providing me privileges in this department.

I wish my appreciation and deepest thanks to PD. Dr. Abdul Rahman Asif for his consistent guidance, precious advice, and motivation from the commence of my work. He has been a brilliant mentor and friend to me.

I would like to thank mythesis committee members, Prof. Dr. Stefanie Pöggeler and Prof. Dr. Jürgen Brockmöller for their valuable suggestions and constructive scientific criticism which kept me on the right tract during my research project. I wish to thank my subject examination committee memmbers Dr. Michael Hoppert, Dr. Rolf Daniel, Prof. Dr. Petr Karlovsky, and Dr. Marko Rohlfs.

My special thanks to (Late) Prof. Dr. Victor Armstrong for his valuable scientific conversations. I thank to Prof. Dr. Philip Walson for his detailed review, constructive criticism and excellent advice during the preparation of this thesis.

The financial support of the Kohat University of Science and Technology and Higher Education Commision, Pakistan is gratefully acknowledged.

I offer my special thanks to Muhammad Qasim and Misbah Misdaq for their suggestions and continous help. I feel very luckyl to have such nice colleagues. Many thanks to my colleague and friend Bharat Singh for his motivation and social interaction. I would like to show my gratitude to Prof. Nicolas von Ahsen, Dr. Lutz Binder, Dr. Gunner Brandhorst, Dr. Saima Zafar, Dr. Darinka Petrova, Dr. Christoph Eberle, Dr. Saadia Zahid, and Dr. Sagrika Biswas for their scientific conversation and help.

Many thanks go in particular to our proteomics research technical staff, Christina Wiese, Christa Schultz, and Susanne Goldmann. Their cooperation, technical support, and providing me a pleasant work atmosphere which is never forgettable. My special thank to Rainer Andaq, Ulrike Bonitz, and Sandra Hartung for providing technical assistance whenever I needed. Special thanks to Prof. Dr. Giuliano Ramadori and Dr. Ihtizaz Malik for providing access to the confocal microscopy facility. I offer my regards and blessings to all of those who supported me in any respect during the completion of the project. 
I express my gratitude to my dear friends Muhammad Qasim, Hayat Muhammad Sherani and Tayab Tahir for their help and support. I would like to thank Altaf Hussain, Dr. Adnan Khan, Dr. Abdul Malik Tareen, Dr. Waheed Murad, Dr. Noor Muhammad, Sajjad Khan, Muhammd Naveed, Naeem Misdaq, Muhammad Haroon, Abid Khan, Numan, and Kalimullah Khan for their earnest suggestions and sustain.

It is a great honor for me to express my deepest gratitude to my teachers Prof. Dr. Mansoor ul Hassan Alvi, Prof. Dr Shahana Urooj Kazmi, Prof. Dr. Shahida Hasnain, and Prof. Dr. Shakeel Ahmad Khan for their guidance and motivation in my academic career.

I feel a deepest sense of gratitude for my parents who formed part of my vision and taught me the good things that really matter in life. Moeover their faith in me and allowing me to be as ambitious as I wished for, and it was under their observant eye that I gained so much force and an ability to deal with challenges head on.

I wish to express my gratitude and special heartfelt thanks to my wife for her constant patience, profound understanding, encouragement, support and care, as always, for which my mere expression of thanks likewise does not suffice. I offer many thanks to my daughters Zoha Rahman and Sara Rahman for giving me happiness and pleasure.

I especially thank my sisters and my brothers (Noor Talab Khan, Fazal ur Rehman, Zakir Khan, and Sajid Khan) for their unequivocal and incredible support and prayers throughout my academic career.

Hazir rahman 


\section{Curriculum Vitae}

\section{HAZIR RAHMAN}

Date and Place of birth: $25^{\text {th }}$ March 1980, Mardan, Pakistan.

\section{EDUCATION}

$\begin{array}{ll}2008-2012 & \text { Ph.D (Biology), Georg-August University, Goettingen, } \\ \text { Germany. } & \\ 2006-2008 & \begin{array}{l}\text { M.Phil (Microbiology and Molecular Genetics), University } \\ \text { of the Punjab, Lahore, Pakistan. }\end{array} \\ 2004-2006 & \text { M.Sc (Microbiology), Karachi University, Karachi, Pakistan. } \\ 2000-2003 & \text { B.Sc (Medical Laboratory Technology), University of the } \\ & \text { Punjab, Lahore, Pakistan. }\end{array}$

\section{PROFESSIONAL EXPERIENCE}

2008 - onwards Lecturer

Department of Microbiology, Kohat University of Science and Technology, Kohat, Pakistan.
$2007-2008 \quad$ Junior Scientist
National Institute for Biotechnology and Genetic Engineering (NIBGE), Faisalabad, Pakistan.
2003 - $2004 \quad$ Trainee Medical Technologist
Shaukat Khanum Cancer Hospital and Research Center, Lahore, Pakistan.

\section{PUBLICATIONS}

1. Rahman H, Qasim M, Ahmed R, Oellerich M, Asif AR. mTORC1 interactomics; mTORC1 interplay in the mRNA decapping through Edc4 (Submitted).

2. Qasim M, Rahman H, Ahmed R, Oellerich M, Asif AR. Mycophenolic acid mediated disruption of the intestinal epithelial tight junctions (Submitted). 
3. Rahman H, Qasim M, Schultze FC, Oellerich M, Asif AR. Influence of fetal calf serum heat inactivation and lipopolysaccharides contamination on human $T$ lymphoblasts proteome and phosphoproteome. Proteome Sci. 2011 15;9(1):71.

4. Qasim M, Rahman H, Oellerich M, Asif AR. Differential proteome analysis of human embryonic kidney cell line following mycophenolic acid treatment. Proteome Sci. 2011 20;9:57.

5. Al-Ajlani MM, Rahman $\mathbf{H}$, Tahir $\mathbf{S}$, Hasnain $\mathbf{S}$. Isolation and characterization of newly antimicrobial exhibiting bacteria from Pakistan. Proceeding of international symposium on microbial technologies for sustainable agriculture at NIBGE, Faisalabad, Pakistan. 2009 (pp255-261).

6. Muhammad K, Yasmin A, Rahman H, Faisal M, Hasnain S. Growth responses of Vigna radiate to arid land bacteria exhibiting antimicrobial activity. Research J Environmental Sci. 2008 2(2):139-144.

7. Anwar S, Sabri AN, Rahman H, Faisal M, Hasnain S. Impact of temperature and $\mathrm{pH}$ on soluble protein content and protein profile of PY79 and sporulation defective mutants strains of Bacillus Research J Microbiol. 2007 2(11):86668670 .

\section{RESEARCH PRESENTATIONS}

1. Rahman H. mTORC1 interactomics: Interaction with the enhancer of mRNA decapping protein 4. Symposium of Transporttage 2011 at the Department of Physiology and Pathophysiology, University MedicalCentre, Goettingen, Germany (22 $2^{\text {nd }}$ to $23^{\text {rd }}$ Oct 2011) (Oral).

2. Qasim M, Rahman H, Ahmed R, Oellerich M, Asif AR. Mycophenolic acid modulation of epithelial tight junctions-a mechanism of gastrointestinal toxicity? AACC annual meeting 2011, Atlanta, Georgia, USA (24 $4^{\text {th }}$ to $28^{\text {th }}$ July 2011) (Poster).

3. Sing B, Qasim M, Rahman H, Sharma GL, Oellerich M, Kumar R, Asif AR. Proteomics based identification of diagnostically relevant and vaccine candidate molecules of Aspergillus fumigatus at the meeting of Goettingen International Health Network, Goettingen, Germany (23 $3^{\text {rd }}$ to $24^{\text {th }}$ May 2011) (Poster). 
4. Rahman H, Qasim M, Schultze FC, Oellerich M, Asif AR. Dynamin 2: is a new interacting partner of mechanistic target of rapamycin complex 1 in human $T$ lymphocytes. Berlin Proteomic Forum, Germany ( ${ }^{\text {rd }}$ to $7^{\text {th }}$ April 2011) (Poster).

5. Rahman H, Qasim M, Schultze FC, Oellerich M, Asif AR. Fetal calf serum heat inactivation and lipopolysaccharide contamination influence the human $T$ lymphoblasts proteome and phosphoproteome. Berlin Proteomic Forum, Germany ( $3^{\text {rd }}$ to $7^{\text {th }}$ April 2011) (Poster).

6. Qasim M, Rahman H, Oellerich M, Asif AR. Protein alterations in human cell line in response to mycophenolic acid. DGKL Congress Mannheim, Germany $\left(29^{\text {th }}\right.$ Sept to $2^{\text {nd }}$ Oct 2010) (Poster).

\section{DISTINCTIONS AND AWARDS}

1. PhD Scholarship for Germany under the faculty development scholarship program from the Kohat University Science and Technology, Kohat, Pakistan (2008-2012).

2. First position in the Department of Microbiology in M.Sc, Karachi University, Karachi, Pakistan (2004-2006). 